\title{
BORDERLINE FICTIONS: \\ Spaces of Absurdity in the Korean Demilitarized Zone
}

by

Shaylyn Sarah Kelly

A thesis submitted to the Faculty of Graduate and Postdoctoral Affairs in partial fulfillment of the requirements for the degree of

Master of Architecture

Carleton University

Ottawa, Ontario, Canada

(c) 2021

Shaylyn Sarah Kelly 


\section{ABSTRACT}

This thesis investigates the complexity of the Korean Demilitarized Zone through a series of speculative scenarios that question its future as well as architecture's role and agency in contested landscapes. Media, representation, and collective memory serve as primary themes in this research.

The once united peninsula is a faint memory. North and South have undergone vast changes since the Korean War, and the DMZ remains ever-present in media and social life. "Han," a Korean notion of a deeply rooted collective memory is a key element in interpreting the DMZ's space(s) of absurdity. This thesis explores historical and contemporary modes of interpretation and understanding the DMZ, drawing on traditional Korean art forms, mythologies, and narratives to explore the spatial implications - absurd, satirical, and revelatory - of borderline fictions. 


\section{ACKNOWLEDGMENTS}

To my 할머니 and 할아버지 to whom this document is dedicated. Their memory pushed me to engage in such a topic.

To my advisor, Ozayr Saloojee for his constant guidance and knowledge that I will forever cherish. While the Covid-19 pandemic presented an unexpected thesis experience, it is through your support that this thesis was completed.

To my parents, I will never be able to fully express my gratitude for their constant encouragement throughout my education.

To Charles, for all the patience and reassurance during the late nights spent developing this thesis. 


\section{TABLE OF CONTENTS}

0.1 - Abstract

0.2 - Acknowledgements

0.3 - Table of Contents

0.4 - List of Figures

0.5 - Prologue

0.6 - Introduction

Part One // The Media

1.1 - Two Koreas

1.2 - Drawing from Memory

1.3 - On the Other Side

Part Two // The Absurd

2.1 - Spaces of Absurdity

2.2 - Spaces of the Above

2.3 - Spaces of the Sky

2.4 - Spaces of the Earth

2.5 - Spaces of the Water

69

2.6 - Spaces of the Below

Part Three // The Fictional

3.1 - Preface

3.2 - Spaces of Speculation

3.3 - Erased

3.4 - Infiltrated

94

3.5 - Continued

Postscript

102

Glossary

104

Bibliography

106

Figures

117 


\section{LIST OF FIGURES}

Figure 1: Magpies and Tiger Smoking Pipe ii

Figure 2: Peninsula: Two Koreas 05

Figure 3: South Korean Soldier at the Southern Limit Overlooking the Han River 07

$\begin{array}{ll}\text { Figure } 4 \text { : Portrait } & 08\end{array}$

Figure 5: Portrait of Lady Un 08

Figure 6: The Conquest of Korea 09

Figure 7: Political Cartoon of China and Japan Trampling Korea as Russia Watches 09

Figure 8: Seoul Avenue during the Japanese Occupation 10

Figure 9: Korean Liberation Army 11

Figure 10 : Syngman Rhee 12

Figure 11: Kim Il-Sung $\quad 12$

Figure 12: Armistice Agreement for the Restoration of the South Korean State 13

Figure 13: Delegates Signing the Korean War Armistice Agreement 13

Figure 14: Archive 19-24

Figure 15: Tiger Family 26

Figure 16: Landscape With Streams and Mountains 27

Figure 17: “Let Us Achieve The Party’s Agriculture Revolution Policy Thoroughly 29

And Brighten The Year With Increased Grain Production"

Figure 18: "Rice is Socialism. Let us Concentrate all Efforts on Agriculture!” 30

Figure 19: Magpies and Tiger Smoking Pipe 35

Figure 20 : Jeolla-do Mujanghyeondo 36

Figure 21: Detail of Map Royaume de Corée 37

Figure 22: A Squad of South Korean Army Soldiers Near their Guard Post 38

Figure 23: Borders: A Shifting Peninsula 39

Figure 24: Porosity: Crossings and Connections 40

Figure 25: Satellite imagery of the Korean Peninsula 44

Figure 26: Environments: Green Spaces, Urban Spaces, and Parks for Peace 45

Figure 27: Absurdities: Interactions, Meetings, Messages 46

Figure 28: Spaces of Absurdity: Sites and Instances 47

Figure 29: Tank Model Display 48

Figure 30: Tank Model Explorations

Figure 31: Tank Model Explorations $\quad 50$

Figure 32: South Korean Highway Landing Strip 52 
Figure 33: Murderboard: Spaces of the Above 53

Figure 34: Spaces of the Above 54

Figure 35: Spaces of the Above: Highway Landing Strips 55

Figure 36: Hydrogen Balloon Deployment 56

Figure 37: Hydrogen Balloon Deployment 56

Figure 38: Hydrogen Balloon Deployment 56

Figure 39: South Korean Speaker Installation 57

Figure 40: South Korean Speaker Installation 57

Figure 41: Cranes During a Marshland Stopover 58

Figure 42: Murderboard: Spaces of the Sky 59

Figure 43: Spaces of the Sky 60

Figure 44: Spaces of the Sky: Hydrogen Balloons 61

Figure 45 : JSA $\quad 62$

Figure 46: Sites of Dark Tourism 63

Figure 47: Amusent Park Ride at the DMZ 64

Figure 48: Village of Kijong-Dong 66

Figure 49: Murderboard: Spaces of the Earth 69

Figure 50: Spaces of the Earth 67

Figure 51: Spaces of the Earth: Potemkin Villages 68

Figure 52: Crab Wars 69

Figure 53: Preparation for the Release of Bottles 71

Figure 54: Murderboard: Spaces of the Water 72

Figure 55: Spaces of the Water 73

Figure 56: Spaces of the Water: Crab Wars 74

Figure 57: Tunnels of Aggression 75

Figure 58 : South Korean Soldiers Search for Land Mines 76

Figure 59: Farmers of the DMZ 77

Figure 60: Murderboard: Spaces of the Below 78

$\begin{array}{ll}\text { Figure 61: Spaces of the Below } & 79\end{array}$

Figure 62: Spaces of the Below: Tunnels of Aggression 80

Figure 63: Seven Jeweled Mountain $\quad 88$

Figure 64: Painting of One Hundred Themes 88

Figure 65: Scenarios of Speculation 89 
Figure 66: Erased: Instruments of Absurdity

Figure 67: Erased

Figure 68 : Infiltrated: Instruments of Absurdity

Figure 69: Infiltrated

Figure 70 : Continued: Instruments of Absurdity 


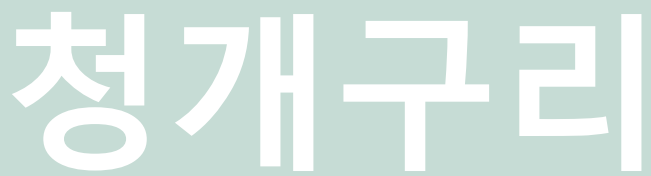




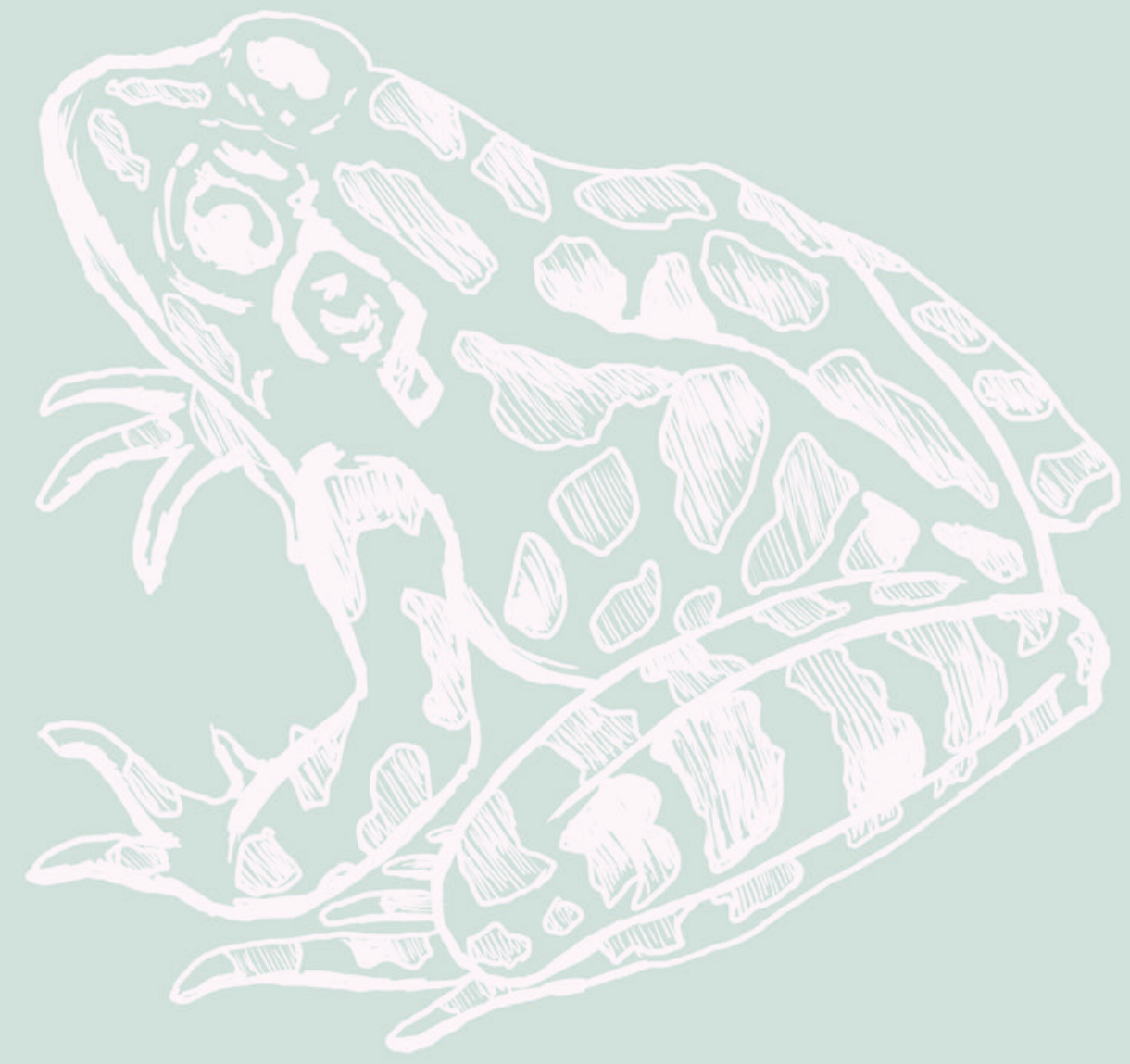




\section{PROLOGUE}

As a mixed-race Korean, I experience a level of imposter-syndrome in attempts to identify with my Korean heritage. Although Korean culture and language was omnipresent throughout my childhood, I still straddled between two cultures, one of my father's multi-generational Canadian family, and that of my mother's, a Korean immigrant. My understanding of Korean-ness is perhaps frozen in the time of my family's immigration. While family trips to South Korea brought brief moments of immersion, Korean culture was largely understood through my mother's memories prior to immigrating and the presence of traditions taught by my grandparents, as well as their Korean cable package. Leaving South Korea in the eighties, the country that my mother's family left was still managing the direct effects of the Korean War, and currently in its fifth (of six) South Korean republics. The first peaceful transfer of political power would not be seen until several years after my mother's immigration.

Much later in my life, I learned of the term han, or "the ineffable sadness of being Korean," something that is thought to be possessed by every Korean. Although han lacks a direct English translation, it can loosely be described as a sense of angst, endurance, or yearning for revenge; the ability to endure years of hardship linked to Korea's tumultuous history. While still 
unsure if I in fact possess this sense of han, the idea of collective memory that is present in Korean culture brought an interesting layer to the understanding of my identity. While this thesis explores themes of collective memory in understanding the Korean Demilitarized Zone, it is perhaps also the exploration of my own grappling of han.

Thinking back to my childhood, Korean folk arts such as songs and stories, shaped much of my understanding of Korean culture. As such, the theme of folk art comes into play, with the deciphering and creation of DMZ narratives, as well as the presence of references to proverbs and stories of my childhood that divide each section of the thesis. 


\section{PENINSULA}

Two Koreas

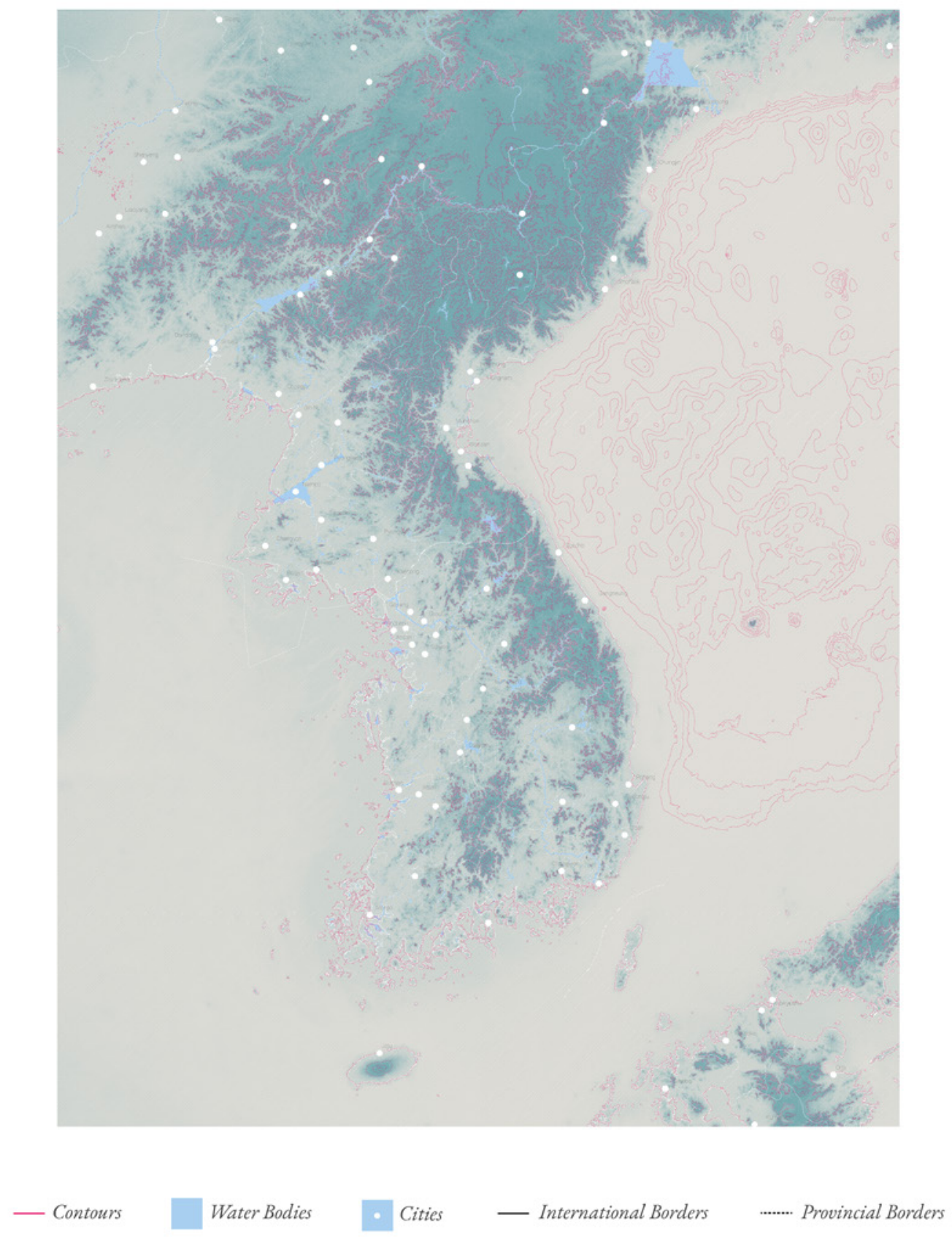

Figure 2| Peninsula: Two Koreas 


\section{INTRODUCTION}

\subsection{A Series of Divides}

"The place a group occupies is not like a blackboard, where one may write and erase figures at will. No image of a blackboard can recall what was once written there. The board could not care less what has been written on it before, and new figures may be freely added. But place and group have each received the imprint of the other."

- Maurice Halbwachs, The Collective Memory

While both the Democratic People's Republic of Korea (DPRK) and the Republic of Korea (ROK), more commonly referred to as North and South Korea respectively, have undergone vast changes in nearly seventy years since the signing of the Korean Armistice Agreement, it is impossible to speak of one without referring to the other. Among the last remnants of the Cold War, the Korean Demilitarized Zone remains a current topic in today's media with its headlines often contextualized through fear, curiosity, and recurring themes of a fetishized Western view. Despite this, now seventy years later, today's Korean population, both North and South, hold a very faint memory, if one at all, of a once united peninsula. As such, collective 
memory, or what may be referred to in the Korean sense as han, becomes a key method in interpreting the current scenario.

Still grappling with the effects of the Korean War, a tumultuous past is revealed when looking deeper into the history of the Korean peninsula: past of invasions, hardships, colonization, and repeated foreign intervention. The rise of the DPRK and its fears of imperialism, countered with the ROK's development as a capitalist nation under American guidance is easily seen. Despite these realities, it is perhaps the collective memory however faint - of the Korean peninsula's people that bears the last hopes for reunification. Through recollections of the past, the identities of the North and South "are continually crafted and recrafted out of memory" ${ }^{1}$ and perhaps through these recollections of the past, can imaginations of the future also emerge.

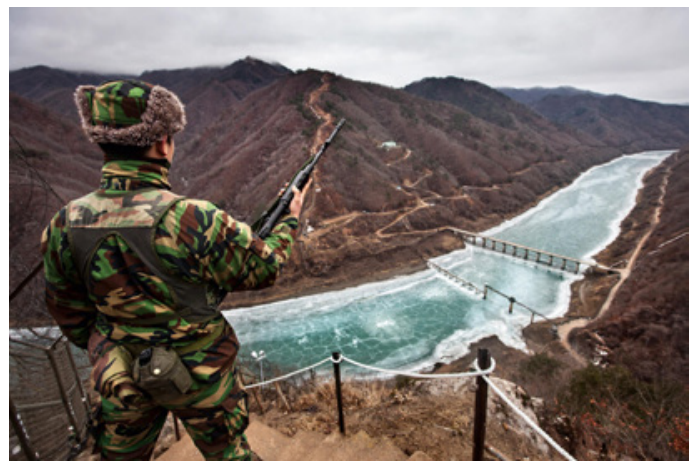

\section{Figure 3| South Korean Soldier at the Southern Limit Line Overlooking the Han River}

1 Barbara Bender and Margot Winer, Contested Landscapes: Movement, Exile and Place (Oxford: Berg, 2001). 4. 


\subsubsection{Death of a Dynasty}

During the Joseon dynasty, 26 monarchs ruled over the Korean peninsula during the span of several hundred years, from 1392 to 1910 . While this era of relative stability allowed advances in the arts and technology, earlier Japanese invasions in the late $16^{\text {th }}$ century left the country in ruins. Scholars and artisans were kidnapped, along with the destruction of homes, palaces, and cultural treasures. This was quickly followed by the invasion of the Manchu, the capturing of Seoul, the Joseon king's surrender, and the establishment of the Chinese Qing Dynasty. Following these events, the Joseon dynasty reacted with isolationist policies, resulting in its status as a hermit kingdom, although paired with future years of peace and prosperity. It is perhaps this period of history that could be called the height of Korean culture, where the development of the arts and literature flourished.

Despite the best efforts of the hermit kingdom, unrest re-emerged at the end of the $19^{\text {th }}$ century. Through foreign imperial advances, influences of the West helped stoke political instability with the rise of new political factions and the Gabo

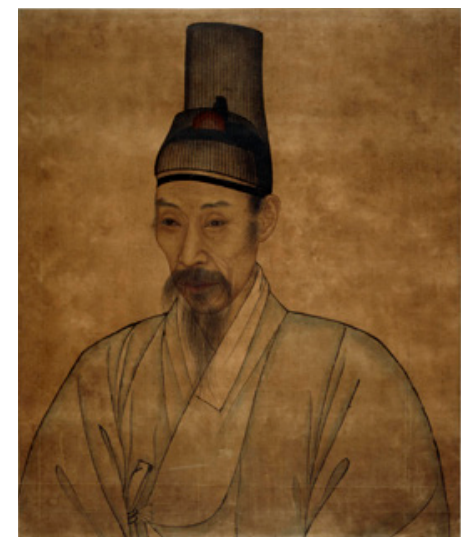

Figure 4 | Portrait

Joseon portrait depicting Western techniques shading techniques.

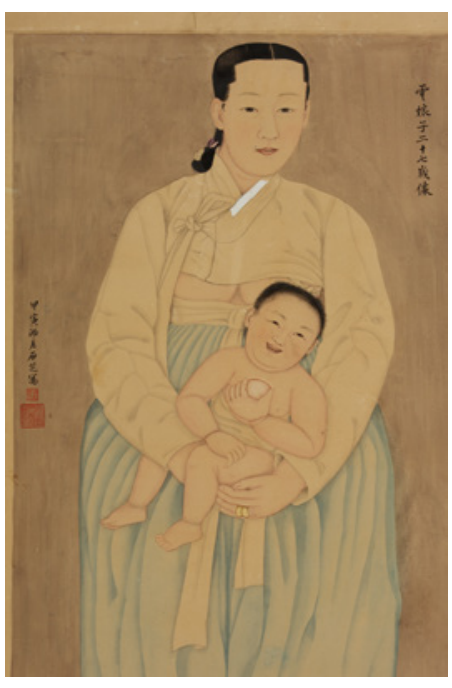

Figure 5 | Portrait of Lady 
Peasants' War. ${ }^{2}$ A call for Chinese aid in the rebellions ushered the start of the Sino-Japanese War and the eventual annexation of Korea by the Japanese Empire. With the signing of the 1910 Japan-Korea Annexation Treaty, any remaining hope for Korean independence was lost, ushering the death of a dynasty.

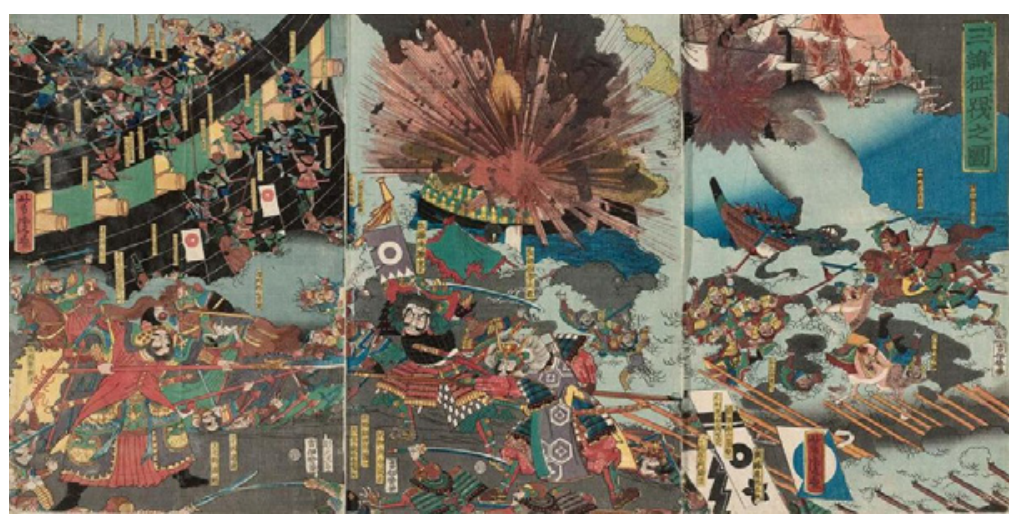

Figure 6 | The Conquest of Korea

Japanese woodblock print by Yoshitora Utagawa.

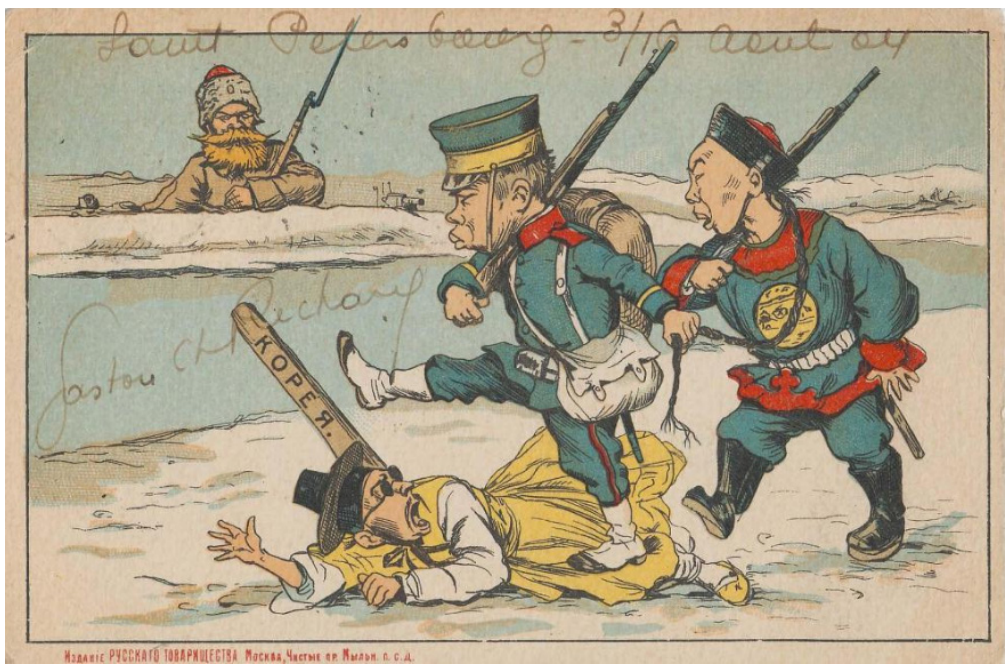

Figure 7| Political Cartoon of China and Japan trampling Korea as Russia Watches

2 Michael D. Shin et al., Korean History in Maps: From Prehistory to the Twenty-First Century, ed. Michael D. Shin (Cambridge: Cambridge University Press, 2020). 


\subsubsection{Annexed and Assimilated}

Under Japanese rule, an era of annexation and assimilation was underway. Koreans were deprived of freedom of assembly, speech, press, and association, with any attempts of rebellion or resistance met with further repression. Colonial Japanese authorities utilized the Korean school system as a method of erasure, removing the teaching of the Korean language, history, and culture. Resistance movements such as that of the March First Movement of 1919, resulted in thousands of deaths. The height of Japanese colonisation was seen during the Second World War, with Koreans forced to worship at Japanese Shinto shrines, the adaptation of Japanese-style names, the drafting of Koreans to Japanese forces, and the thousands of Korean women forced to become comfort women for the sexual pleasure of the Japanese military.

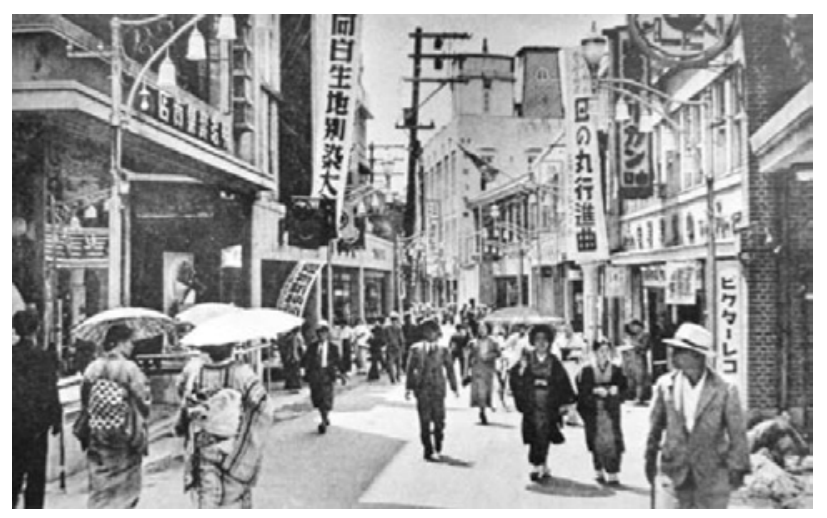

Figure 81 Seoul Avenue during the Japanese Occupation

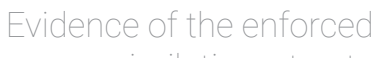
assimilation, streets 
While resistance to the Japanese occupation was met with harsh repercussions, outside the peninsula resistance continued. The Korean Provisional Government was formed under exile in Shanghai, organizing the Korean Restoration Army from afar. However, when Japanese rule finally ended, the political climate was quite different. Despite the pledge of Korean independence in the Cairo Declaration, the peninsula was still heavily under imperial pressure. Perhaps under the promise of an expedited Japanese surrender, or the fear of Soviet influence by the Americans, General Order No. 1 divided control of Korea with a line drawn at the $38^{\text {th }}$ parallel, with Japanese soldiers in the North surrendering to the Soviets, and those in the South surrendering to the Americans. Although seen as a temporary solution, this arbitrary line had much more permanent repercussions.

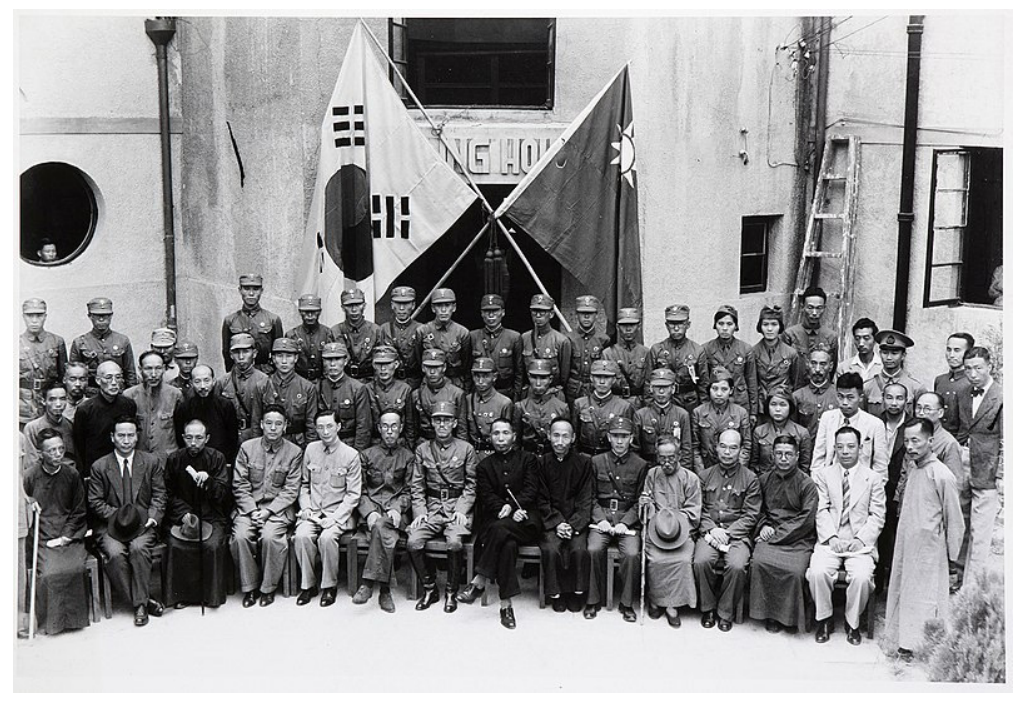




\subsubsection{Division}

With this division between North and South created, tensions rose between the Soviets and Americans. The UN General Assembly called for the unification of the Korean peninsula, instating a Temporary Commission to observe general elections. The USSR barred the Temporary Commission from the North, and general elections continued in the South, with the election of Syngman Rhee. The Republic of Korea was created, and, declared as the only lawful Korean government by the UN

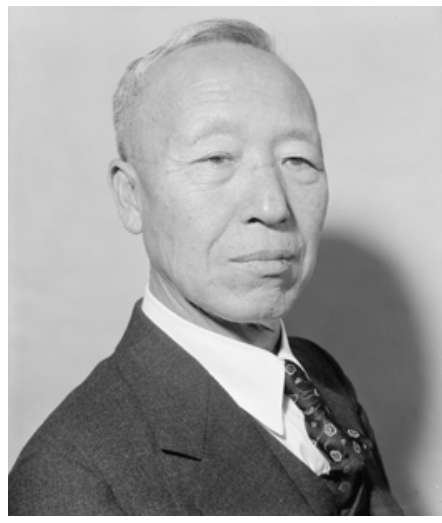

Figure 10| Syngman Rhee General Assembly. This declaration was met, in the North, with the creation of the Democratic People's Republic of Korea, the appointment of Kim Il-Sung as leader, and its declaration as the only lawful Korean government by the USSR. The Korean War soon broke out with a full fledged North Korean invasion on June $25^{\text {th }}, 1950$. Heavily armed and trained by the Soviets, thousands of troops crossed the $38^{\text {th }}$ parallel, invading the capital of Seoul and occupying much of the peninsula. Sixteen members of the UN sent armed contingents in an effort to push back the advancements of the North, with the United States of America

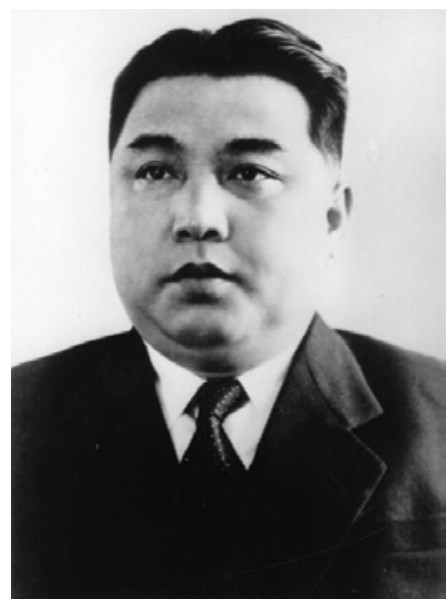

Figure 11 | Kim II-Sung providing much of the aid, financing, and supplies. While UN forces managed to reclaim the South and enter Pyongyang, the addition of Chinese forces brought the war to a deadlock, and 
the eventual agreement to a Korean armistice. Following a threeyear war and roughly 4 million deaths, the line at the $38^{\text {th }}$ parallel still remained.
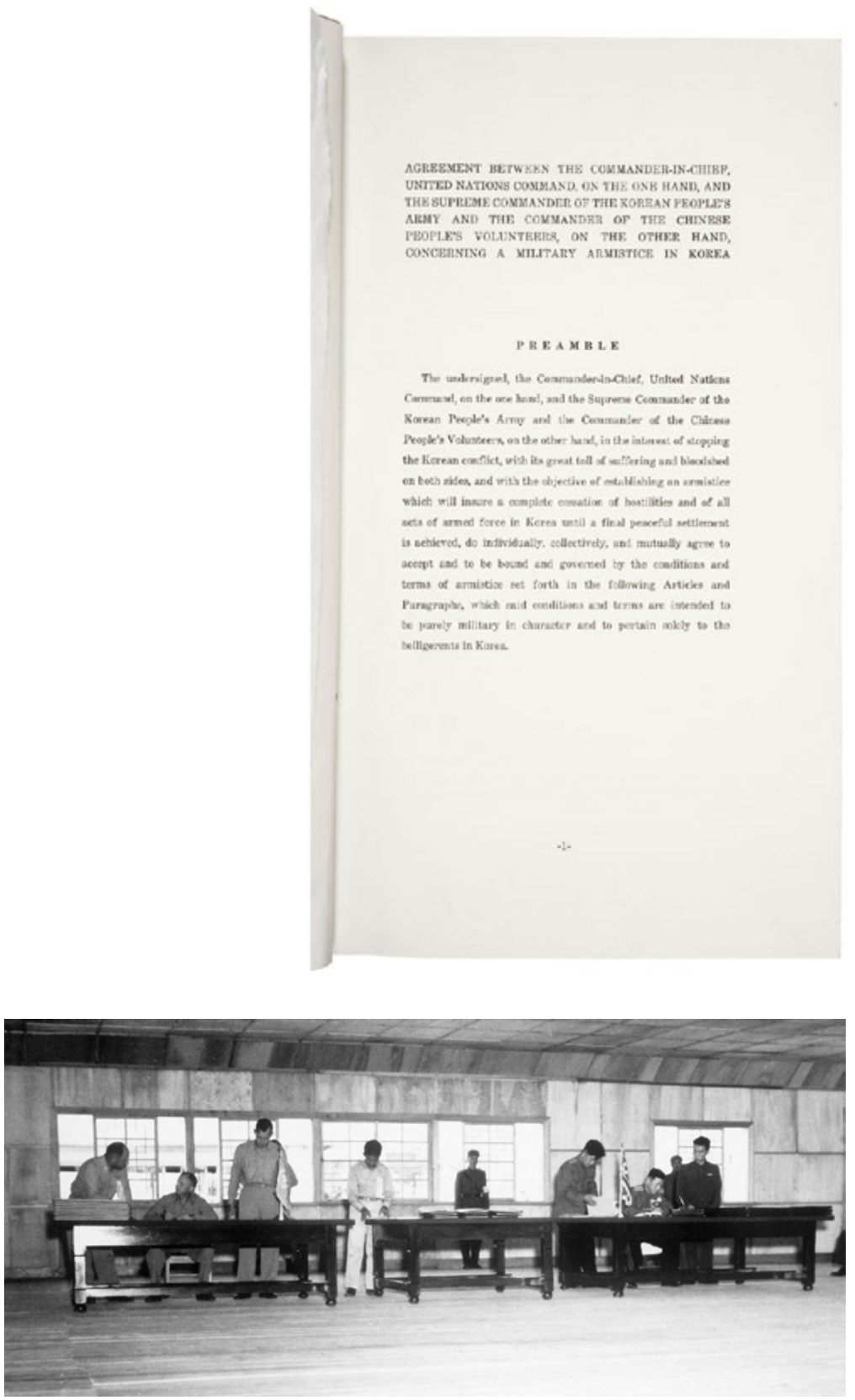

Figure 12 | Armistice Agreement for the Restoriation of the South Korean State

Figure 13 | Delegates signing the Korean War Armistice Agreement 


\subsubsection{After Armisitce}

Following the signature of the Korean Armistice Agreement on July $27^{\text {th }}, 1953$, two-fifths of Korea's industrial facilities were lost, and one-third of homes destroyed. The staunchly anti-imperialist state of the DPRK saw rapid reconstruction and the development of an industrialized economy under Soviet and Chinese aid. ${ }^{3}$ However, the nineties marked the fall of Soviet power, rapid economic decline, and the death of Kim Il-Sung. In an almost opposite chain of events, the Republic of Korea saw its first peaceful transfer of power in 1988, and its first election of a civilian president in 1993, marking the end of years of political unrest, martial law, coup d'états, assassination attempts, and six different republics. With the securing of democratic stability in the South, and the establishment of a dynastic dictatorship in the North, the years since the nineties have seen both acts of aggression and calls for reconciliation between the two. And yet, a 250 -kilometre line along the $38^{\text {th }}$ parallel remains.

3 David Heather and Koen de. Ceuster, North Korean Posters: The David Heather Collection (Munich, London: Prestel, 2008). 


\section{PART ONE // THE MEDIA}
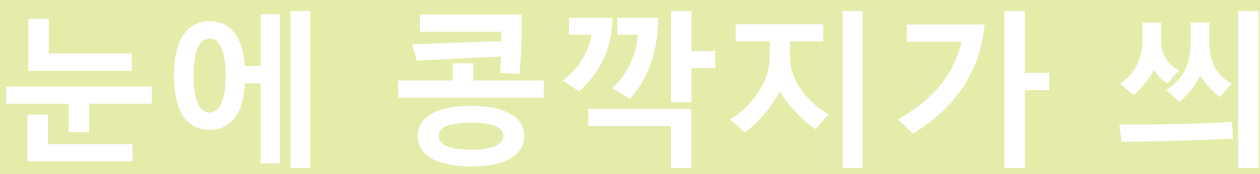


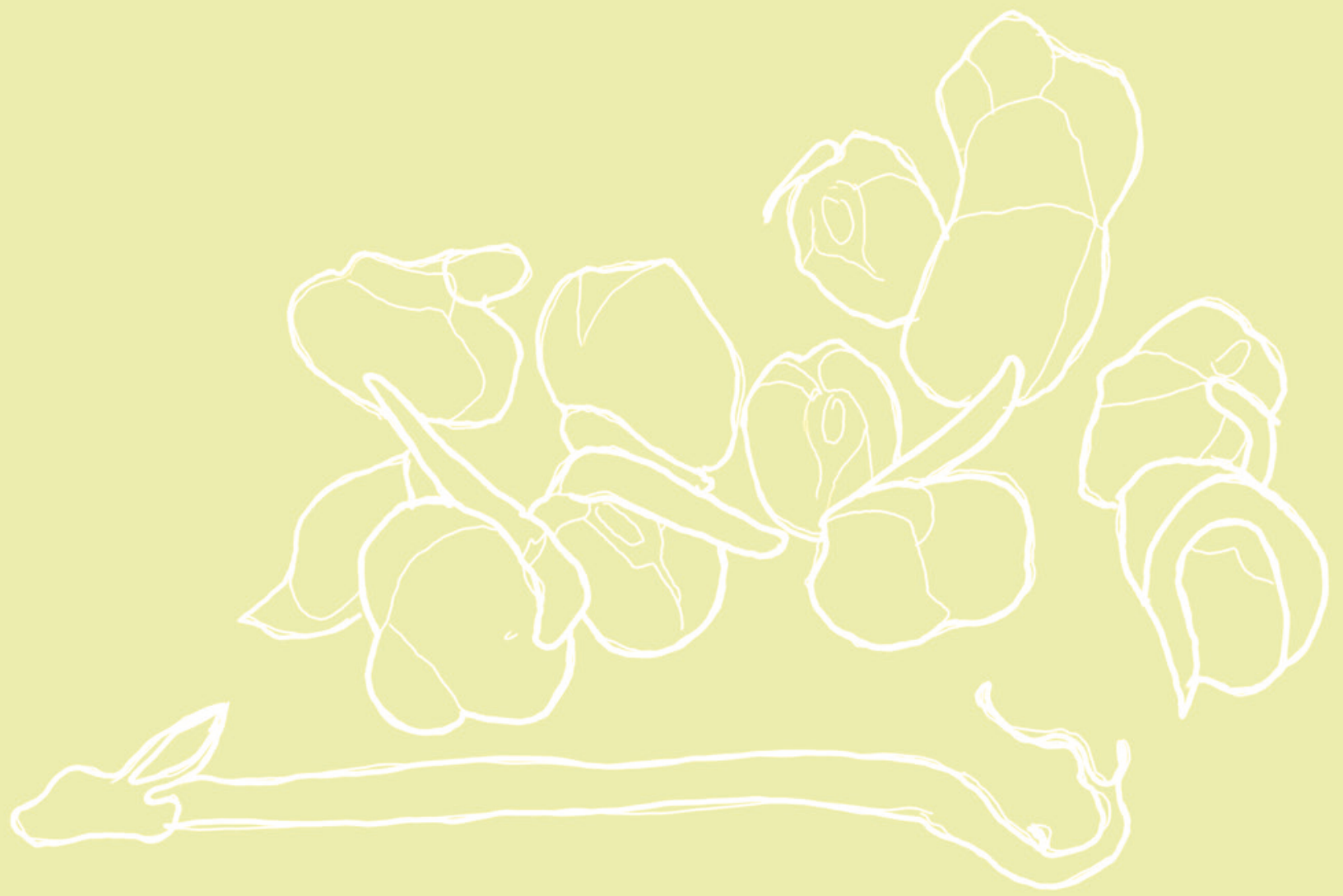




\section{THE MEDIA}

\subsection{Two Koreas}

"The successor to politics will be propaganda, not in the sense of a message or ideology, but the impact of the whole technology of the times. So politics will eventually be replaced by imagery. The politician will be only too happy to abdicate in favour of his image, because the image will be so much more powerful than he could ever be."

\section{- Marshall McLuhan, The Lost Marshall McLuban Tapes}

Often, the sole insight, for those of us on the outside, on the Korean peninsula is through the media, and it is for this reason, that the idea and context of "media" serves as a key concept in this thesis. While images of the South are ubiquitous hightech metropolises, K-Pop groups, and popular Korean drama and variety shows, the North offers a much more curated image of mystery and uncertainty, a final glimpse into a Cold War era controlled by state-mandated images of parades, missiles, and the power of a purportedly socialist regime. Peering Western eyes, and a techno-orientalist ${ }^{1}$ gaze has created a sensationalized

1 David S. Roh, Betsy Huang, and Greta A. Niu, eds., Techno-Orientalism: Imagining Asia in Speculative Fiction, History, and Media (New Jersey: Rutgers University Press, 2015). 
vision of both countries. These different views and appearances divide the peninsula and its people further, and yet, it also provides a connection. It is through the media that South Koreans witness scenes of the North, a region that many will never visit in their lifetime, providing a reminder of the division at the $38^{\text {th }}$ parallel, and perhaps a sense of han. Marshall McLuhan observes that, "... media study considers not only the "content" but the medium and the cultural matrix within which the particular medium operates." ${ }^{2}$ It is perhaps through this study of media that the scenario of the Korean peninsula can begin to be understood in today's era, and in its potential futures. While differences in politics may have divided the Korean peninsula, the power of the image holds truer today, as the agency of representation in its communicative, story-telling and mythologizing power is realized.

2 Marshall McLuhan, Understanding Media (Berkley California: Ginnko Press Inc, 2013). 

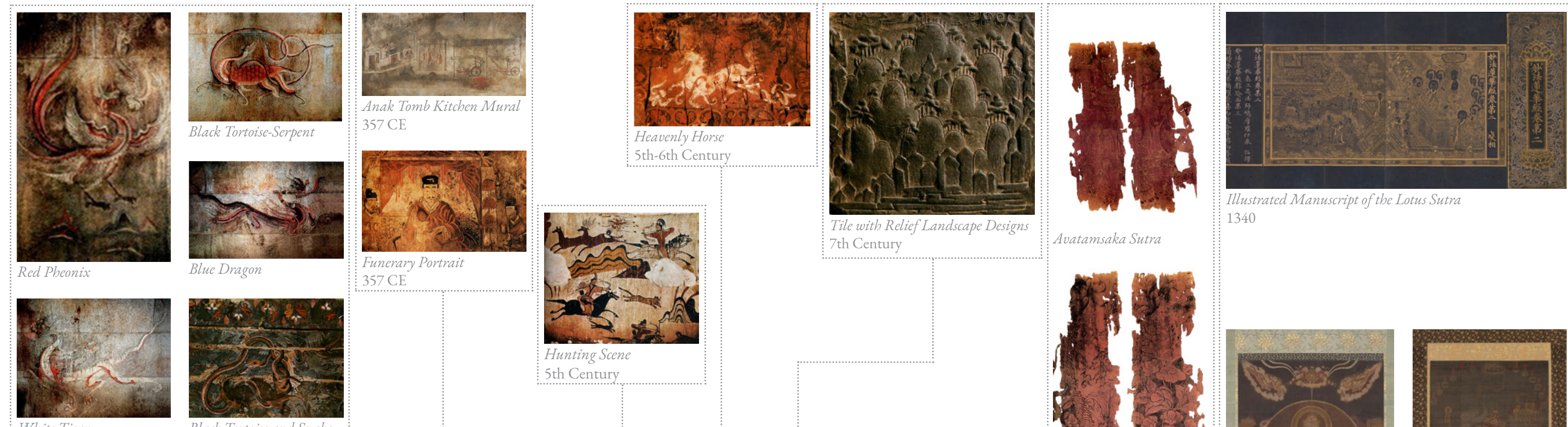
$357 \mathrm{CF}$

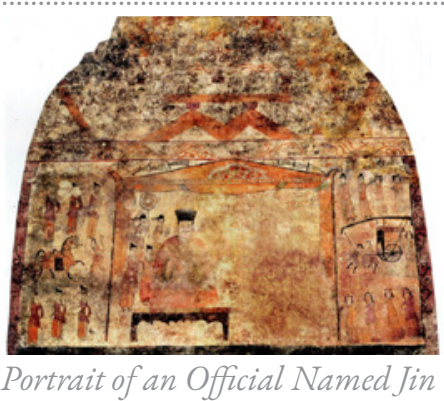

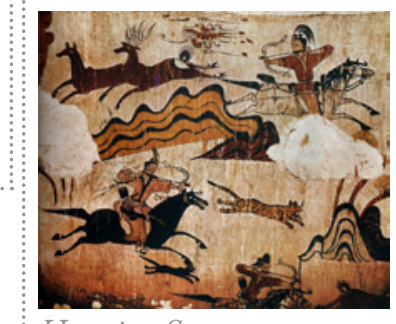

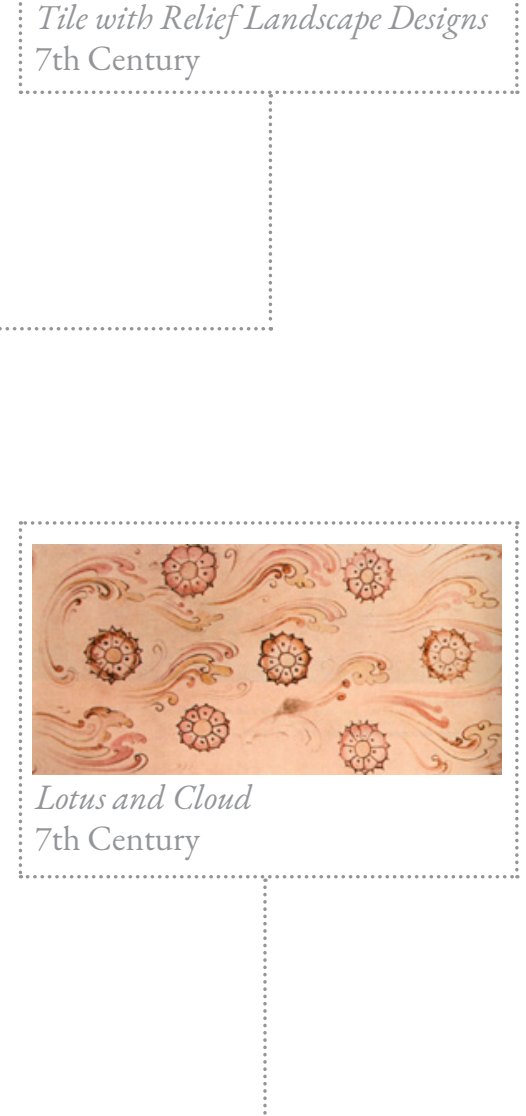

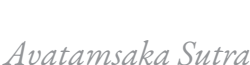

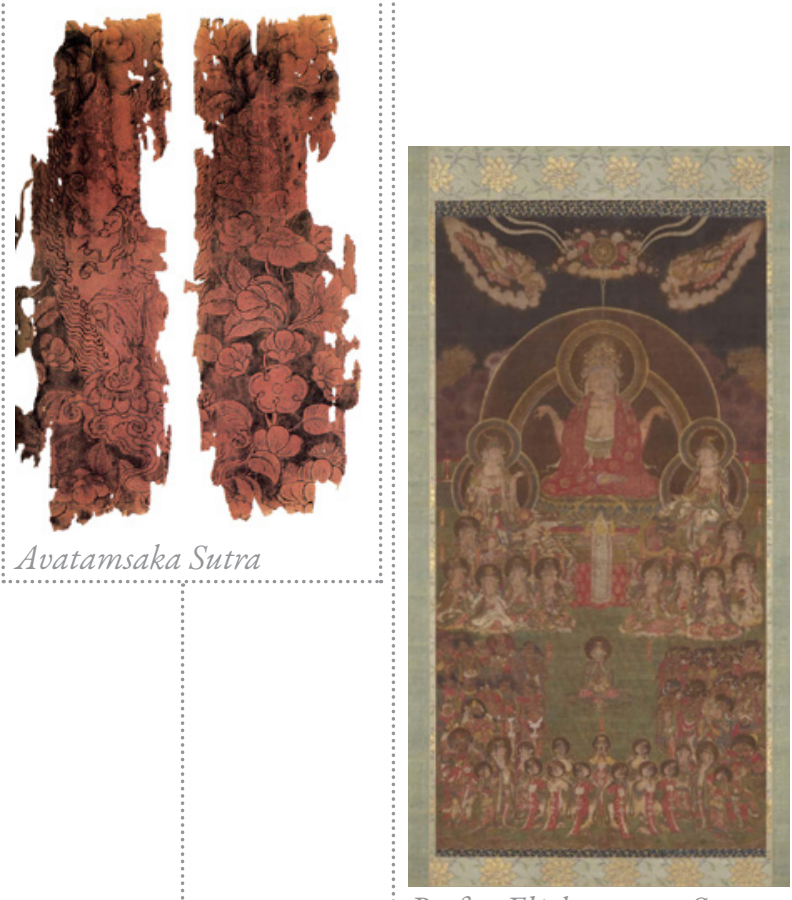

Illumintaion

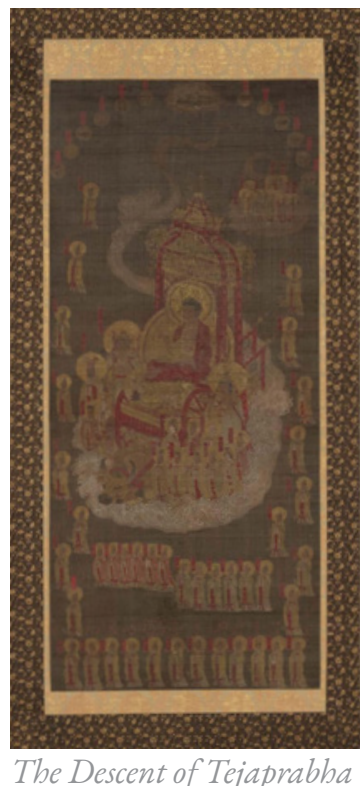

Buddha ate 14th Century

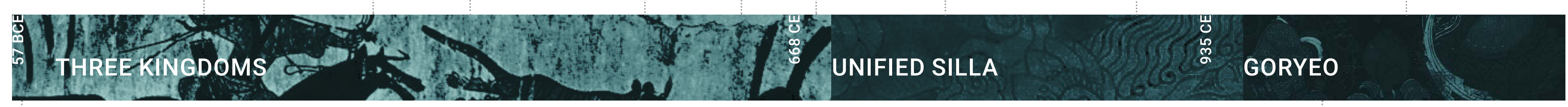



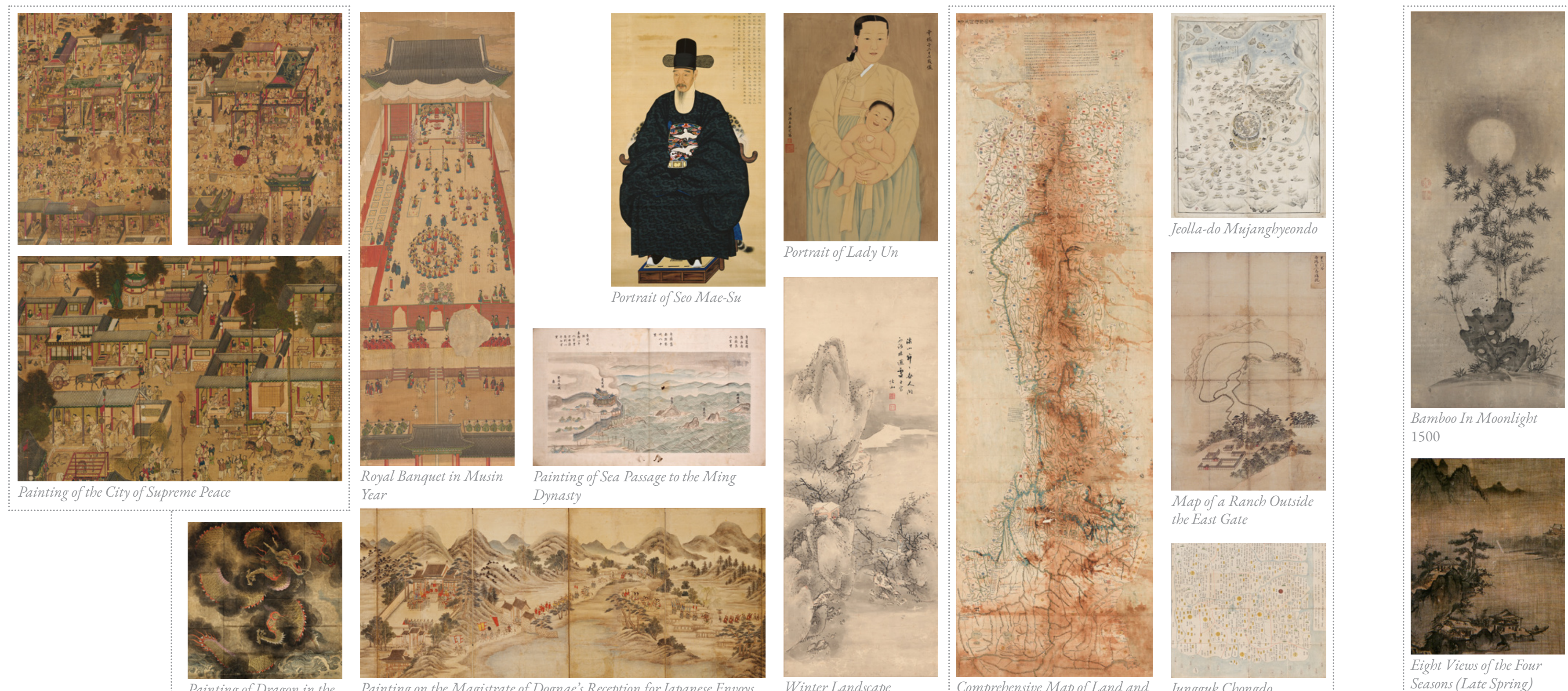


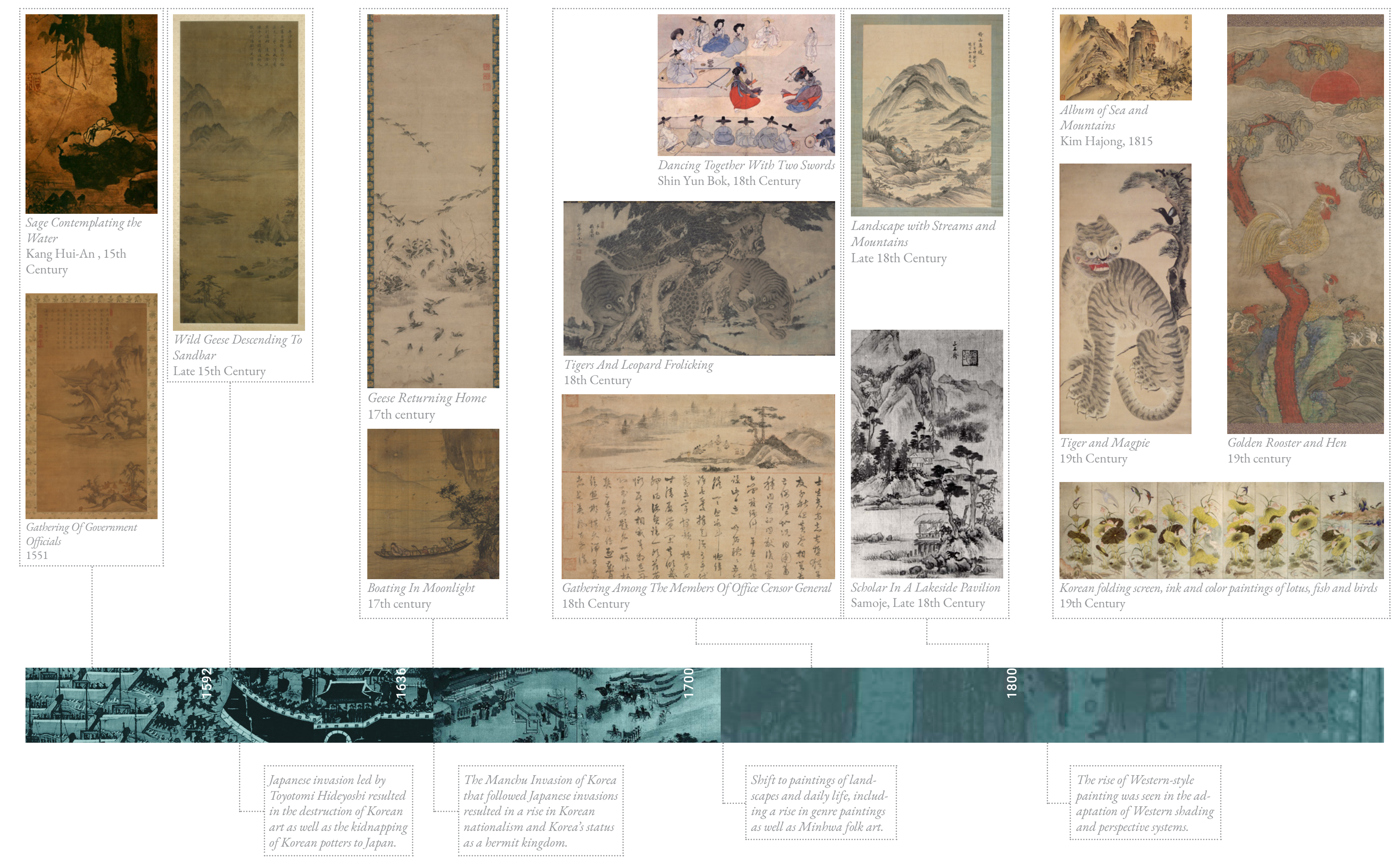




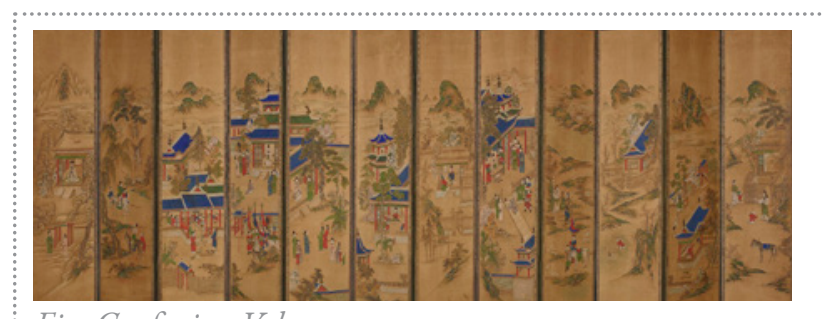

19th Century

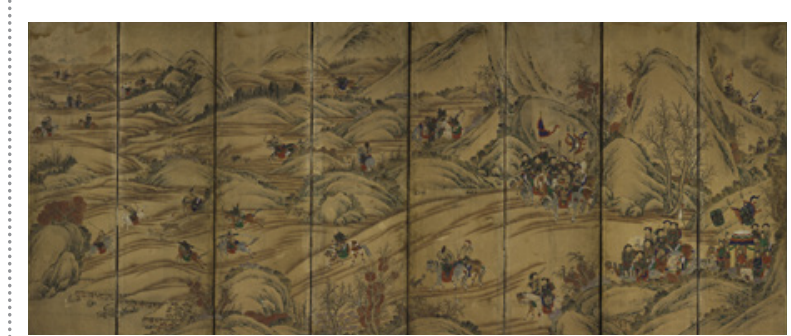

Hunting Scene
19th Century

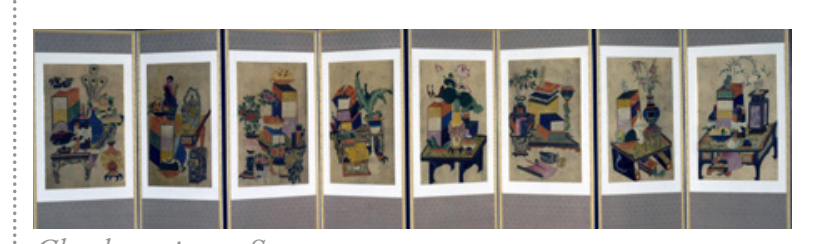

Chaekgeori-ty

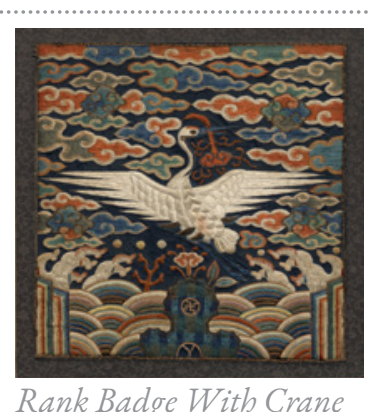

Motif
19 th Century

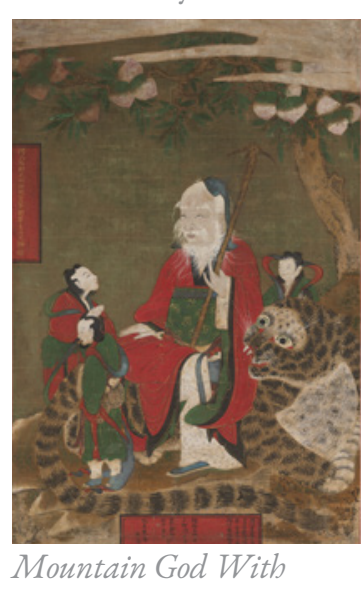

Tiger And Attendants
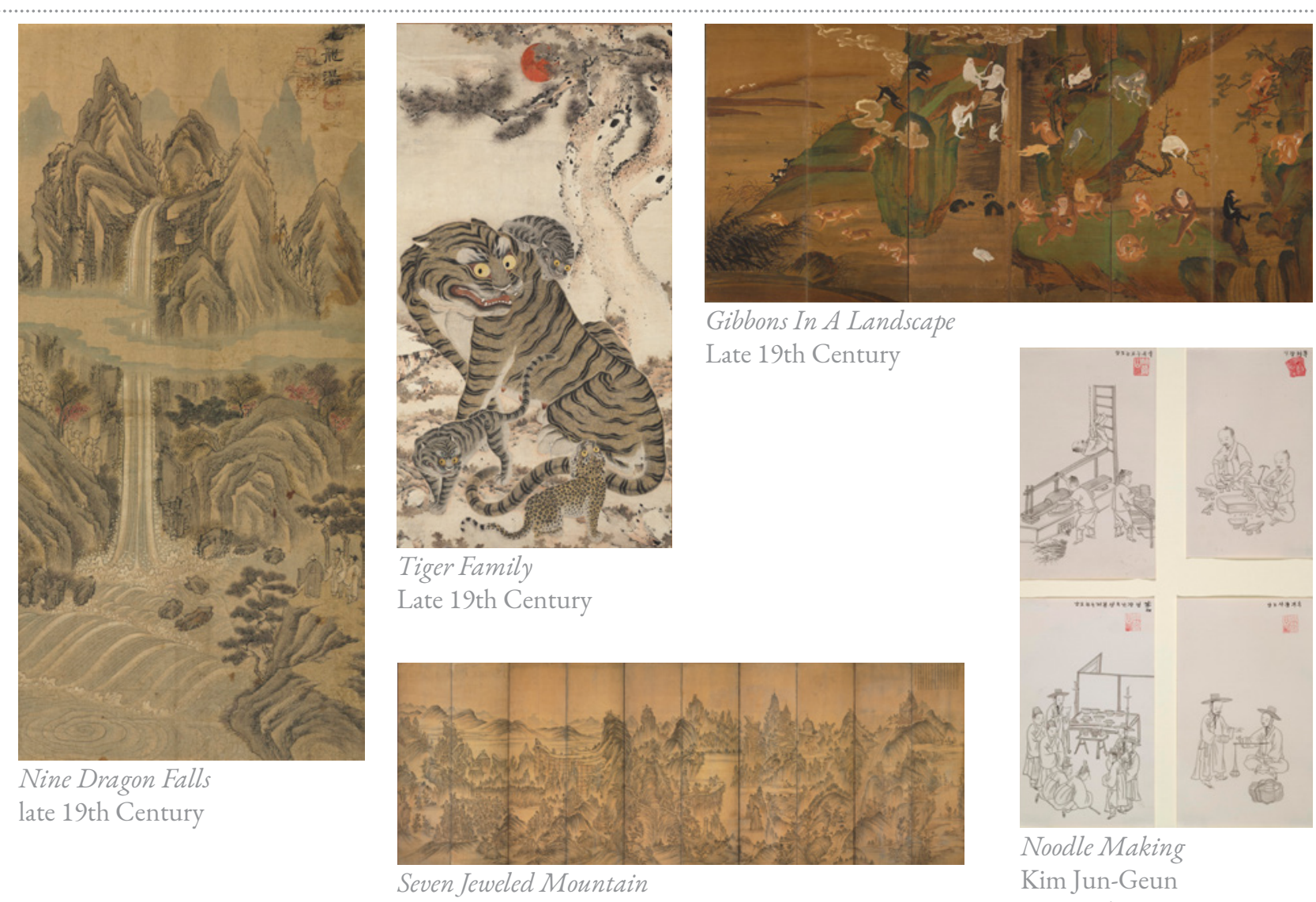

$\because-1)^{2}$

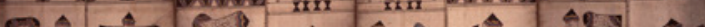
ค슨

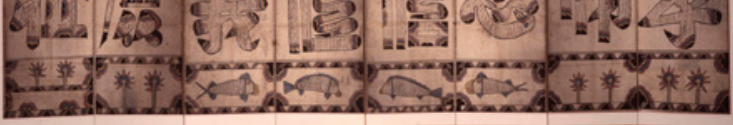
The Eight Confucian Values

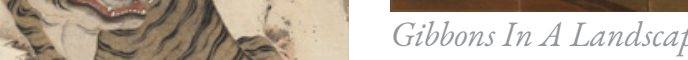
The Eight Confucia

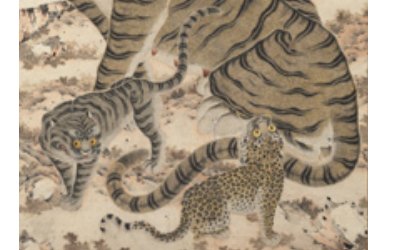

Late 19th Centur
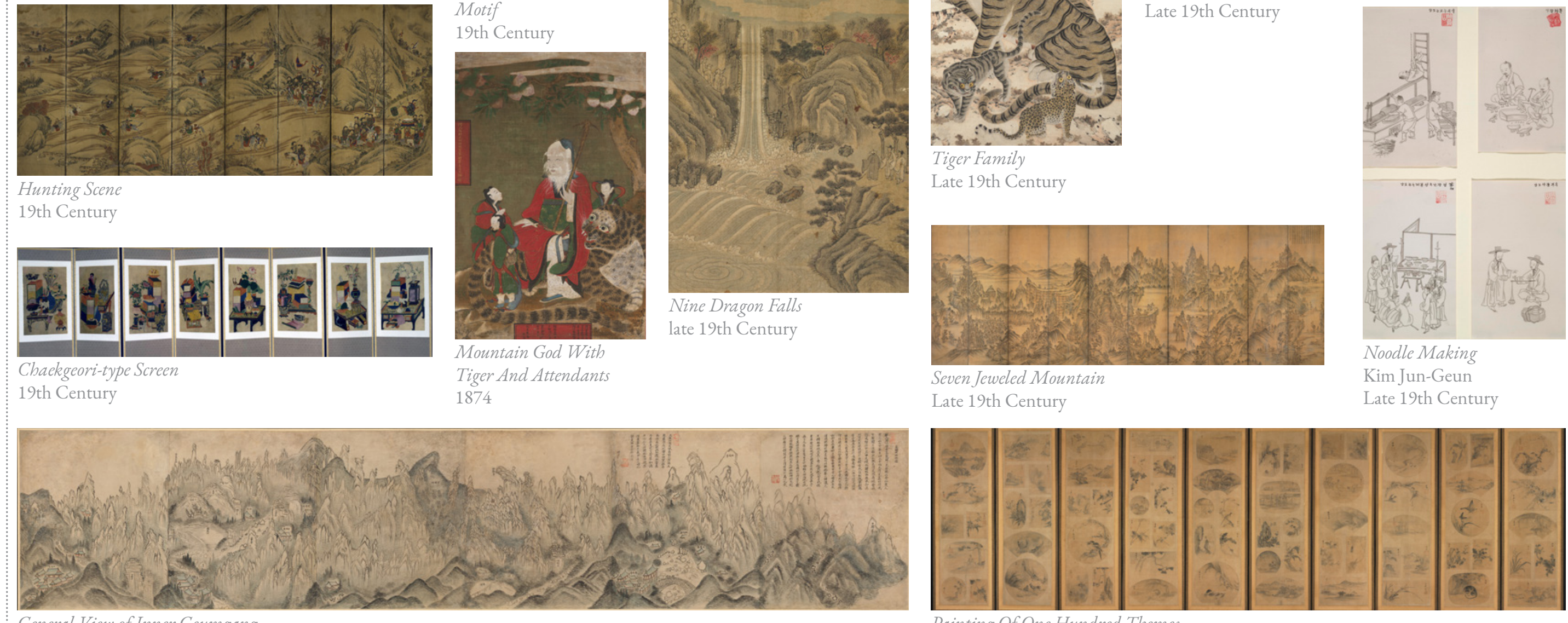

Tiger Family

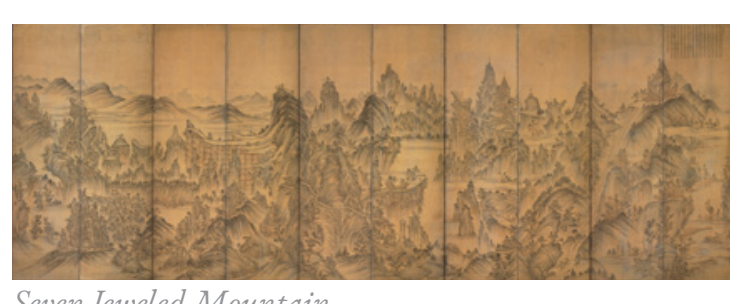

Seven Jeweled Mountain
Late 19th Century

Kim Jun-Geun
Late 19th Century

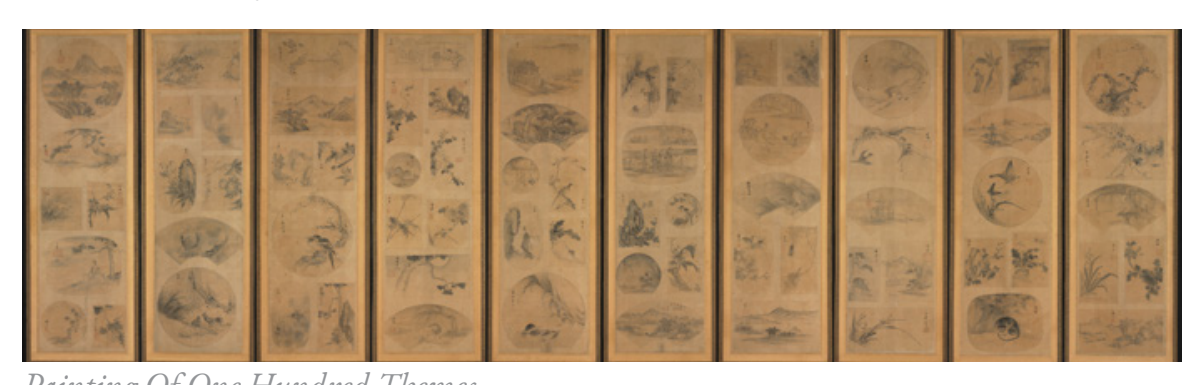

Sin Hakgwon, mid 19th century

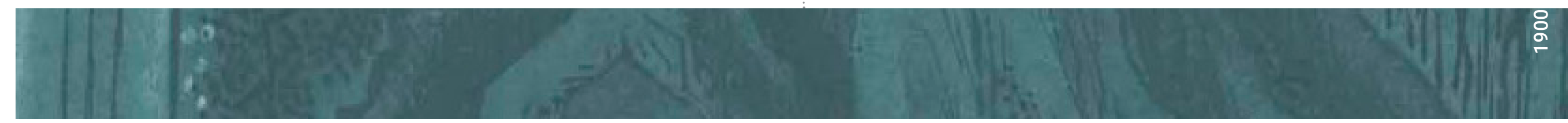




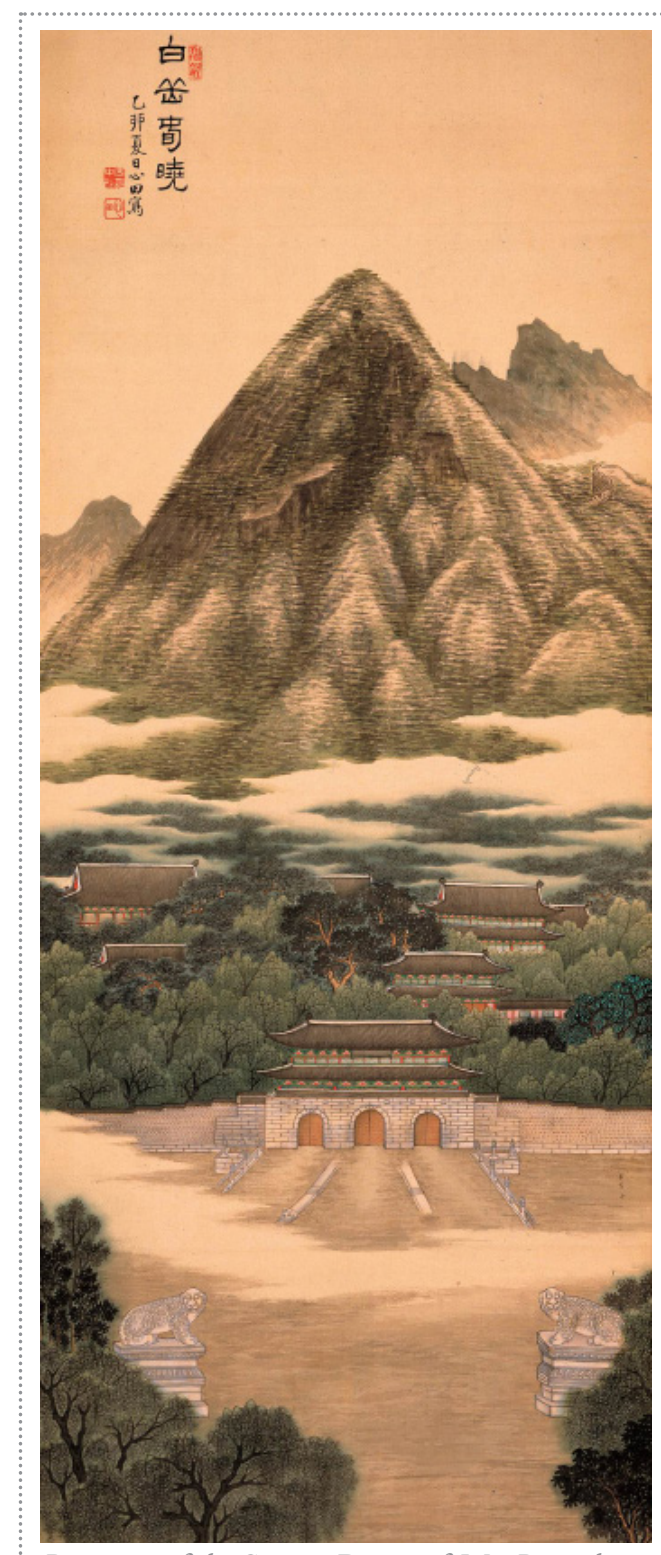

An Jung Sik, 1915

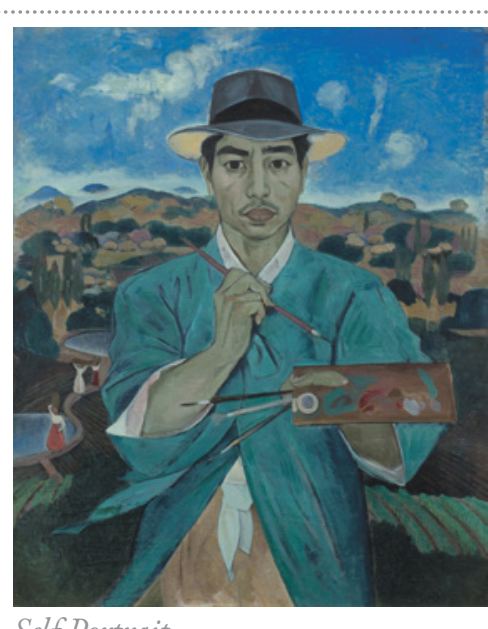

Lee Quede, 1940 s

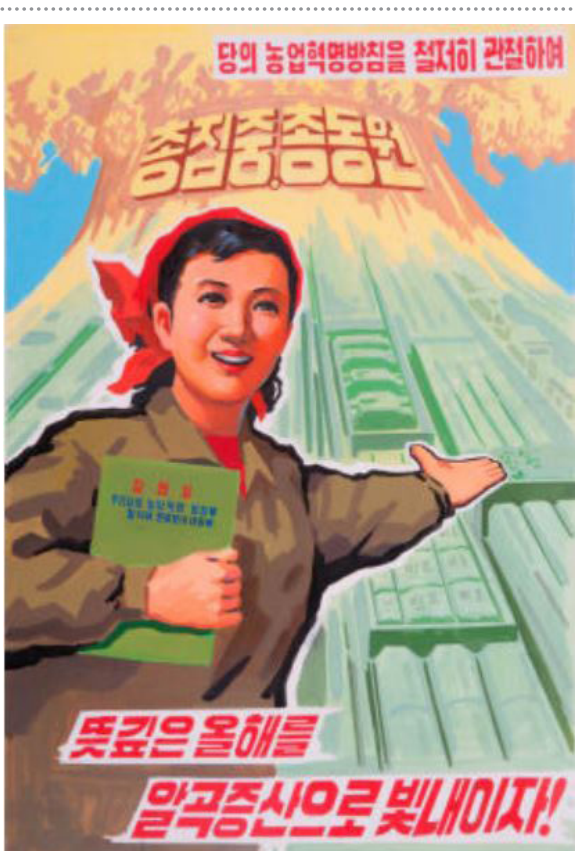

olution Policy Thorougbly and Brighten the

Year with Increased Grain Production

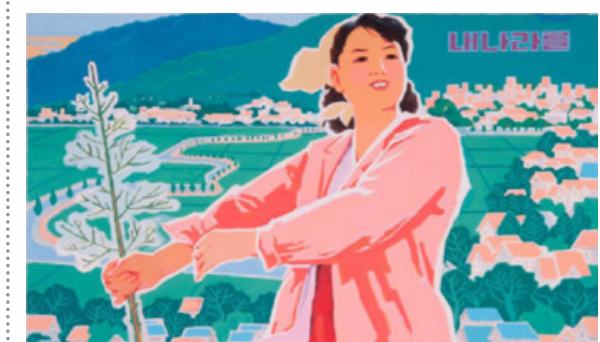

F)

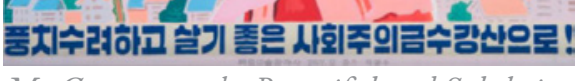
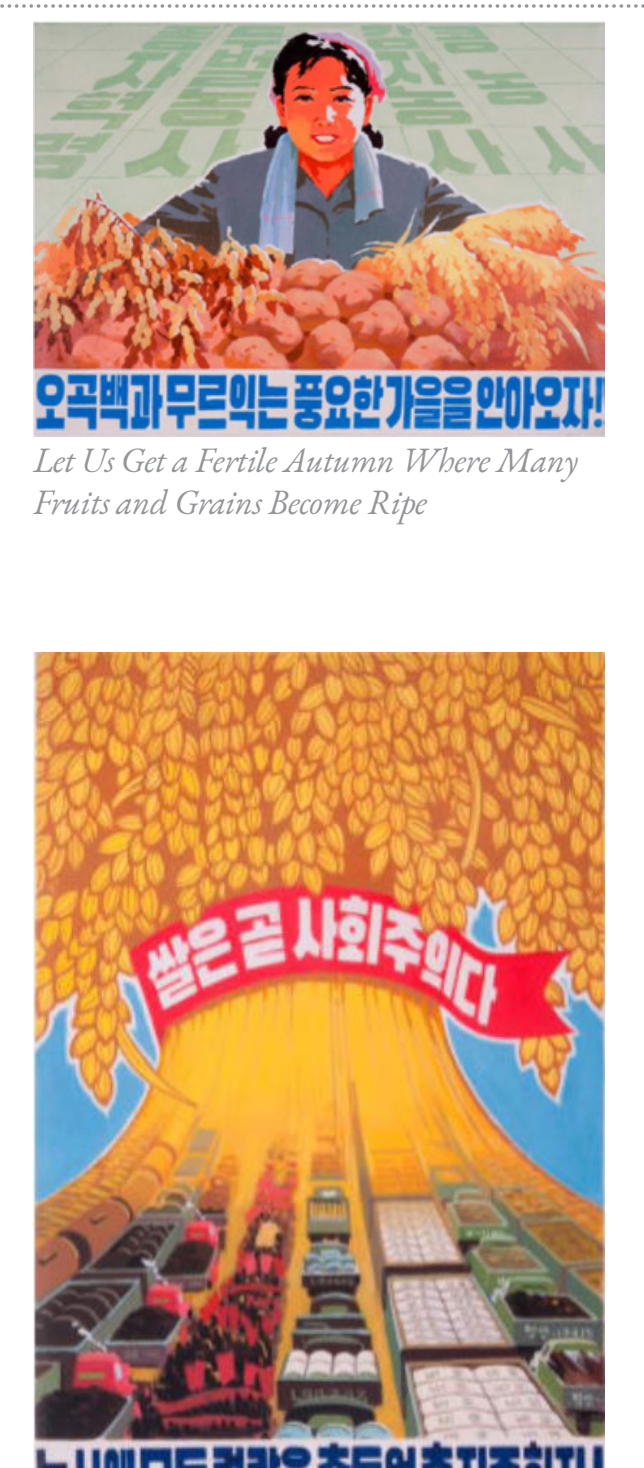

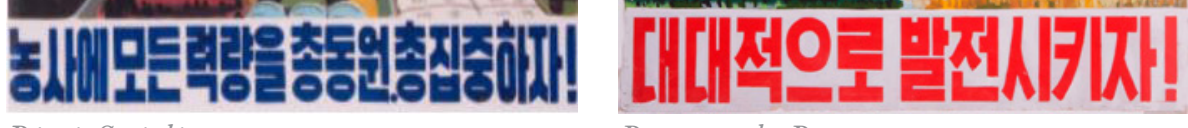

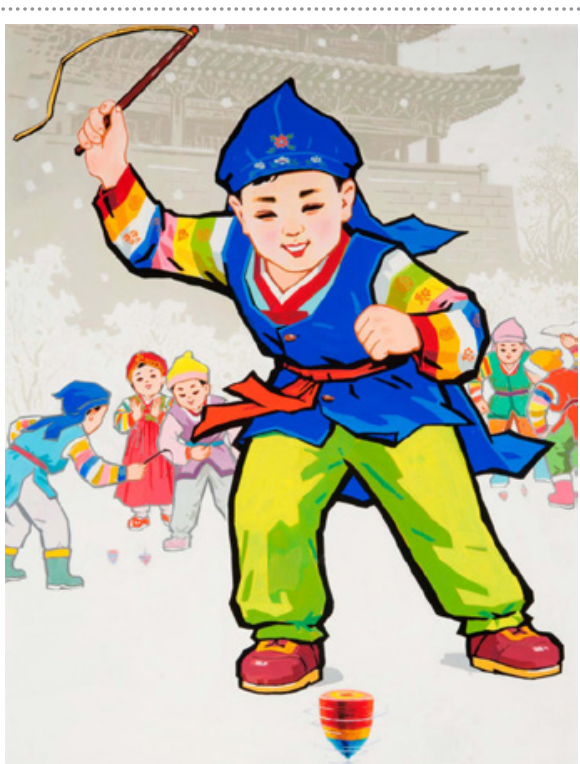

팽이치기 신나용!

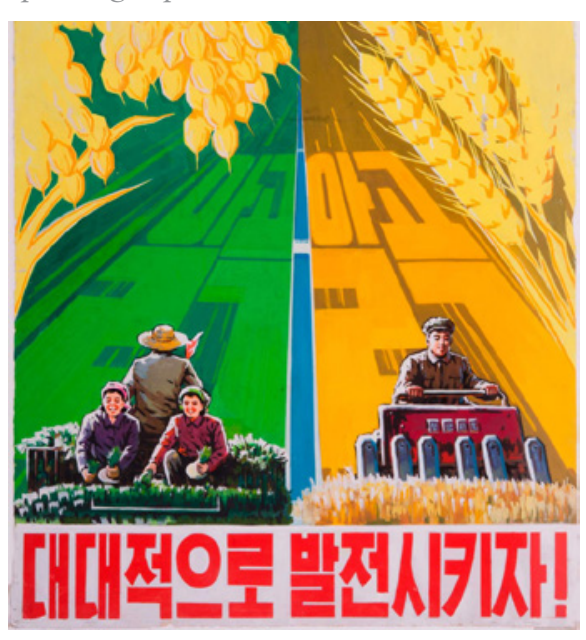

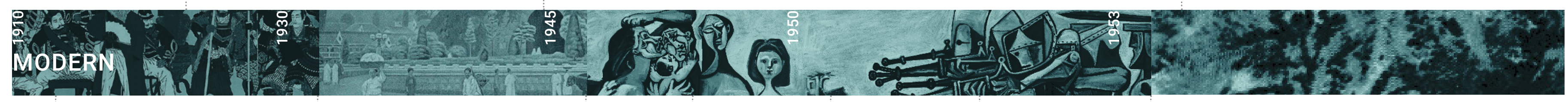

Japan formally annexed
Korea with the Japan-Korea Treaty of 1910 .

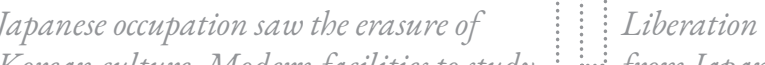

Korean culture. Modern facilities to stud

the arts were Japanese. As such, Korean ant

Western Influences. from Japanes
colonial rule.

Repultic of of the

and the Democratic

People's Republic of
Korea.
Start of the Korean Establishment of Juche Ideol- Armistice Agreement and

ogy by Kim Il-Sung, creatin

Korean policies and media. 

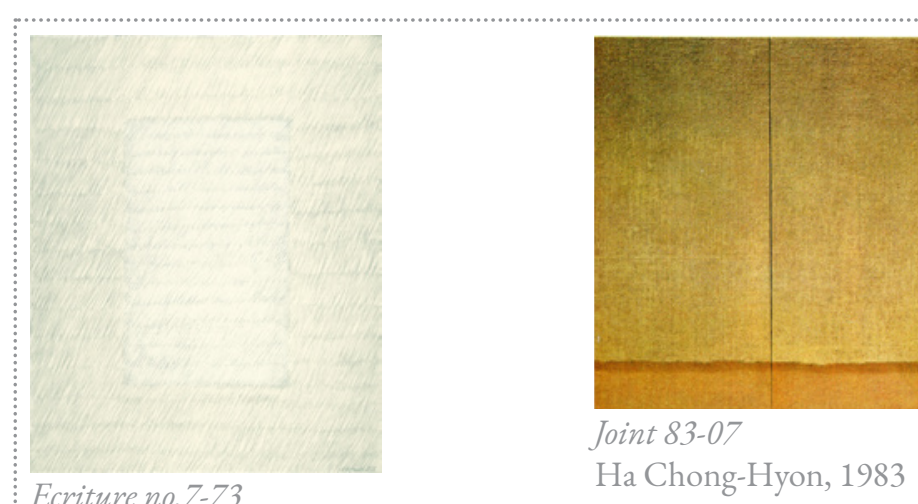

Park Seo-bo, 1973

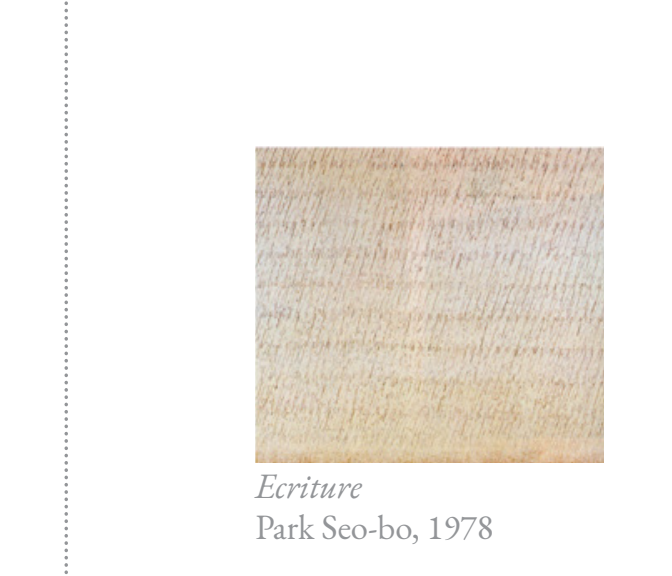

Park Seo-bo, 1978

Joint 83-07
Ha Chong-Hyon, 1983

a Chong Hyon, 1983

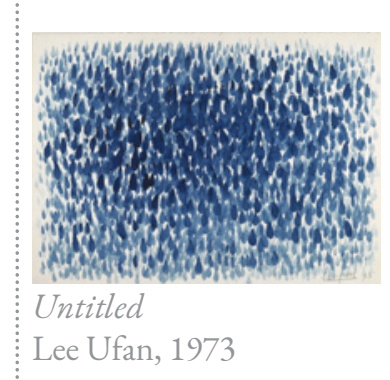

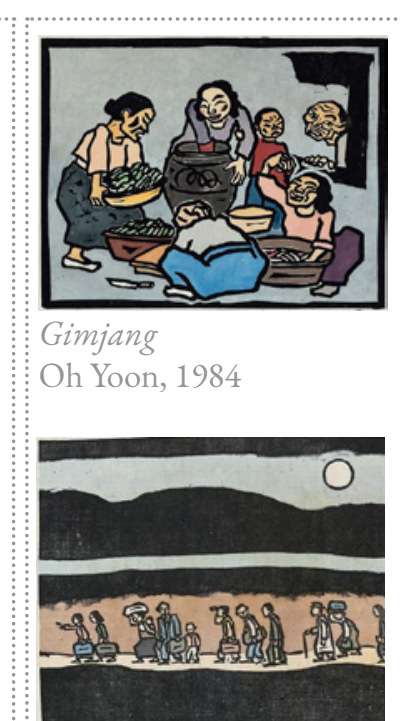
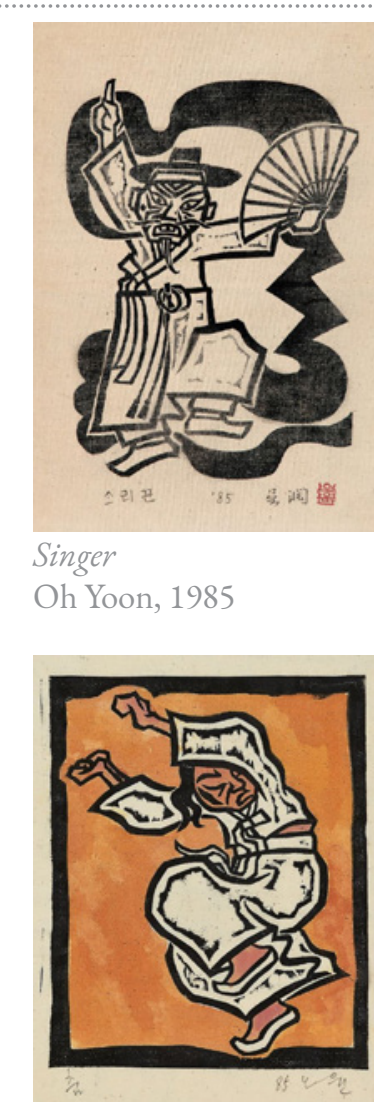

12 Years

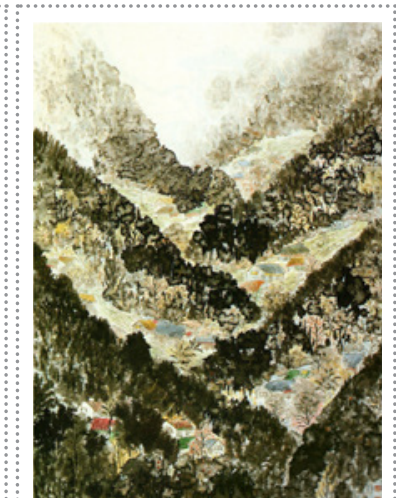

In Daily Life Yi Wal-Chong, 1985

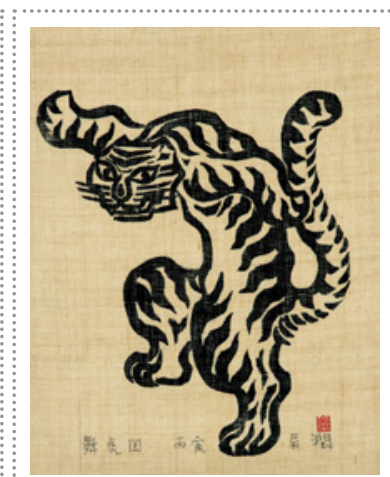

Dancing Tiger
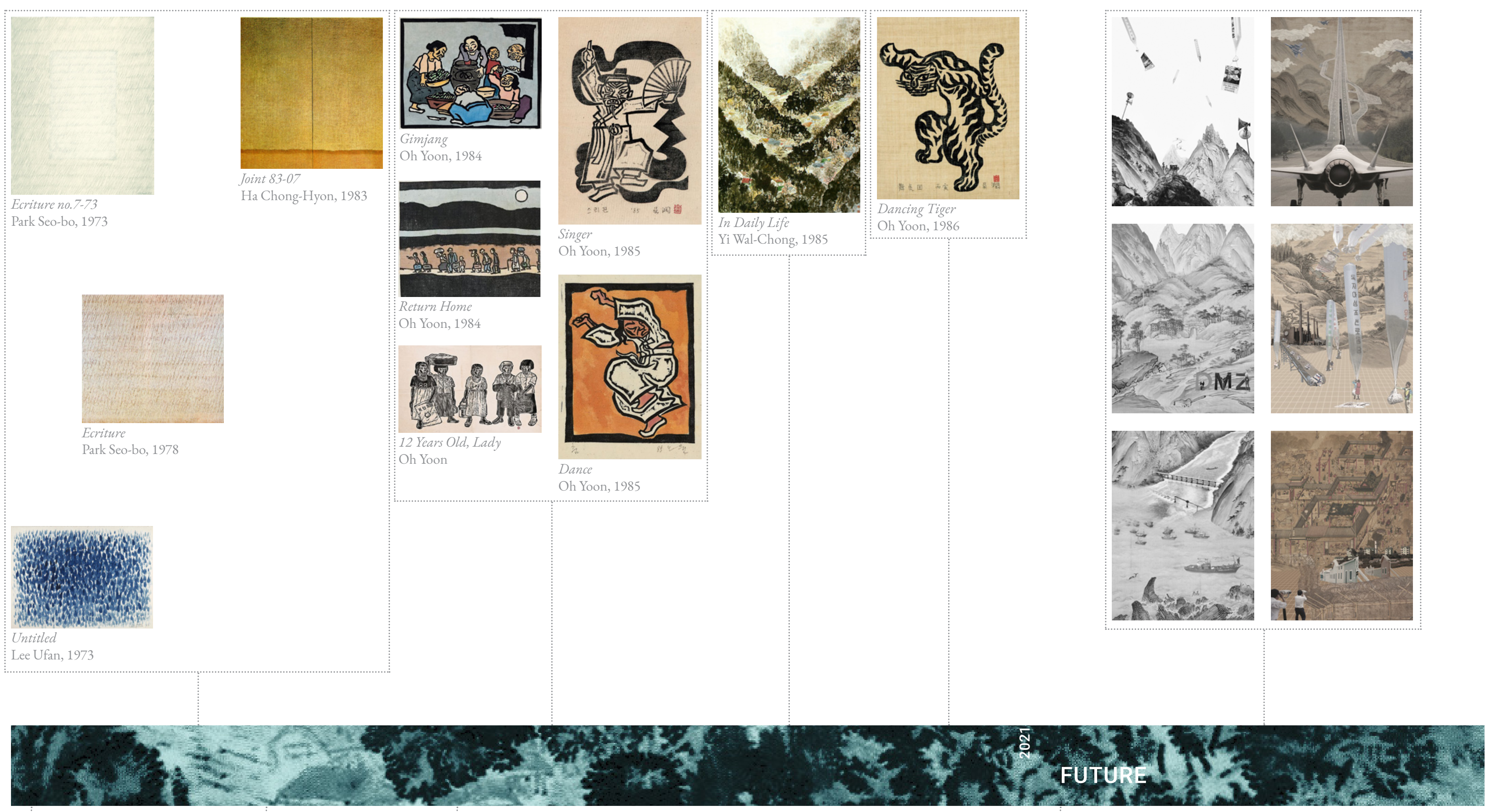

Creation of Monocbrome truly Korean art form
Gwangju Uprising Minjung Misul or People's
Arr built on themes of polit-
ical unrest and traditional
Korean art styles. 


\subsection{Drawing from Memory}

"An archive may be largely about 'the past' but it is always 're-read' in the light of the present and the future: and in that reprise, as Walter Benjamin reminds us, it always flashes up before us as a moment of danger.” - Stuart Hall, Constituting an Archive

Realizing the agency of media and representation, as well as its accompanying cultural matrices, traditional forms of Korean art provide a key point of departure for this thesis. As our current understandings of both Korean nations is through the lens of media, traditional Korean art provides useful analysis and point of entry into the Korean landscape as it has been shaped over the years. This analysis helped produce an archive - a collection of works of visual landscape culture - and allowed for "an object of reflection and debate" ${ }_{3}$ to be created. This collection of images date from the Joseon dynasty onwards, when Korea experienced a growth in cultural developments and relative peace, allowing for a concentration on the arts, and the development of a distinctive Korean style of art and visual ex(2001): 89-92, https://doi.org/10.1080/09528820108576903. 89. 
pression. This archive was to help generate an understanding of Korean landscape representation as a means of imagining the Korean Demilitarized Zone, images of other subjects such as Buddhist paintings, court scenes, flora and fauna aided in interpreting its accompanying cultural matrix, and how these were represented in contrast to landscapes, as well as acting as inspiration for representational devices within my own work.

In the archive, common themes within Minhwa folk art, or the art of the commoner, were found. Despite the influence of court paintings, subjects such as tigers and magpies that are traditionally absent are seen. Other themes such as the 10 symbols of longevity (the crane, deer, fungus, rocks, water, clouds, the Sun, the Moon, the pine tree, and the tortoise) $)^{4}$ are also evident and depicted in a flat, symbolic, or sometimes abstract style. Additionally, images collected from the Joseon era further display and reveal other techniques of imaging and seeing; landscapes are depicted through ink and light colours, and dots or short rhythmic lines create a sense of texture. Within these landscapes, mountains often appear as wavy strips arranged to create distance and depth, while elements echo each other in shapes and forms. Other devices include one-corner compositions, or the use of multiple perspectives acts as a tool to emphasize the

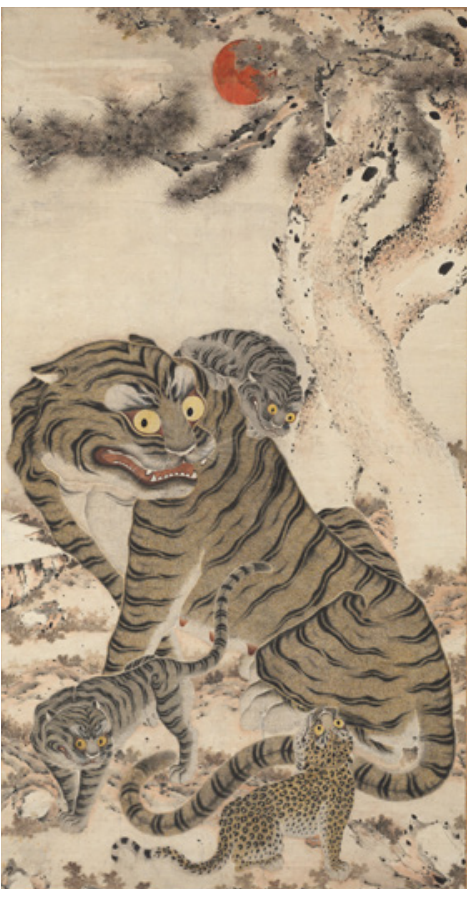

Figure 15 | Tiger Family

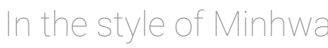
folk art

$4 \quad \mathrm{~S} Y \mathrm{i}$, Youngna Kim, and Won-Yong Kim, "Korean Art," Encyclopedia Britannica, 2015, https://www.britannica.com/art/Korean-art. 
height of mountains, constructing a series of strange fantasies. The identification of these key devices, as well as the recurring medium of the scroll or panel, help establish a method of representation and narrative in imagining the $\mathrm{DMZ}$ through the subsequent thesis work.

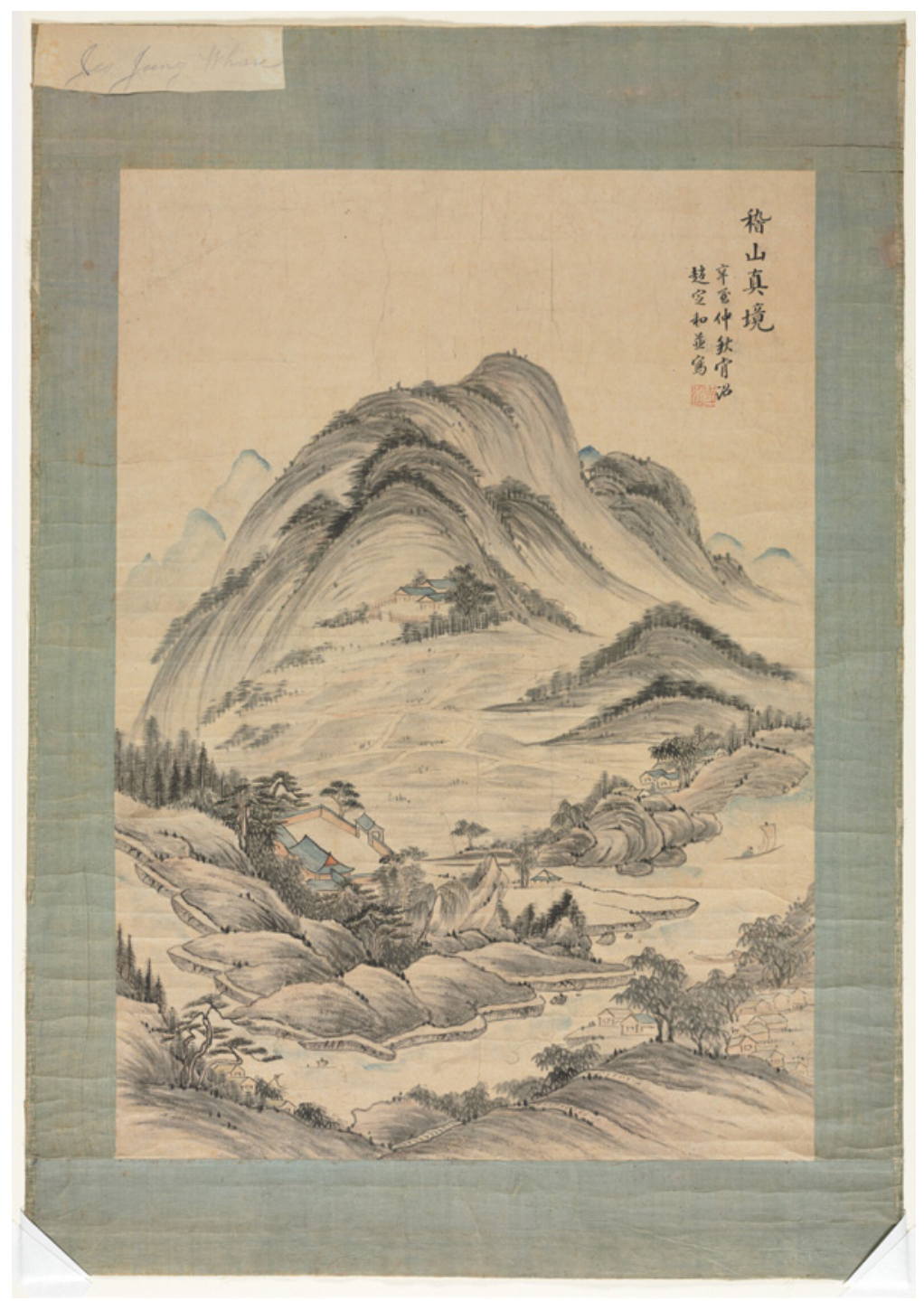

Figure 16 | Landscape With Streams and Mountains

This image depicts the use of shifting perspectives to highlight landscapes 


\title{
1.3 On the Other Side
}

\author{
"The entire life of societies in which modern conditions of \\ production reign announces itself as an immense accumulation \\ of spectacles. Everything that was directly lived has moved away \\ into a representation.” \\ - Guy Debord, The Society of the Spectacle
}

While the archive serves as a tool of reflection in order to re-read the past and provide insights to the future, the agency of representation was a constant question and provocation. In investigating the Korean Demilitarized Zone through the lens of media, it became necessary to consider the particular forces - and rationales - behind the use of said media. Where images and posters of the North Korean regime demonstrate a more obvious example of propaganda, it is important to note that South Korean media crafts an equally controlled image. As outlined in Guy Debord's Society of the Spectacle, social life has become replaced with its mere representation, with the spectacle revealing itself as information, propaganda, advertisement, and other forms of entertainment consumption. ${ }^{5} \mathrm{~A}$ spectacle where 5 Guy Debord, Society of the Spectacle (Detroit: Black \& Red, 1970). 6. 
authenticity versus inauthenticity may be questioned. It is within this spectacle that the "Subliminal and docile acceptance of media impact has made them prisons without walls for their human users." Within this spectacle, media (advertisements, radio-programs, pamphlets, etc.) from both the North and South present a highly curated representation of a model society, one of capitalist origin, and one dictated by the Juche ideology of Kim Il-Sung. ${ }^{7}$ The South Korean model of consumerism is highlighted in the exceptionally competitive and closed talent agencies producing Korean pop media, while the media of the North follows core Juche principles of political autonomy, economic self-reliance, and a strong position of self-defence. Even with these differing models of spectacle, their representation originates from the same key cultural ties. Elements of han are seen throughout pop culture in movies such as The Host, directed by Bong Joon-Ho, as well as traditional art forms like Pansori, or the iconic Korean song Arirang. ${ }^{8}$ This inherent tie to culture and traditions repeats itself in the development of North Korean propaganda art. With the banning of bourgeois art, and socialist realism representing the only acceptable art form, art

\footnotetext{
$6 \quad$ McLuhan, Understanding Media. 26.

$7 \quad$ David Heather and Koen de. Ceuster, North Korean Posters: The David Heather Collection (Munich, London: Prestel, 2008). 9. $8 \quad$ Eunice Kim, "There's a Uniquely Korean Word for Rage and Regret. So Why Had I Never Heard of It?," CBC, May 20, 2019, https:// www.cbc.ca/radio/docproject/there-s-a-uniquely-korean-word-forrage-and-regret-so-why-had-i-never-heard-of-it-1.5118989.
}

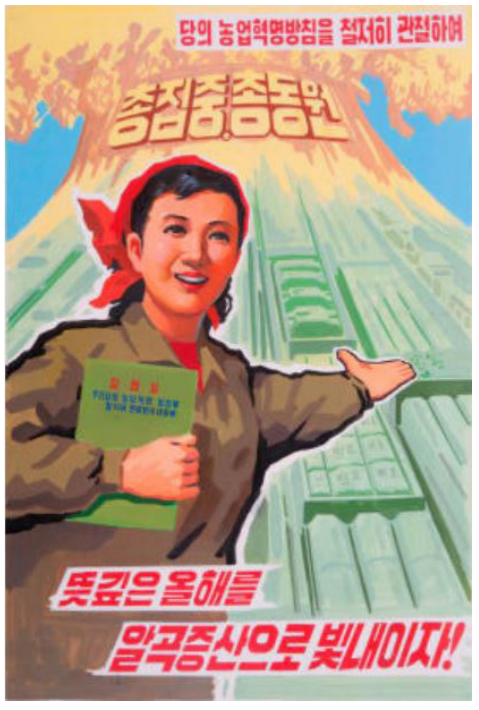

Figure 17| "Let Us Achieve The Party's Agriculture Revolution Policy Thoroughly And Brighten The Year With Increased Grain Production"
Juche I Ideology developed by Kim II Sung as an adaptation of traditional Marxis-Leninism for the Korean context. Juche ideology translates into three essential values, which are political autonomy, economic self-reliance and a strong position of self-defence, and relies on a blind loyalty to a staunchly anti-imperialist state. 
and culture serve as a tool for societal ideals. Under Kim JongIl's Treatise on Art, Korean painting is described as possessing clarity, compactness, and delicacy, deriving from art developed in the Joseon era of traditional ink painting, what was seen as the best representation of Korean style by Kim Il-Sung. ' This portrayal of Joseon art is paired with North Korean poster devices such as slogans and the unmistakable quartet of the soldier, the worker, the intellectual, and the farmer. The division of the Korean peninsula, and the search for national identity also led to traditional Korean art forms being used as a key source in the development of South Korean representation, much like that of North Korean propaganda art. Whereas North Korean art looked to the ideals of the Joseon dynasty, the rise of Minjung art looked at the art of the commoner, where traditional folk scenes were utilized and reimagined under the Minjung style's era of political unrest, depicting labour movements and social justice. ${ }^{10}$ This development from traditional Korean culture to modern Korean forms of representation as a means of expressing ideals of the current society provides a method in expressing speculative representations of a Korean society of the future.

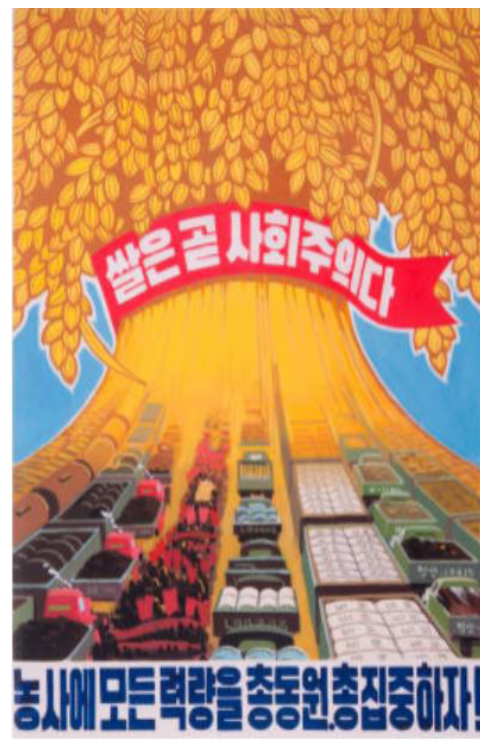

Figure 18| "Rice is Socialism. Let us Concentrate all Efforts on Agriculture!"

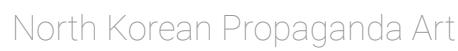

Pansori | A traditiona art form of musical storytelling

Minjung | A form of political art that emerged in reaction to social unrest in the 1980s.

$9 \quad$ Heather and Ceuster, North Korean Posters: The David Heather Collection. 12.

10 Sook-Kyung Lee, “Korean Art after 1970," Grove Art Online, 2010, https://www-oxfordartonline-com.proxy.library.carleton. ca/groveart/view/10.1093/gao/9781884446054.001.0001/oao9781884446054-e-7002088832. 
PART TWO // THE ABSURD

가재는 게 편이라 

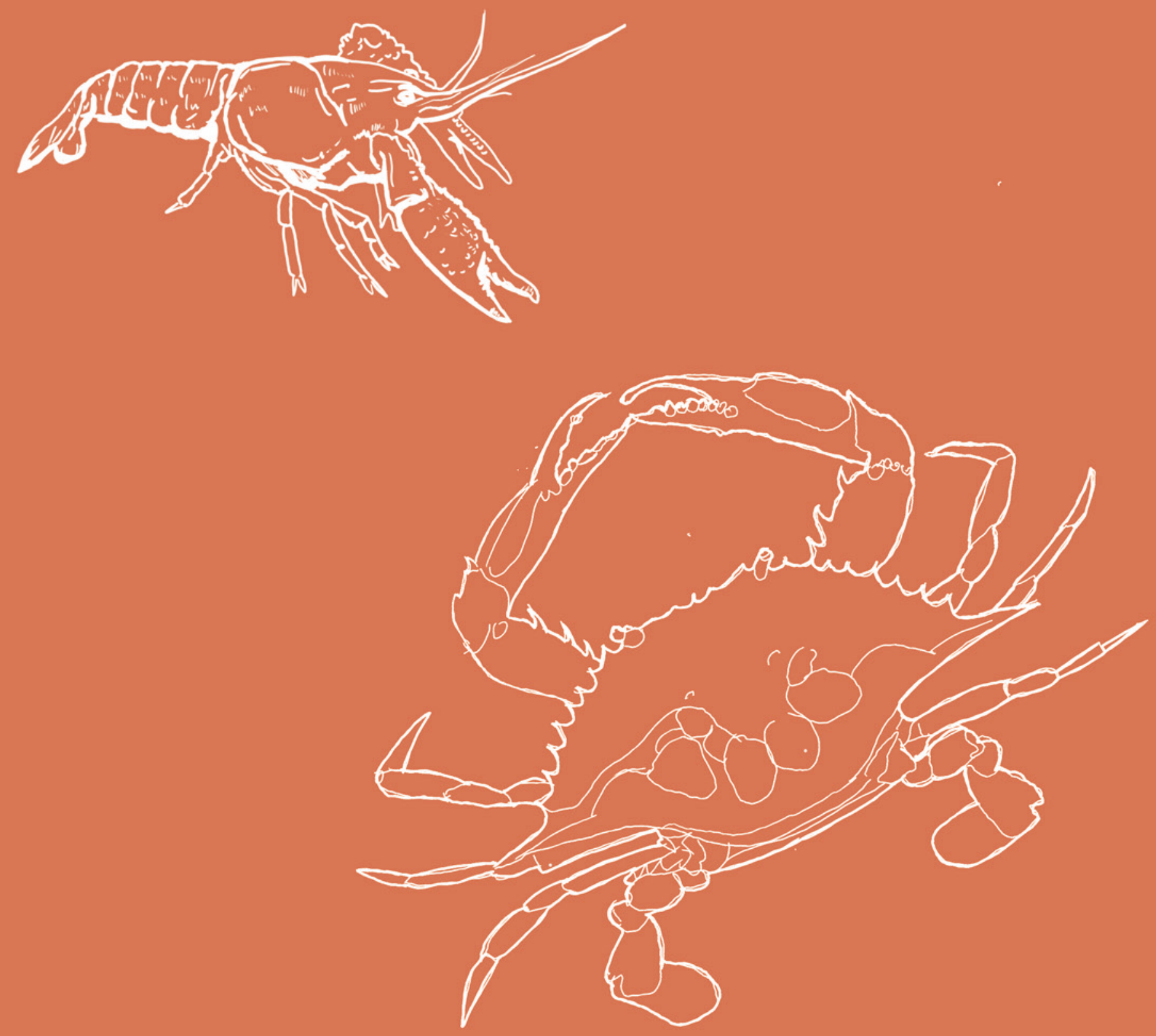


\section{THE ABSURD}

\subsection{Spaces of Absurdity}

“...deconstructions uncover a range of absurd contradictions produced by nation-states that attempt to control their borders.”

- Dongsei Kim, Towards Edge Spaces of Productive Inclusivity: A Subversive Act

When imagining the spaces of the Korean Demilitarized Zone, levels of absurdity come into play. The deconstruction of the border reveals a long history of contradictions, actions and reactions that manifest themselves along a 250-kilometre line. While an immediate example is the absurdity of families torn apart, unable to communicate in such a globalized world, the drawing of an abstract line along an imaginary $38^{\text {th }}$ parallel becomes the ultimate absurdity. James Corner notes that “... maps are taken to be 'true' and 'objective' measures of the world, and are accorded a kind of benign neutrality. By contrast, the other side of this analogous characteristic is the inevitable abstractness of maps, the result of selection, omission, isolation, distance and 
codification." ${ }^{1}$ Although the drawing of lines in maps may seem

Sunshine | Refers to

the sunshine policy

brought forth under

to be a trivial act, or a mere tracing of our territories, this very act unleashes a flurry of repercussions in an attempt to maintain what appears to be 'true' or 'objective' measures. While this history of contradictions may simply be described as a series of absurdities, the Absurd welcomes a much greater interpretation of the myth of the DMZ. Absurd may simply be used as a description for the ridiculous or unreasonable things we witness within our everyday lives, but the Absurd, or absurdism, realizes the sense of purposelessness that many may feel in imagining a future DMZ, a space with a seventy-year history of appealed and repealed policies, threats and violence followed by peace summits, and supposed eras of sunshine. Considering themes that appear in Franz Kafka’s Metamorphosis, or Samuel Beckett's Waiting for Godot, the absurd becomes a distinguishable characteristic of the Korean Demilitarized Zone. Beckettian themes of deadlocks or stalemates that appear in the endless loop of Waiting for Godot reveals itself in the armistice of the never-ending Korean War. Similarly, the irrational scuffles and incursions that occur along the border, compared with the seemingly mundane economic and social concerns of potential reunification, provides a Kafkaesque paradox. When seen through this lens of 1 James Corner, "The Agency of Mapping: Speculation, Critique and Invention," in Mappings, ed. Denis E. Cosgrove (London: Reaktion Books, 1999), 215. 
absurdism, devices of the absurd become a method of imagining design fictions, as well as providing a narrative tool for this thesis. Strategies of juxtaposition (the North and South), deadlock (the Korean Armistice), and the irrational (policies and interactions) appear as a series of investigative drawings. Additionally, scale, as described by El Hadi Jazairy, presents a “... tool to understand relationships, negotiations, and tensions between actors in space. It is plastic because it is a network of dynamic relationships that expands and contracts through the interaction of objects and people.” ${ }^{2}$ These strategies begin to form a more concrete understanding of the myth of the DMZ, and realizes, in the form of narratives, the oddities of Korean folktales and proverbs filled with fantasies of animals and goblins of my childhood.

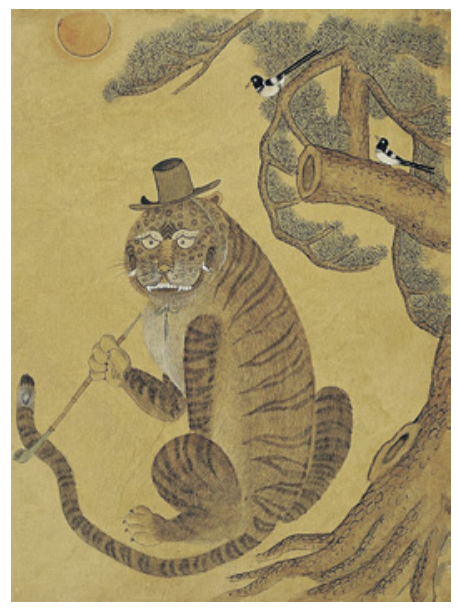




\subsubsection{The Terror of Territory}

"Territory is often seen in terms of control, power and exclusion, primarily a political device, and scholars such as Sassen and Elden stress that the sovereign role of the state is made possible by its control of territory. In modern thinking this makes national boundaries explicit, and legitimises violence so that 'to control territory is to exercise terror.”

- Wendy Pullan, Locating Urban Conflicts: Ethnicity, Nationalism and the Everyday

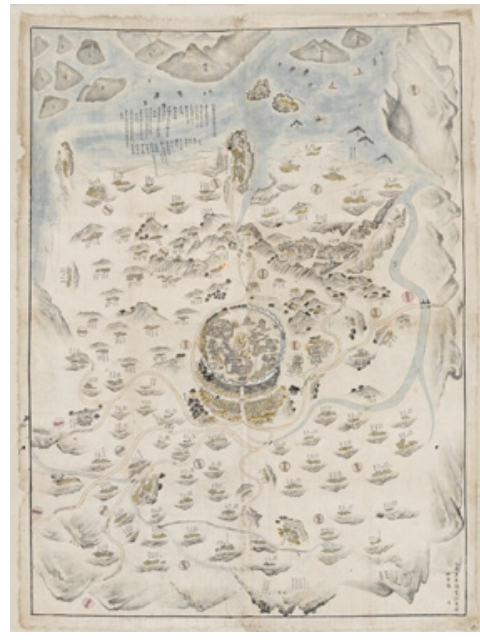

Figure 20 | Jeolla-do Mujanghyeondo

Joseon Dynasty mapping

The concept of territory presents itself as the origin of absurdities present in the Korean Demilitarized Zone. Through the construct of territory, and more specifically the act of tracing the lines of borders, a need to control, or exercise terror is established. Rania Ghosn and El Hadi Jazairy expand upon the relation between terror and territory, where "The etymological linkage between "terror" and "territory" is more than merely coincidental. In Terror and Territory, Stuart Elden draws on two roots of territory: terra, a "piece of earth," a terrain that sustains and nourishes the people, and terrere, "to frighten," a 
place from which people are warned off, and which is closely associated with the maintenance and survival of the state over its territory. ${ }^{3}$ It is through this etymological link that the hidden forces of territory are revealed. By recognizing the terror of territory, the DMZ is viewed in alternative ways. These alternative ways can then be represented in the act of mapping, where contrary to tracings, they "... discover new worlds within past and present ones; they inaugurate new grounds upon the hidden traces of living context." In mapping Borders: A Shifting Peninsula (figure 23), the absurdity of territory and borders is

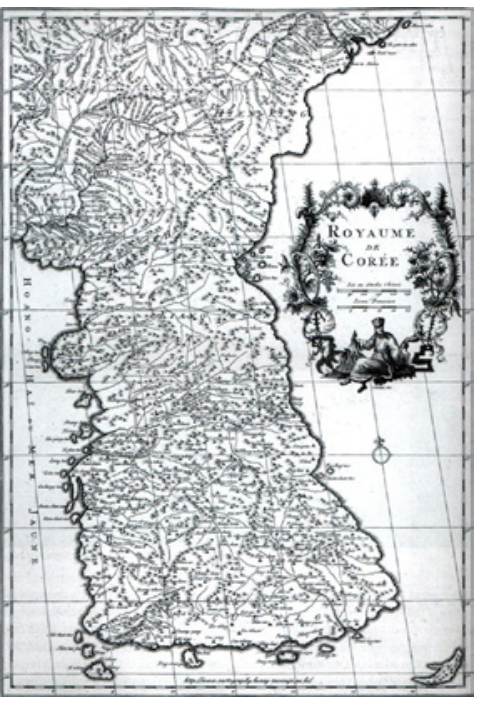

Figure 21 | Detail of Map Royaume de Corée revealed through the flattening of time. The shifting borders of the Korean peninsula are seen as a series of layered opacities, expressing the temporal quality of territory as it is transformed through wars and occupations - terror and territory - demonstrating a space in constant fluctuation. This blurring of territory assists in the transformation of the beholder's eye, described by Dilip Da Cunha as the way in which we understand space, where “... landscape is not composed solely of what lies before us but what lies within our heads.”s By reshaping our preconceived

3 Rania Ghosn and El Hadi Jazairy, Geostories: Another Architecture for the Environment (New York, Barcelona: Actar Publishers, 2018). 14.

$4 \quad$ Corner, "The Agency of Mapping: Speculation, Critique and Invention." 214.

$5 \quad$ Dilip Da Cunha, The Invention of Rivers: Alexander's Eye and Ganga's Descent (Philadelphia: University of Pennsylvania Press, 2019). 13 . 
notion of territory, we begin to "shake off the surveyor's delineations," delineations that can otherwise be known as the border drawn by foreign forces in the pursuit of territory in the Korean Demilitarized Zone. In an act of shaking off these delineations, Porosity: Crossings and Connections (figure 24), demonstrates the fluctuations in territory through the depiction of borders as lines of permeability. The alteration of the borderline itself (based upon documentation of reported crossings), imagines the line in a series of evolutions. Similarly, connections such as roads, railways, and tunnels, further demonstrates the border as porous. These acts of mapping deconstruct the border and reveals the contradictions and absurdities present.

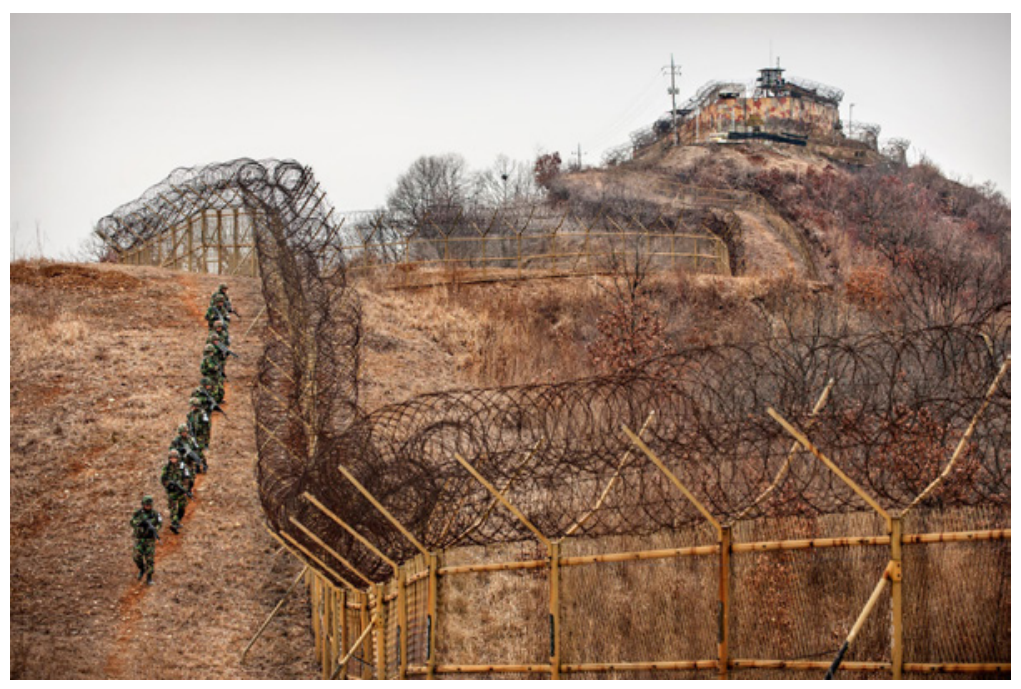

6 Anuradha Mathur and Dilip Da Cunha, "In Depth: Inscribing the Indian Landscape," Architectural Design 77, no. 6 (2007): 70. 
BORDERS

A Shifting Peninsula

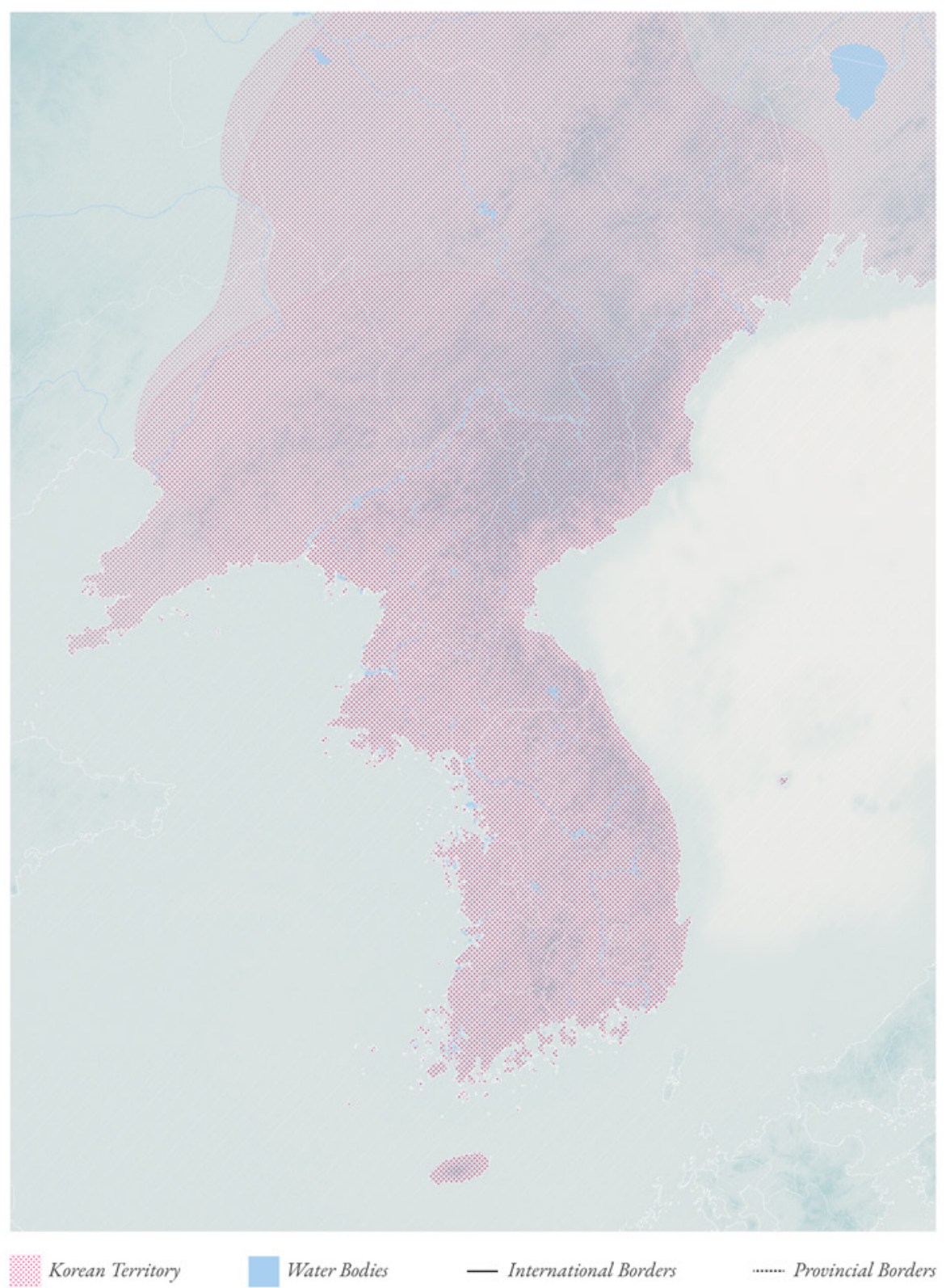

Figure 23| Borders: A Shifting Peninsula 


\section{POROSITY}

Crossings and Connections

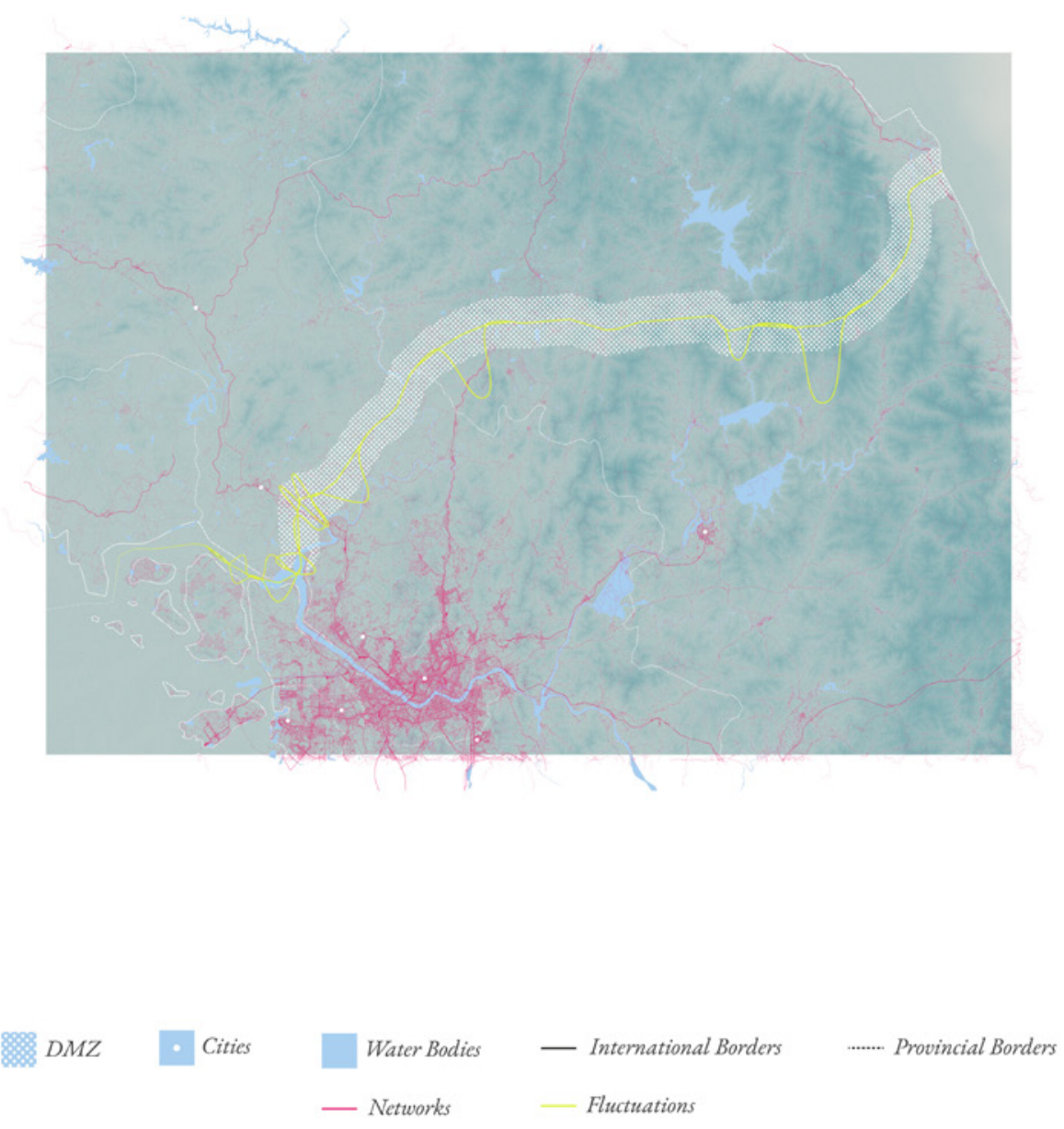

Figure 24| Porosity: Crossings and Connections 


\subsubsection{Study, Surveillance, Speculation}

In creating alternative ways of representing the Kore-

Kremlinology

linology refers to the

study and analysis of

politics and policies of

the Kremlin, Russia's

government. It is often

used to describe the

study of secretive

states such as North Korea.

linology began. This tactic of Kremlinology relied upon concepts of surveillance, and the reverse engineering of media reports. As an initial steppingstone to speculate what may become of the Demilitarized Zone, Environments: Green Spaces, Urban Centres, and Parks of Peace (figure 26), explores one of the most recent proposals by the South Korean government. In the summer of 2013, the creation of a Peace Park was proposed, with potential sites located in Paju, Yeoncheon, Cheorwon, Yanggu, and Goseong.' Environments: Green Spaces, Urban Centres, and Parks of Peace explores these potential sites in relation to the present green spaces and urban spaces of the peninsula. The creation of such a Peace Park feeds off the growing ecotourism industry of the Demilitarized Zone, where its uniquely isolated status has created a sheltered refuge for endangered species. Although unlikely to ever come to fruition due to the required Zone," Volume 40, no. 2 (2014): 42. 
negotiations between North and South, the project is referred to as a "Trojan Horse used to discuss a kind of unification that both absorbs and negates the existence of North Korea." ${ }^{8}$ In search for a more dialogical approach to speculating the future of the DMZ, Absurdities: Interactions, Meetings, Messages (figure 27), locates specific instances and spaces of absurdity. These initial spaces of absurdities mapped along the DMZ include the location of prayer ribbons, the Bridge of No Return, Tunnels of Aggression, and the Joint Security Area. Wanting to explore these spaces of contradiction and absurdity, the tactic of Kremlinology began to be implemented.

The extensive presence of satellite surveillance in today's world allows tactics of Kremlinology to be used in deciphering events within the secretive Democratic People's Republic of Korea. This tactic is commonly seen across news reports, where satellite imagery tracks missile deployment, military developments, nuclear sites, and even the whereabouts of Kim Jong-Un following reports in April 2020 of a cardiovascular operation near Mount Myohyang. $\quad$ Translating Kremlinology into methods of architectural representation, allowed for the development

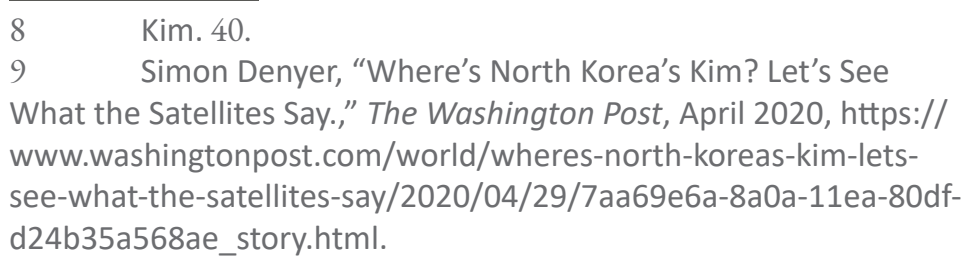


of a series of narratives surrounding spaces of absurdity. Having pinpointed initial sites of investigation within the mapping Absurdities: Interactions, Meetings, Messages, further instances were identified, then explored as a series of sections. These sections act as a series of cross-sections, or MRI slices, through the body of the DMZ, where different elements of absurdity can be highlighted, and interior narratives can be revealed. Rather than framing the border as an object within mappings, the use of the section reveals the border to be "a complex web of interactions rather than a mere object." ${ }^{10}$ Thinking through section, potential absurdities were categorized into spaces of the above, the sky, the earth, the water, and the below. Each identified space is accompanied by a "murder board" where connections between instances of absurdity are made, acting as a form of investigative Kremlinology. These investigative murder boards set a series of narratives into play within each individual section of the above, sky, earth, water, and below. The scenes of absurdity are investigated further with the creation of collages, where much like the Situationist Internationale method of détournement, a process involving the removal of "cultural signs and media elements (painting, literature, film, words, and gestures) from their original context and recontextualizing them in a new context, of(2018): 77. 
ten for the purposes of social and political critique," ${ }^{11}$ is used to imagine these absurdities at play. Additionally, the use of a tank model, developed as part of a course titled Miniaturising the Gigantic, imagines each of these spaces within the confines of an aquarium, and deciphers instruments of absurdity through experimentation, as well as plays on scale. Inspired by the prevalence of the scroll in traditional Korean art, a drawing set evolves to act as a form of investigative architecture, reconstructing spaces of the absurd.

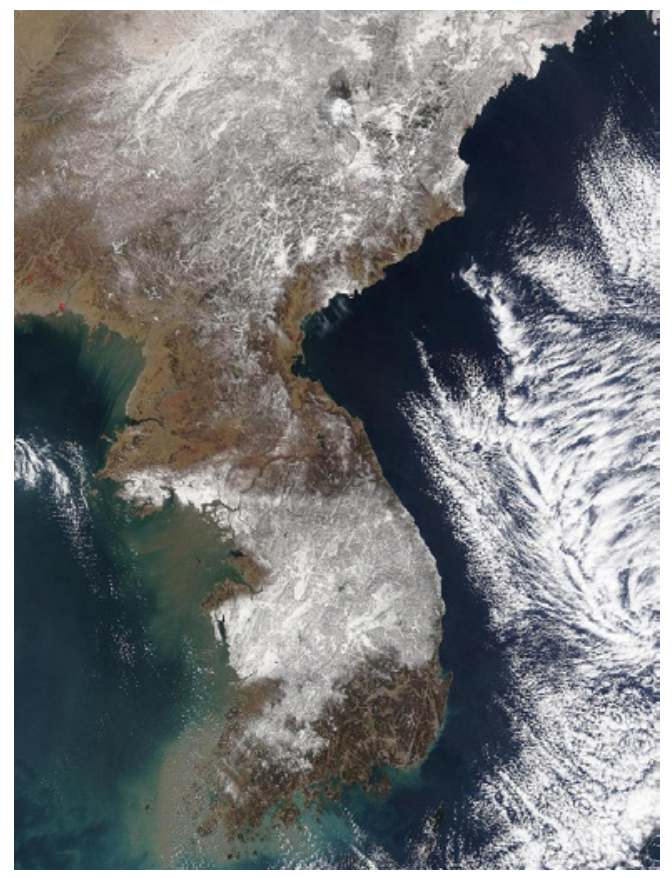

\footnotetext{
11 Catherine D'Ignazio, "Art and Cartography," in International Encyclopedia of Human Geography, ed. Rob Kitchin and Nigel Thrift, vol. 1 (Oxford: Elsevier, 2009), 190.
} 


\section{ENVIRONMENTS}

Green Spaces, Urban Centres, and Parks for Peace

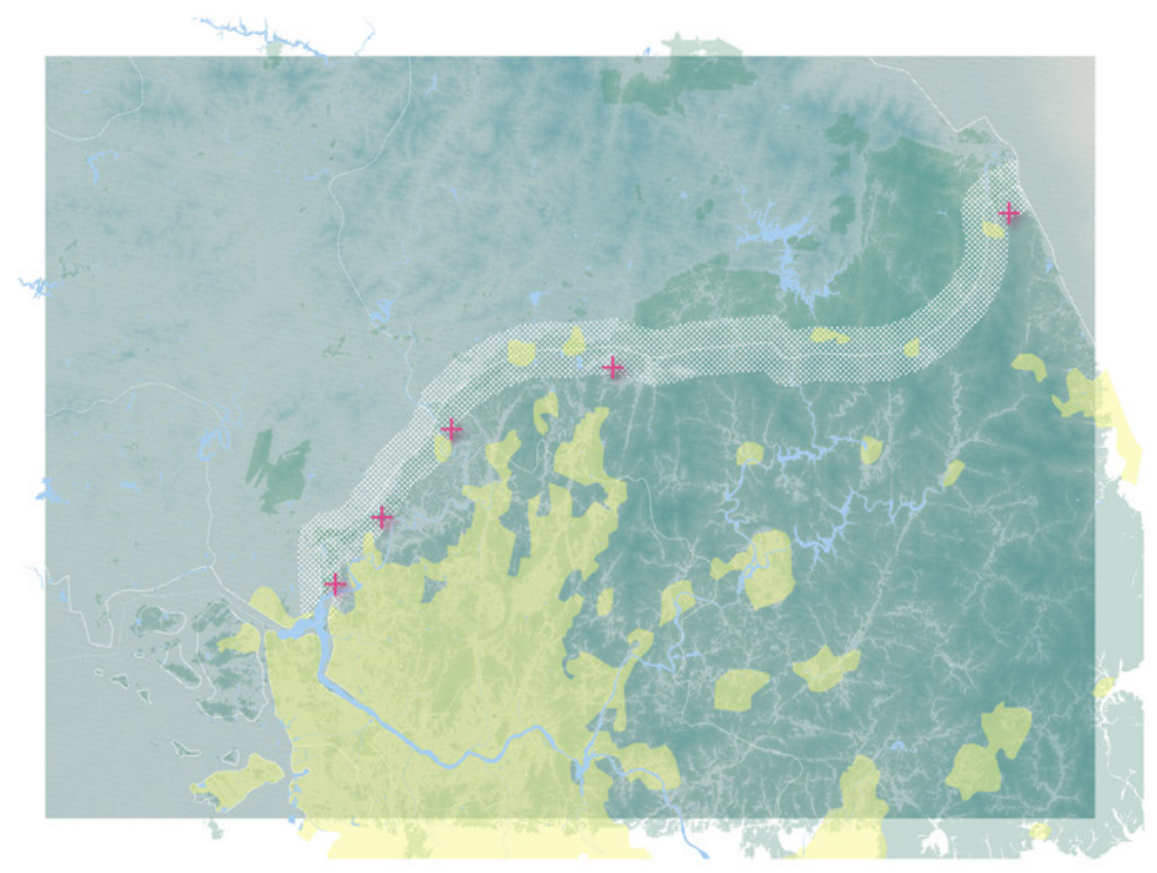

$\begin{array}{ccc}\text { Water Bodies } & \text { International Borders } & \text { ….... Provincial Borders } \\ & \text { Urban Areas } & \text { Green Spaces }\end{array}$

Figure 26 | Environments: Green Spaces, Urban Spaces, and Parks for Peace 


\section{ABSURDITIES}

Interactions, Meetings, Messages

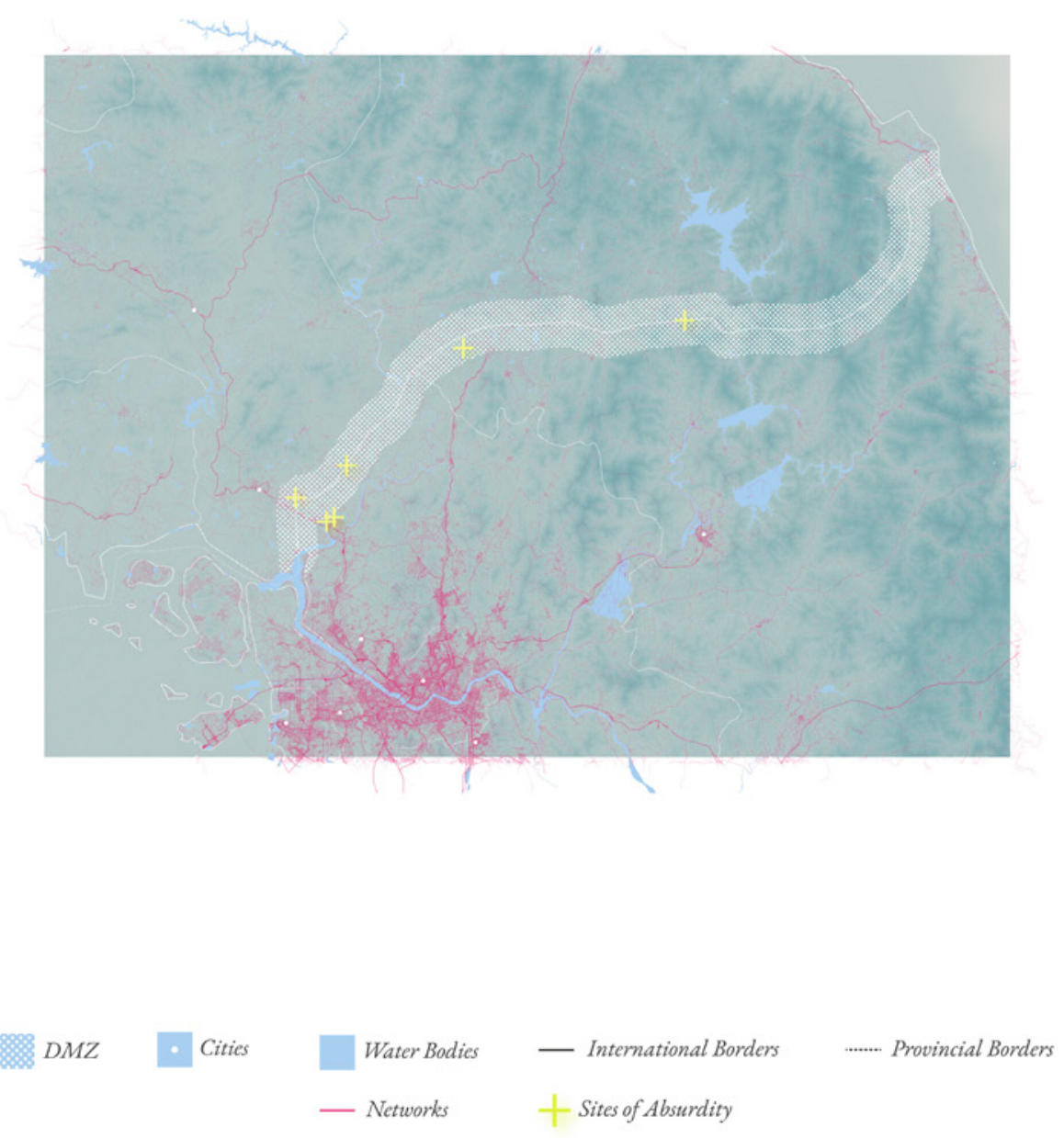

Figure 27 | Absurdities: Interactions, Meetings, Messages 
SPACES OF ABSURDITY

Sites and Instances

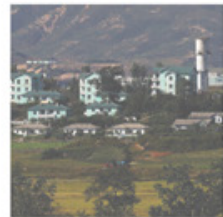

PROPAGANDA WLLAOES

remangan

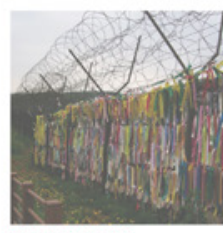

PEACE RIBBONS

Lyowsuk

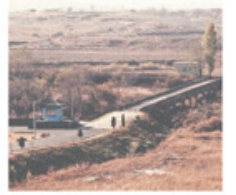

BRIDGE OF NO RETURN

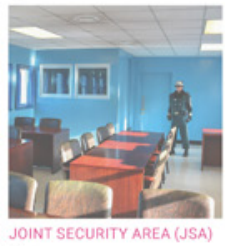

JOINT SE

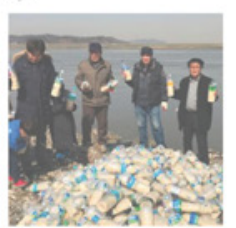

BOTTLED MESSAGES

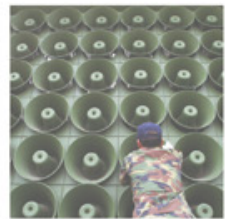

PROPAGANDA SPEAKERS

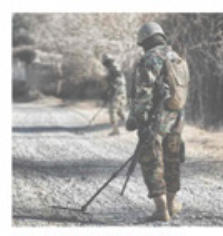

LANDMINE DETECTION

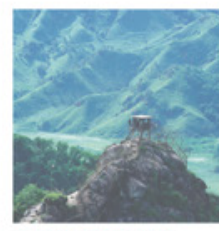

SURVEILLANCE POSTS

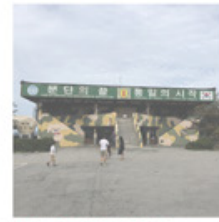

DORA OBSERVATORY

Asist

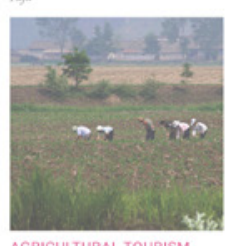

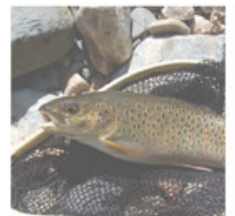

MANCHURIAN TROUT FLY

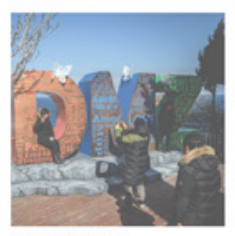

DARK TOURISM

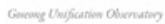

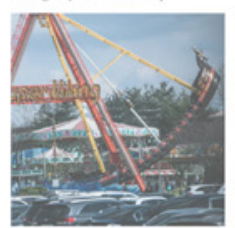

DARK TOURISM

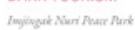

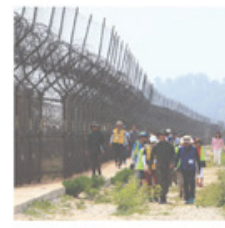

DMZ TOURS

$n_{y j}$

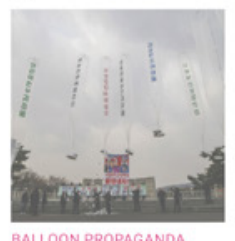

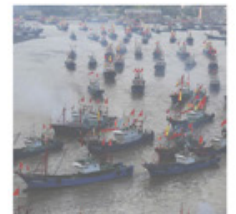

CRAB WARS

Fitherser
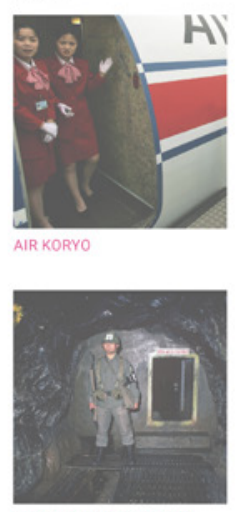

SECRET TUNNEL SYSTEM

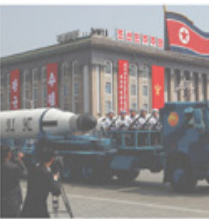

MISSILE PARADES

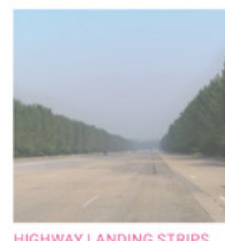

Figure 28 | Spaces of Absurdity: Sites and Instances 

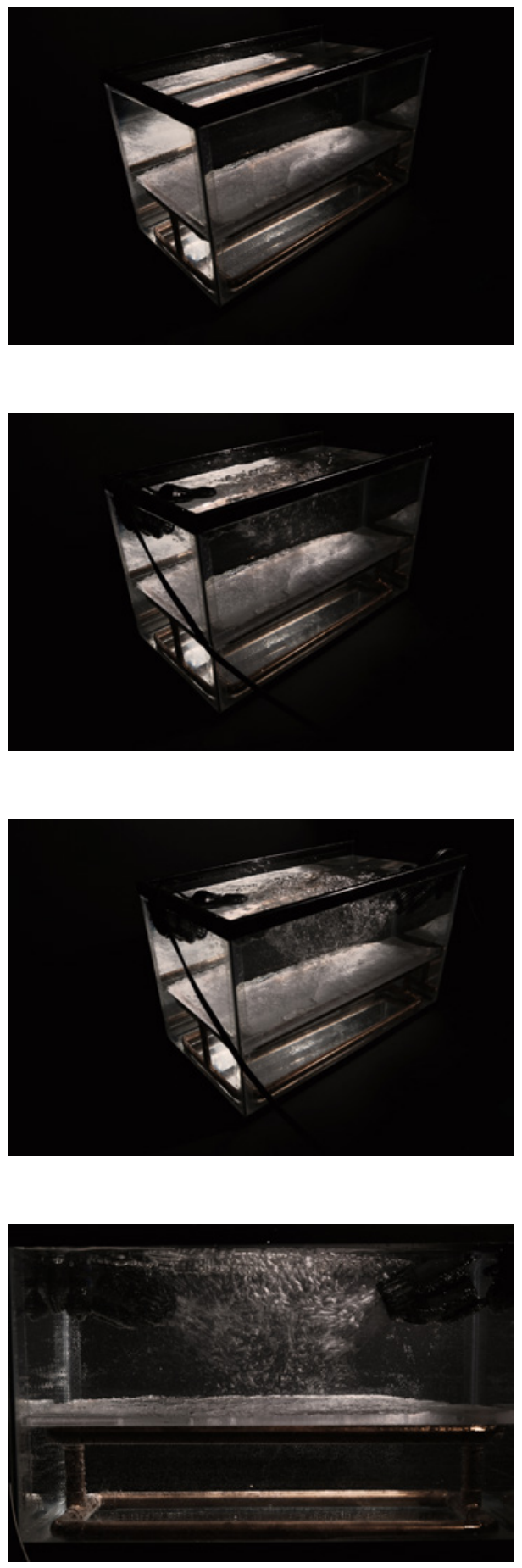

Figure 29 | Tank Model Display 

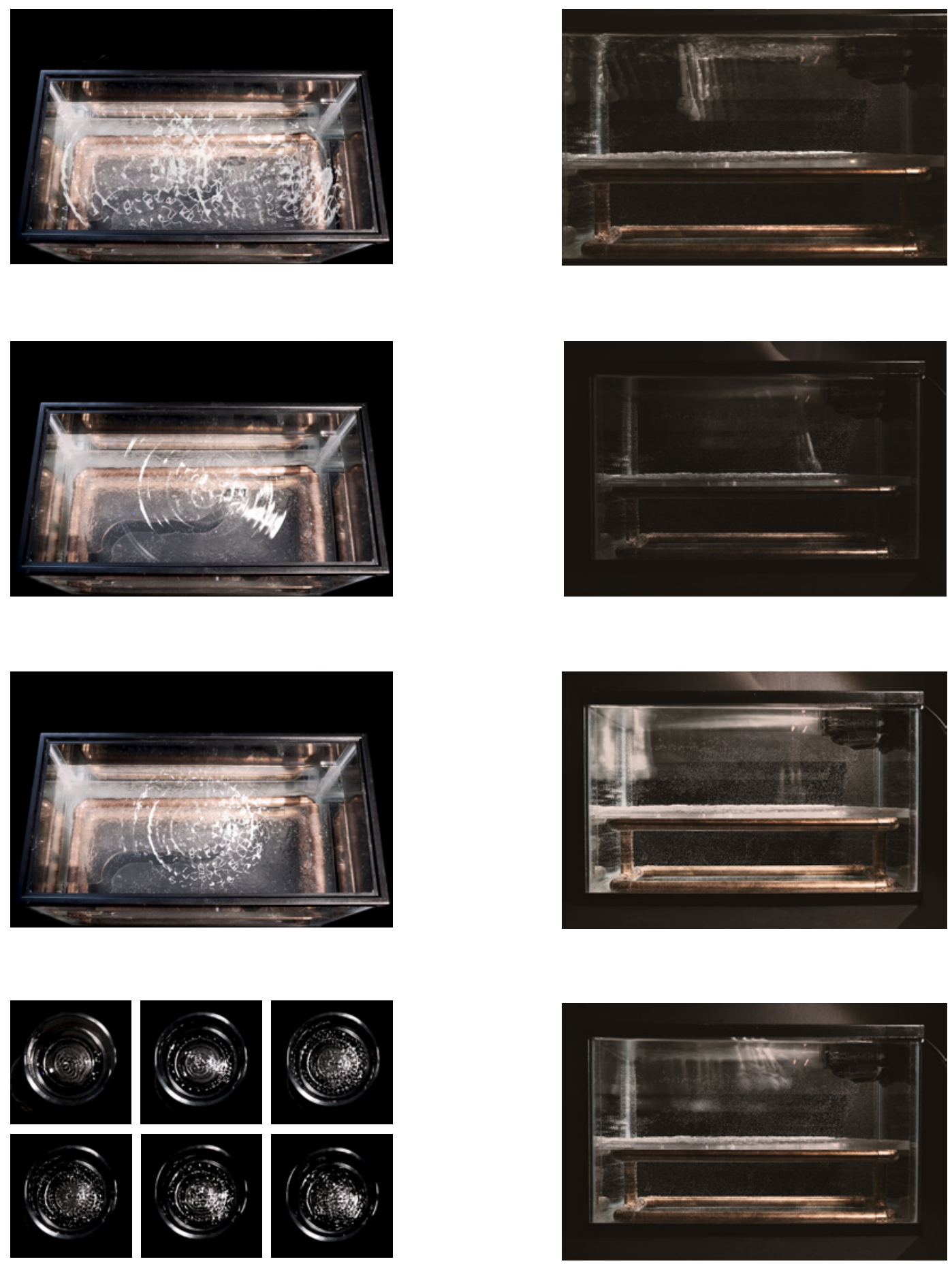

Figure 30| Tank Model Explorations

Left: Speaker War Explorations Right: Hydrogen Balloon Explorations 

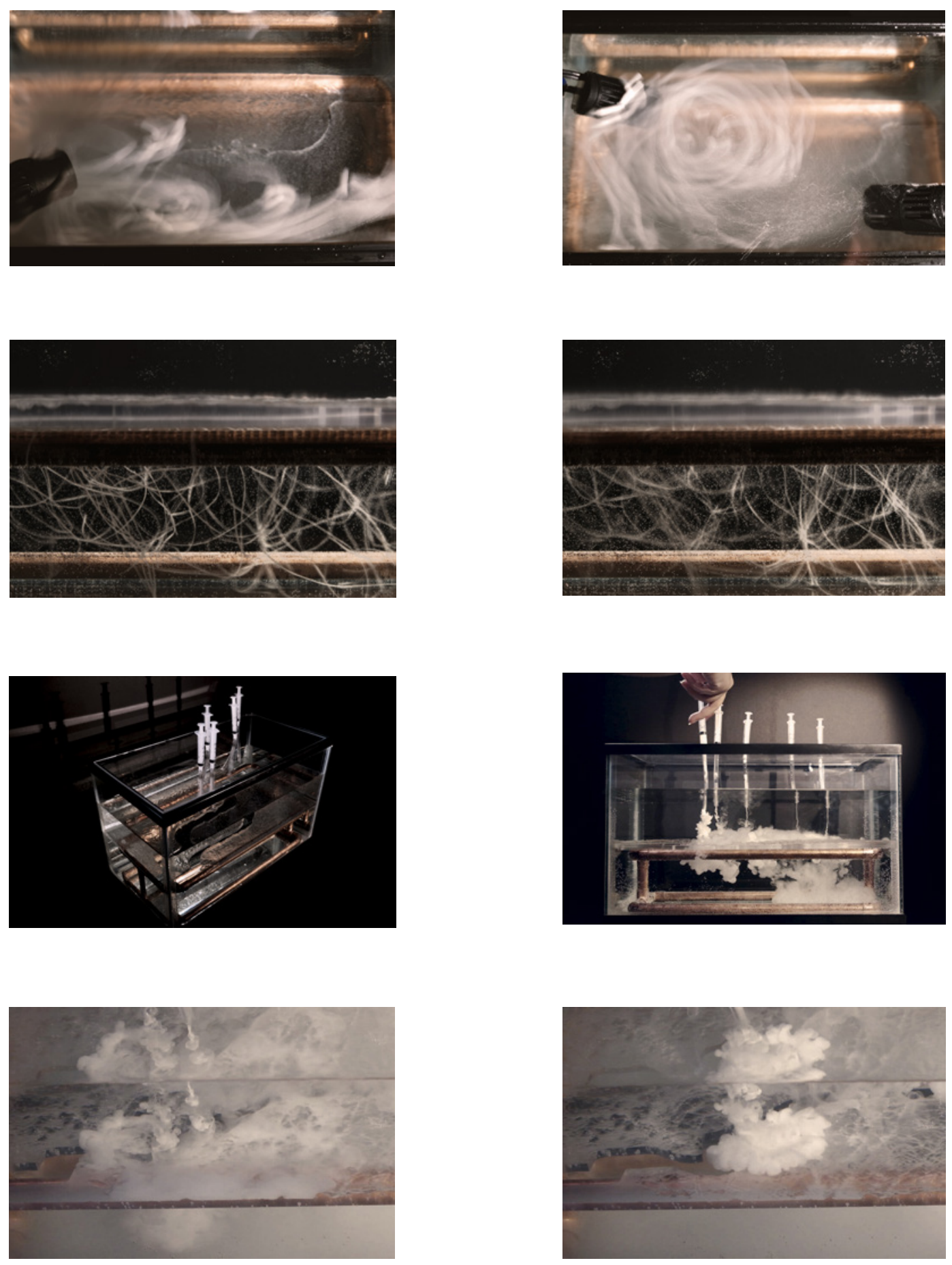

Figure 31 | Tank Model Explorations

First Row: Bottled Message Explorations Second Row: Tunnel Detection Explorations Third to Fourth Row: Dark Tourism Explorations 


\subsection{Spaces of the Above}

Spaces of the Above (figure 34) explores the use of satellites, missiles, and the effects of the Korean Demilitarized Zone on the airspace above. The drawing highlights themes of surveillance against the backdrop of receding mountaintops and the distinctive spiral clouds found throughout Korean paintings. Although the DPRK had agreed to suspend missile and nuclear weapon development in exchange of food aid in $2012,{ }^{12}$ the fear of missile development continues as it appears in images of propaganda parades released by the North Korean regime. While the threat of missile launches and other military development is maintained through the DPRK's control of media, satellites and their surveillance serve as a tool to witness further absurdities. Within this same space, the role of tourism plays a key factor, where Air Koryo, the state-owned airline of North Korea, transports tourists between Beijing and Pyongyang. These flights represent one of the only methods of travelling to the North, allowing tourists guided visits, with the constant monitoring of two guides and a driver, and costing up to 1500 euros. ${ }^{13}$ Tour companies such as Koryo Tours, a British-owned compa-

12 H Im et al., "South Korea," Encyclopedia Britannica, 2021, https://www.britannica.com/place/South-Korea.

13 "FAQS DPRK (NORTH KOREA) TOURS," Koryo Tours, n.d., https://koryogroup.com/dprk-north-korea/faqs. 
ny in operation since 1993, assures potential travellers on their FAQ page that should they travel to North Korea, the threat of brainwashing or being spied upon is highly unlikely. ${ }^{14}$ Spaces of the Above is explored further through collage (figure 35) where the micro narrative of highway landing strips and their relation to the air space above is seen at play. While highway air strips are found both North and South of the Demilitarized Zone, providing emergency landing strips for military aircrafts in case of war, the act of surveillance reveals examples North of the border, such as the Sunan-Up Airfield (discovered by the CIA. ${ }^{15}$ Lastly, tank model experimentation (figure 31 ) explores the use of propaganda balloons that straddle the space of air and the above. Within the space of the above, the tank model (figure 31) represents the unseen phenomena of propaganda balloons as they travel across the Korean Demilitarized Zone, documenting the factors that control their flight patterns and success.

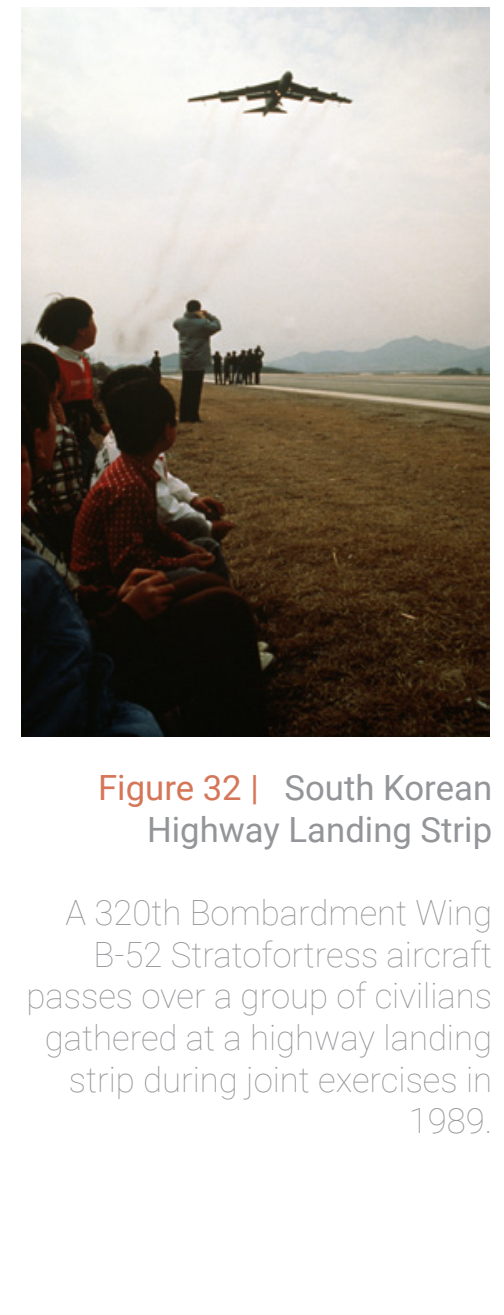

14 "FAQS DPRK (NORTH KOREA) TOURS."

15 CIA, "SUNAN-UP AIRFIELD NORTH KOREA," 1968. 


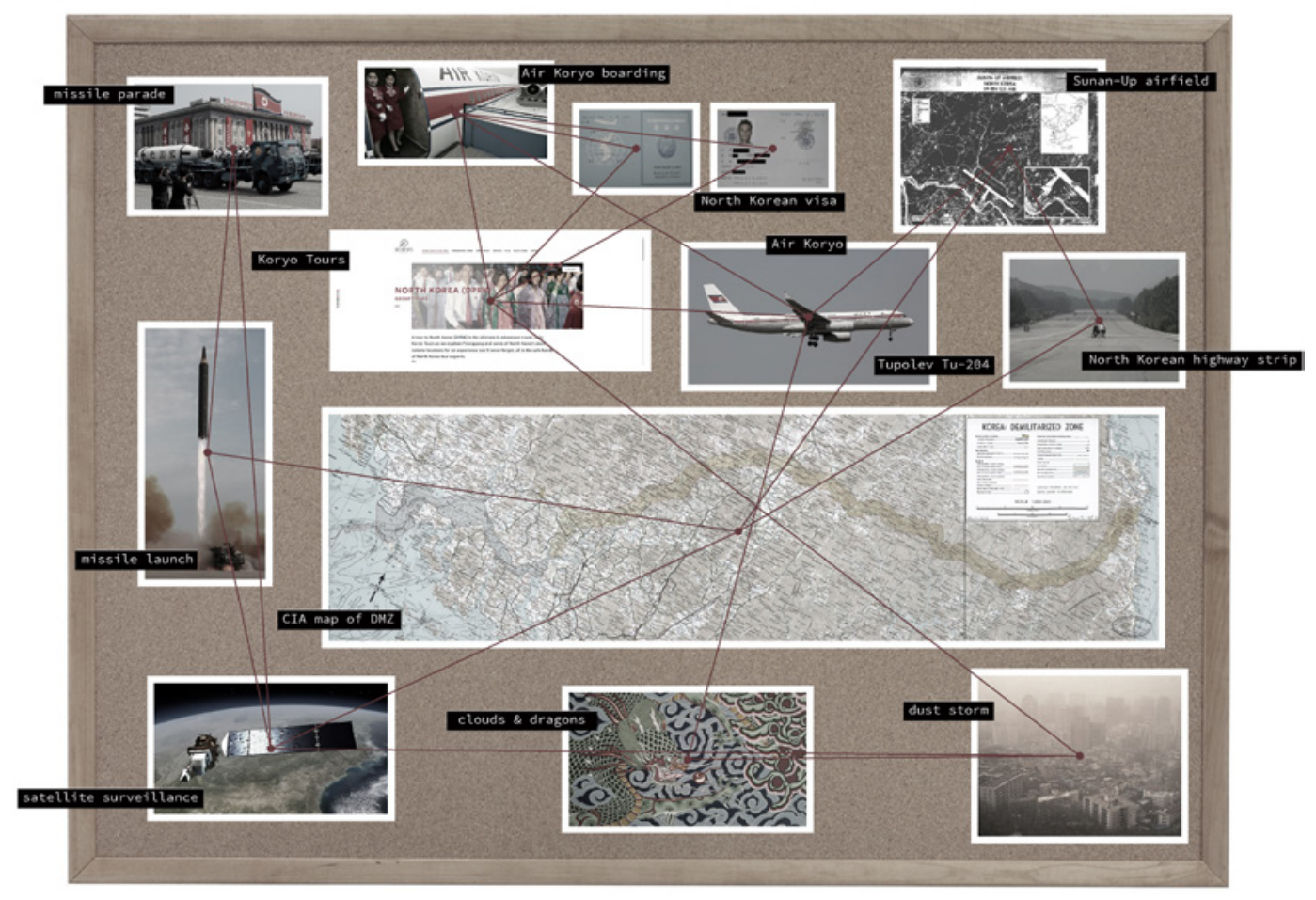

Figure 33| Murderboard: Spaces of the Above 


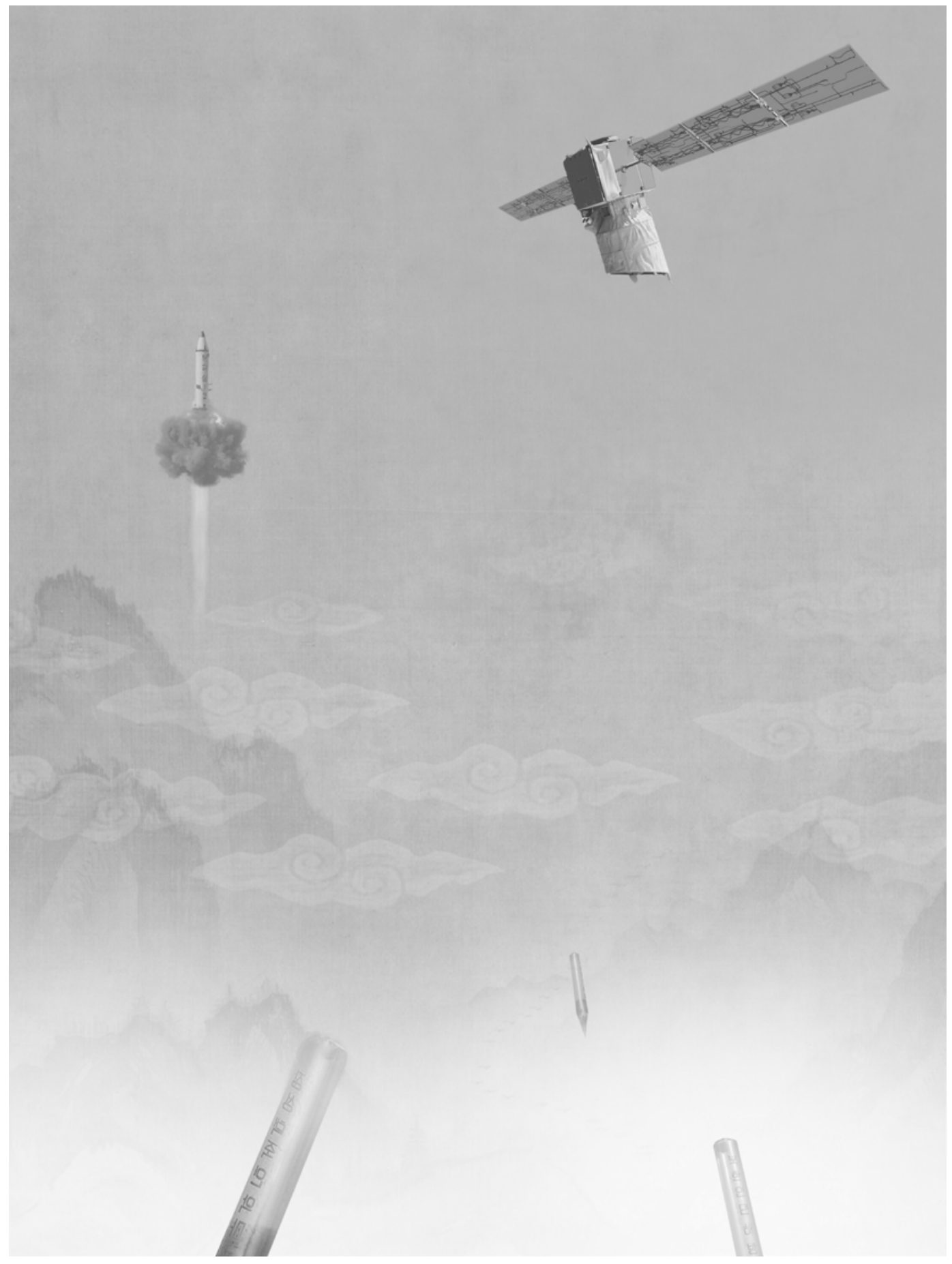

Figure 34 | Spaces of the Above 


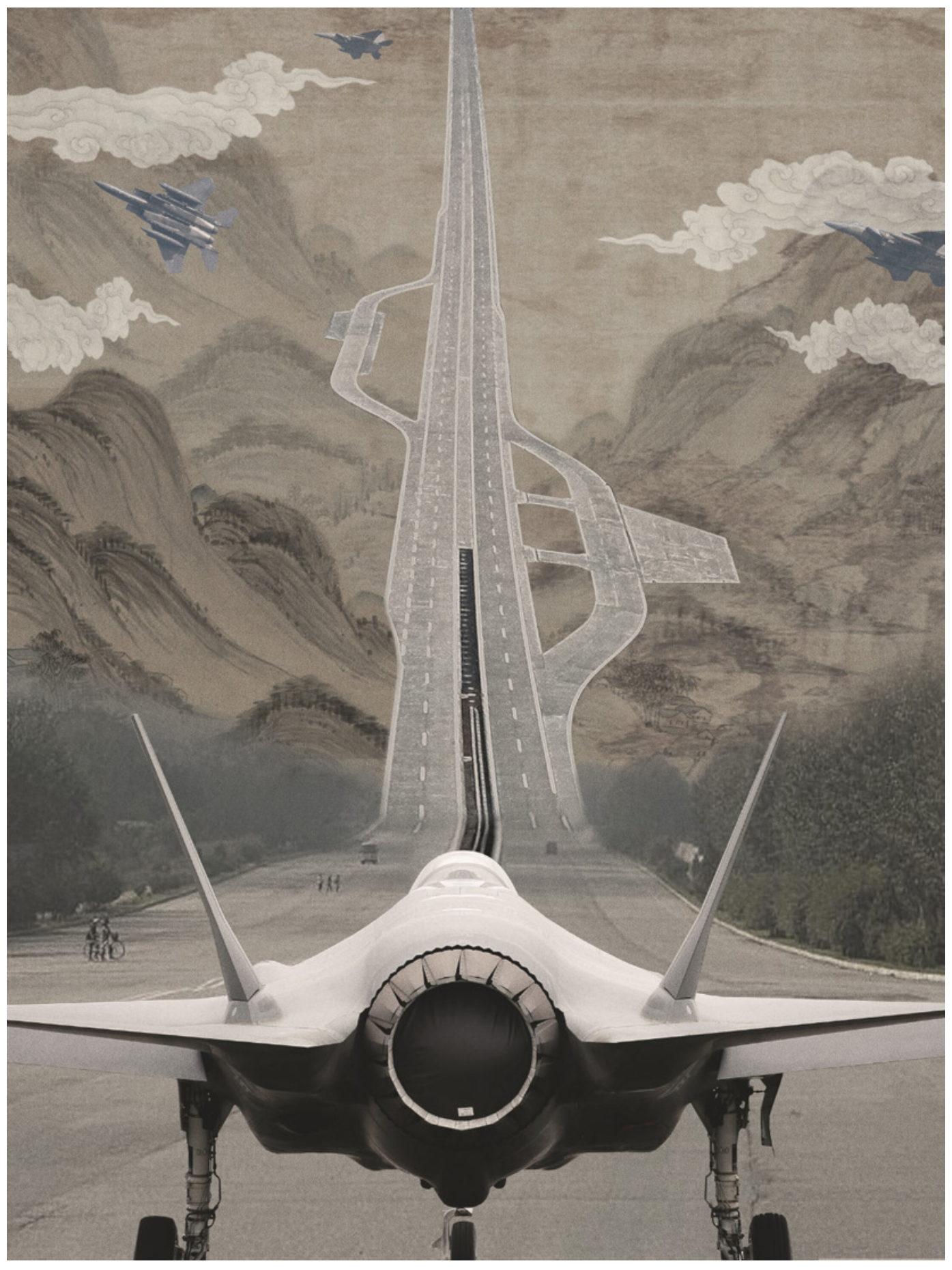

Figure 35| Spaces of the Above: Highway Landing Strips 


\subsection{Spaces of the Sky}

Instances of absurdity included within Spaces of the Sky (figure 43) continues the investigation of propaganda balloons, while also examining speaker wars, observatories, and the migration of endangered cranes that render the $\mathrm{DMZ}$ a permeable space. The release of propaganda balloons has been led by activists such as Park Sang-Hak who, since 2004, has organized their deployment. ${ }^{16}$ Seen as an act of aggression by the Democratic People's Republic of Korea, and consequently a source of tension for the Republic of Korea, activist groups, such as Park SangHak's Fighters for a Free North Korea, deploy hydrogen filled balloons, accompanied by leaflets, bibles, American dollar bills, radio sets, memory sticks, and even chocolate. ${ }^{17}$ While many of these balloons never cross the Demilitarized Zone, whether due to wind patterns or the efforts of North Korean soldiers, activists
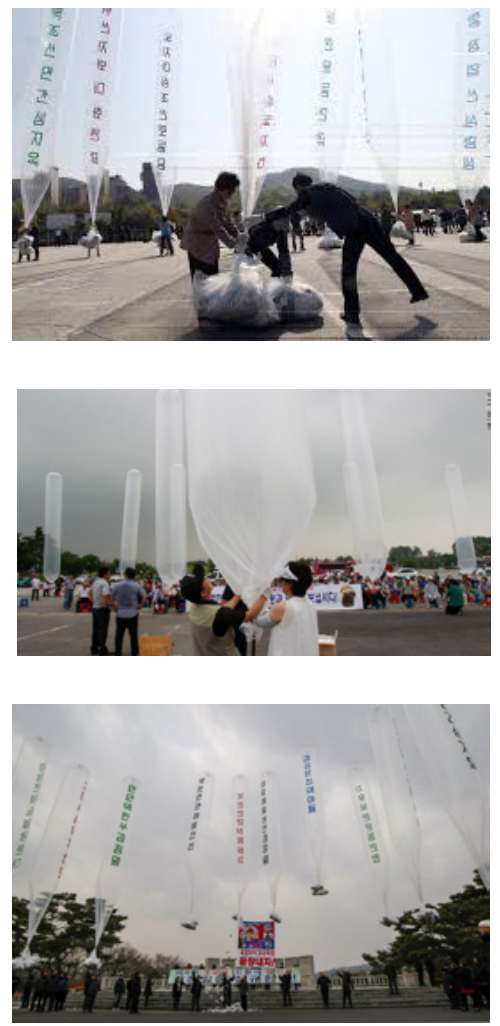

Figure 36-38 | Hydrogen Balloon Deployment view these balloons as a way to promote change within North Korea, and threaten the use of drones, should their balloon deployments ever be blocked. These activists, who Kim Yo-Jong,

16 Choe Sang-Hun, "As Floating Propaganda Irks North Korea, the South Isn't Happy Either," The New York Times, June 2020, https:// www.nytimes.com/2020/06/11/world/asia/north-korea-balloons-propaganda.html?

17 Sang-Hun. 
the sister of the DPRK leader, refers to as "human scum," that these deployments aid in slowly chipping away at the information blackout that is present in North Korea. Despite threats of lawsuits from the South Korean government, activists believe this guerilla tactic of balloon deployment is a manner to exercise their freedom of speech, a freedom that is ever more important to North Korean defectors such as Park Sang-Hak. The act of deploying hydrogen propaganda balloons is investigated further (figure 44), by imagining their assembly and release in the form of collage. What may be referred to as the "speaker wars," is also demonstrated within Spaces of the Sky, where the installation of loudspeakers by both North and South Korea blast propaganda. This practice was first established in the 1960s with speakers installed in over 40 sites along the southern zone of the DMZ, allowing sounds to travel over 10 kilometers in the hopes of sowing doubts in North Korean soldiers of the DPRK's leadership. ${ }^{19}$ While a gesture of peace following a Korean summit in 2018 initiated the removal of the loudspeakers that North Korea labels an act of war, souring relations in 2020 have seen their reimplementation with North Korea once again engaging

18 "South Korean Balloons: Plans to Stop People Sending Cross-Border Messages," BBC News, June 2020, https://www.bbc.com/ news/world-asia-52917029.

19 "South Korea Takes down Propaganda Speakers at Border," BBC News, May 2018, https://www.bbc.com/news/worldasia-43958366.

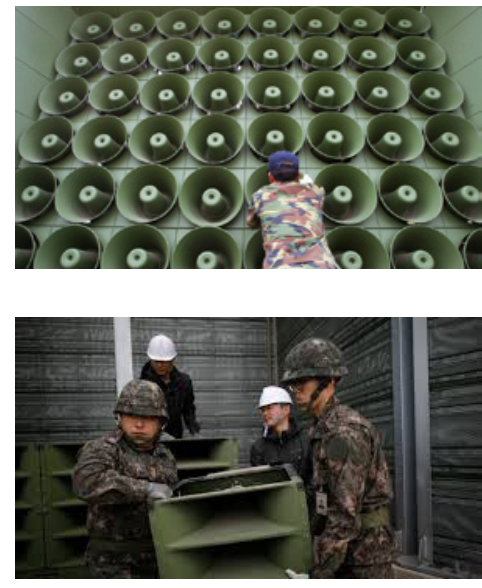

Figure 39-40 | South Korean Speaker Installation 
in this instrument of absurdity. While the south blasts K-Pop songs from the likes of IU and Big Bang, ${ }^{20}$ news reports, television dramas, and anti-North Korean propaganda, loudspeakers installed by the DPRK attempt to cancel out these sounds, engaging in an absurd battle of speaker wars. This very battle is investigated through tank model sound experiments that reconstruct the devices and natural factors of the speaker wars (figure 30). Spaces of the Sky also highlights the presence of the endangered Red-crowned Crane. ${ }^{21}$ The crane, which presents itself as a common subject in traditional Korean art, inhabits the Demilitarized Zone where rice fields and marshes provide a stopover along their migration paths. This unexpected haven for wildlife reinforces the absurdity of the DMZ as a border, where crane migrations produce flows within the supposedly impermeable border line.

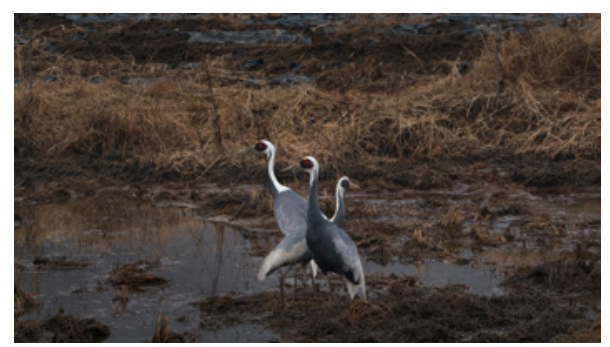

20 Simeon Paterson, "Korean Loudspeakers: What Are the North and South Shouting About?," BBC News, January 2016, https://www. bbc.com/news/world-asia-35278451.

$21 \quad K w i-G o n$ Kim, The Demilitarized Zone (DMZ) of Korea: Protection, Conseration and Restoration of a Unique Ecosystem, The Demilitarized Zone (DMZ) of Korea (Heidelberg: Springer, 2013). 12. 


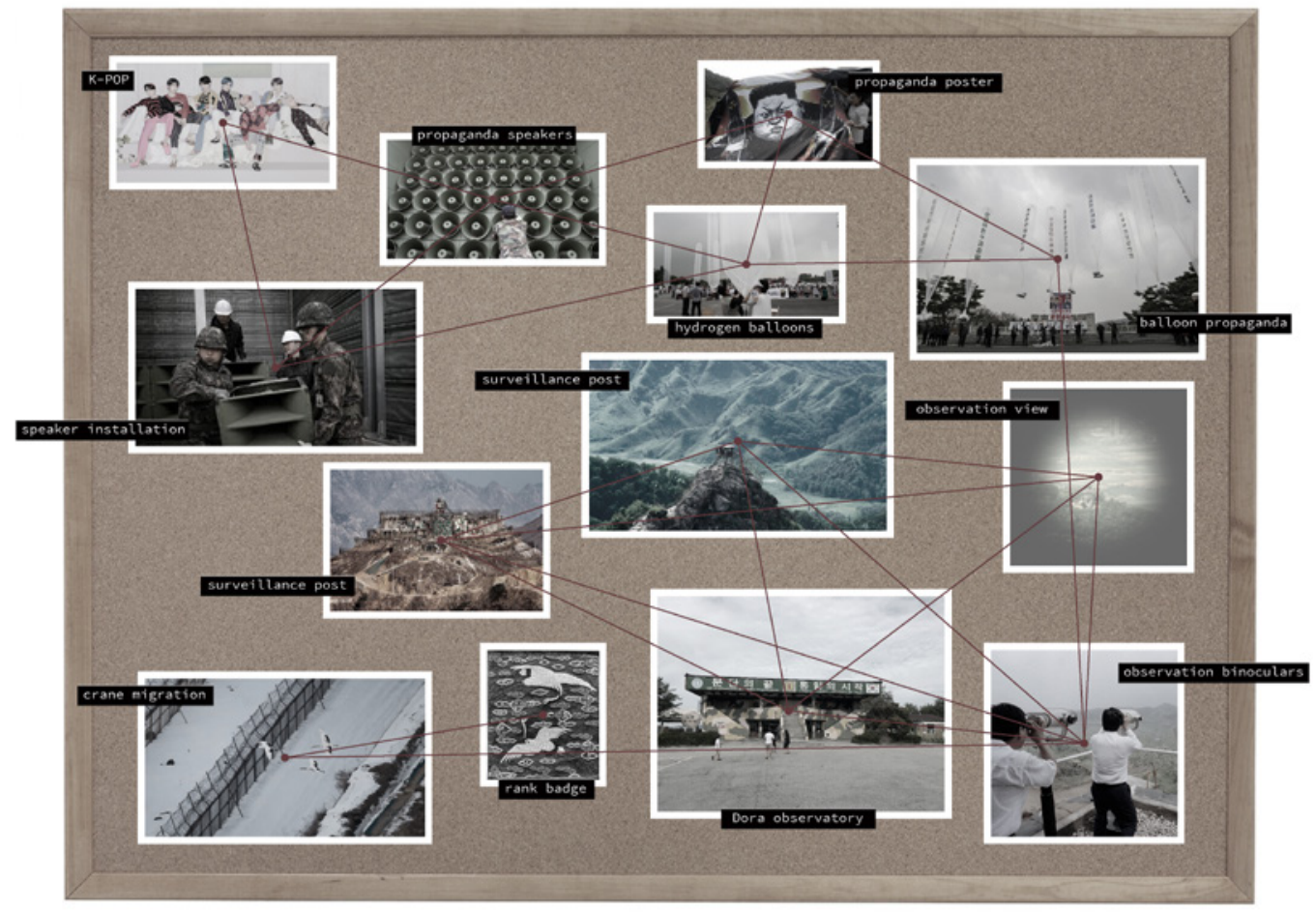

Figure 42 | Murderboard: Spaces of the Sky 


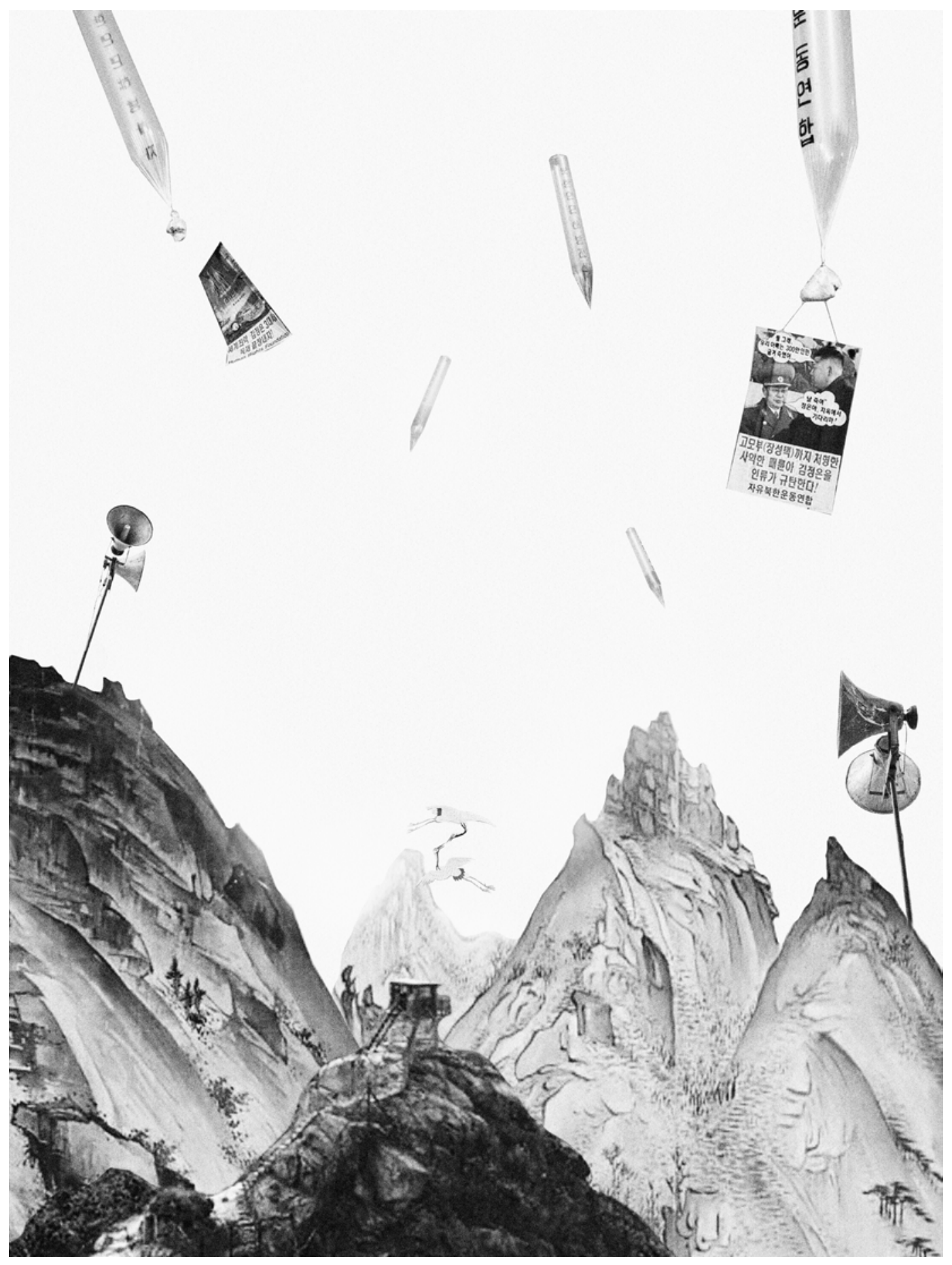

Figure 43 | Spaces of the Sky 


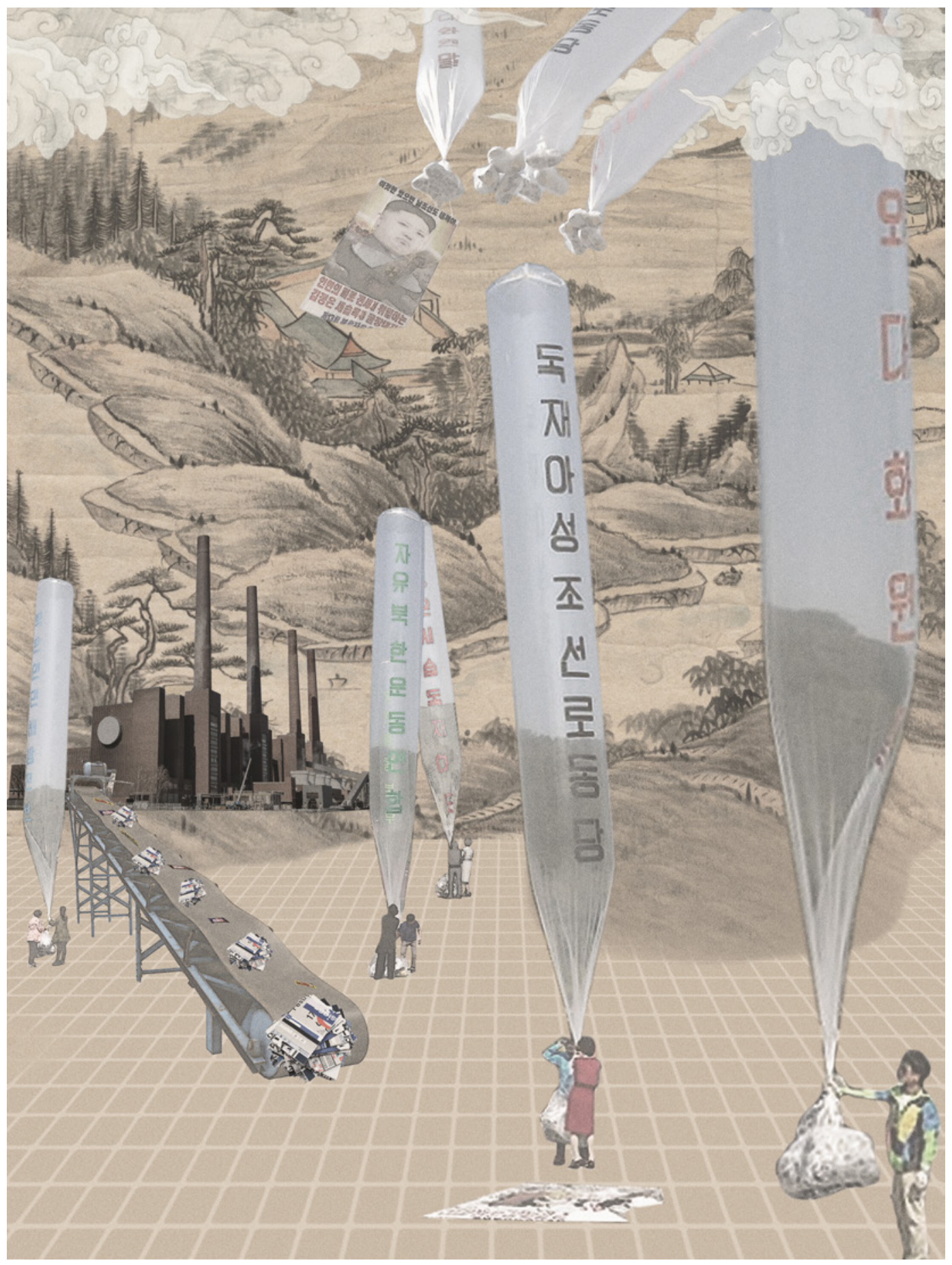

Figure 44| Spaces of the Sky: Hydrogen Balloons 


\subsection{Spaces of the Earth}

The presence of dark tourism, the absurd space of the Joint Security Area of Panmunjom, the construction of propaganda villages, as well as the search for the last tigers of the Korean peninsula form the series of absurdities depicted in Spac-

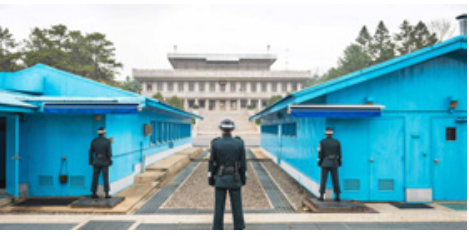
es of the Earth (figure 50). Typically, the images of the Korean Demilitarized Zone that appear in the media are of the Joint Security Area (JSA), also known as the truce village. It is here that soldiers of the Democratic People's Republic of Korea, and soldiers of the Republic of Korea, stand face to face. What has been the location of diplomatic interactions, also forms a site of dark tourism. It is within the absurd space of the Joint Security Area that tourists may step into the Military Armistice Commission Conference Room, and freely straddle one of the most heavily fortified borders in the world. While sites such as the JSA present a space of dark tourism that can "represent inherent political dichotomies of a 'heritage that hurts' and, in so doing, offer a socially sanctioned, if not contested, environment

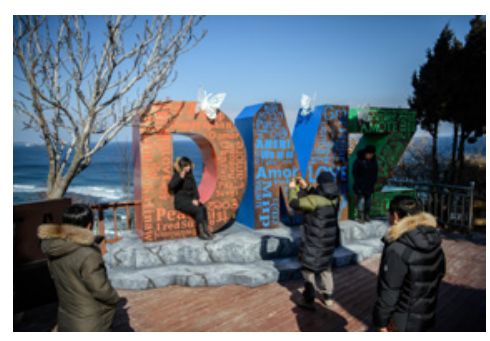

Figure 46 | Sites of Dark Tourism in which difficult or displaced heritage is consumed," 22 they also

22 Catherine Roberts and Philip Stone, "Dark Tourism and Dark Heritage: Emergent Themes, Issues and Consequences," in Displaced Heritage: Dealing with Disaster and Suffering, ed. Ian Convery, Gerard Corsane, and Peter Davis (Woodbridge, Suffolk; Rochester, NY: Boydell \& Brewer, 2014).C. \& Stone, P.R. (20149. 
present the conflict of consuming of traumascapes. Millions of tourists have visited the DMZ from both sides of the border, but this consumption of trauma possesses the dangerous capacity of trivializing the Demilitarized Zone, a source of han and a dark collective memory for much of the Korean population. What

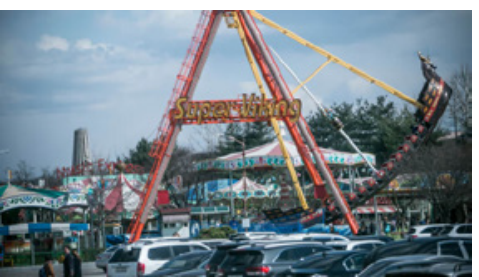

Figure 47 | Amusent Park Ride at the DMZ was called the "scariest place on Earth" by Bill Clinton in 2003, ${ }^{23} \mathrm{can}$ now be witnessed through the simple signing of a consent form, removing liability from tour companies should you wander off onto military grounds, or happen across a landmine. ${ }^{24}$ While consent forms, dress codes, and the banning of waving or unpermitted photography is heavily enforced, visits to the DMZ have not gone without incident, with the death of Park Wang$\mathrm{Ja}$, a South Korean tourist, who was fatally shot upon accidently crossing the military zone. ${ }^{25}$ Nevertheless, tourism continues, and itineraries include such sites as hidden infiltration tunnels, the now barricaded Freedom Bridge (once used to exchange prisoners), Nuri Peace Park and its amusement park rides, Dora Observatory, and Mount Odu. These sites, coupled with the rise of ecotourism in the area, present a unique set of contradictions that form a space of absurdity. The aid of the tank model critically interprets the draw towards dark tourism sites through the

23 Dongsei Kim, "The First Iteration," SITE, no. 35 (2016): 25.

24 Kate Springer, "How to Visit the Korean Demilitarized Zone,"

CNN Travel, February 2019, https://www.cnn.com/travel/article/visit-korean-dmz/index.html.

25 Kim, "Metamorphosis of a Zone."74. 
use of non-Newtonian fluid that mimic patterns of movement around identified sites of tourism (figure 31). The investigation of other sites of absurdity within the Spaces of the Earth is continued in the collage representation (figure 51) of propaganda villages. The Propaganda Village of Kijong-Dong, alternative-

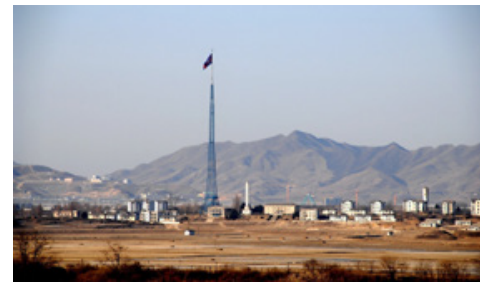

Figure 48 | Village of Kijong-Dong ly named the Peace Village by North Korea, is the result of an agreement by both North and South to construct model villages following the events of the Korean Armistice. ${ }^{26}$ The goal of these villages was to display the virtues of each nation within the confines of the Demilitarized Zone. While the South Korean village primarily partakes in the agriculture industry, with its population comprised of inhabitants located there before the war, the Propaganda Village of Kijong-Dong claims to have a population of 200 residents. However, this claim has long been disputed by South Korean soldiers who monitor the area and have witnessed lights operating on timers, painted windows, and indications that the buildings are in fact just shells with no floor plates. ${ }^{27}$ With its only population appearing to be maintenance workers who sweep the streets, this failed attempt to lure South Korean

26 Motoko Rich, "As North Korea Tensions Rise, Farming in the Demilitarized Zone Goes On," The New York Times, April 2017, https:// www.nytimes.com/2017/04/20/world/asia/as-tensions-rise-betweenthe-koreas-farming-in-the-demilitarized-zone-goes-on.html? 27 David Wharton, "'Peace Village," a Fake City Just Outside the DMZ, Serves as Metaphor for North Korean Athletes at the Olympics,'” Los Angeles Times, February 2018, https://www.latimes.com/sports/ olympics/la-sp-olympics-north-korea-mystery-20180217-story.html. 
citizens into defecting to the North creates a literal Potemkin village. This absurd competition of facades reached a peak in the 1980s when South Korea erected a 330-foot flagpole, towering over the 164-foot North Korean, which swiftly resulted in the new construction of a 560-foot flagpole, ${ }^{28}$ that still stands in Kijong-Dong today, enforcing an assertion of power and the play of propaganda. As a result of these findings, the collage depicts the gaze of South Korean citizens upon North Korean Potemkin villages, set upon the backdrop of City of Supreme Peace, a Joseon era painting depicting the inner workings of a bustling city that the Propaganda Village attempts to portray. While absurdities of dark tourism and fake villages play out, a more obscure instance of absurdity is the hunt for the last Korean tigers. While observers have reported sightings of the Siberian tiger, one of the most endangered cats in the world, there is no evidence to support such sightings. However, eco-warrior Lim Sun-Nam, also known to children as the "Tiger Man," stands by his claim that 10 Siberian tigers prowl the habitat of the DMZ. ${ }^{29}$ Having tracked the tigers for over 20 years, Lim's claim that Siberian tigers still inhabit the peninsula, while true or not, presents a much more significant layer of absurdity through its symbol of

29 Norimitsu Onishi, "Does a Tiger Lurk in the Middle of a Fearful Symmetry?," The New York Times, 2004, https://www.nytimes. com/2004/09/05/world/asia/does-a-tiger-lurk-in-the-middle-of-a-fearful-symmetry.html. 
Korean cultural identity, which Lim affirms in stating that he is "searching not only for the tiger, but the spirit and soul of Korea." 30

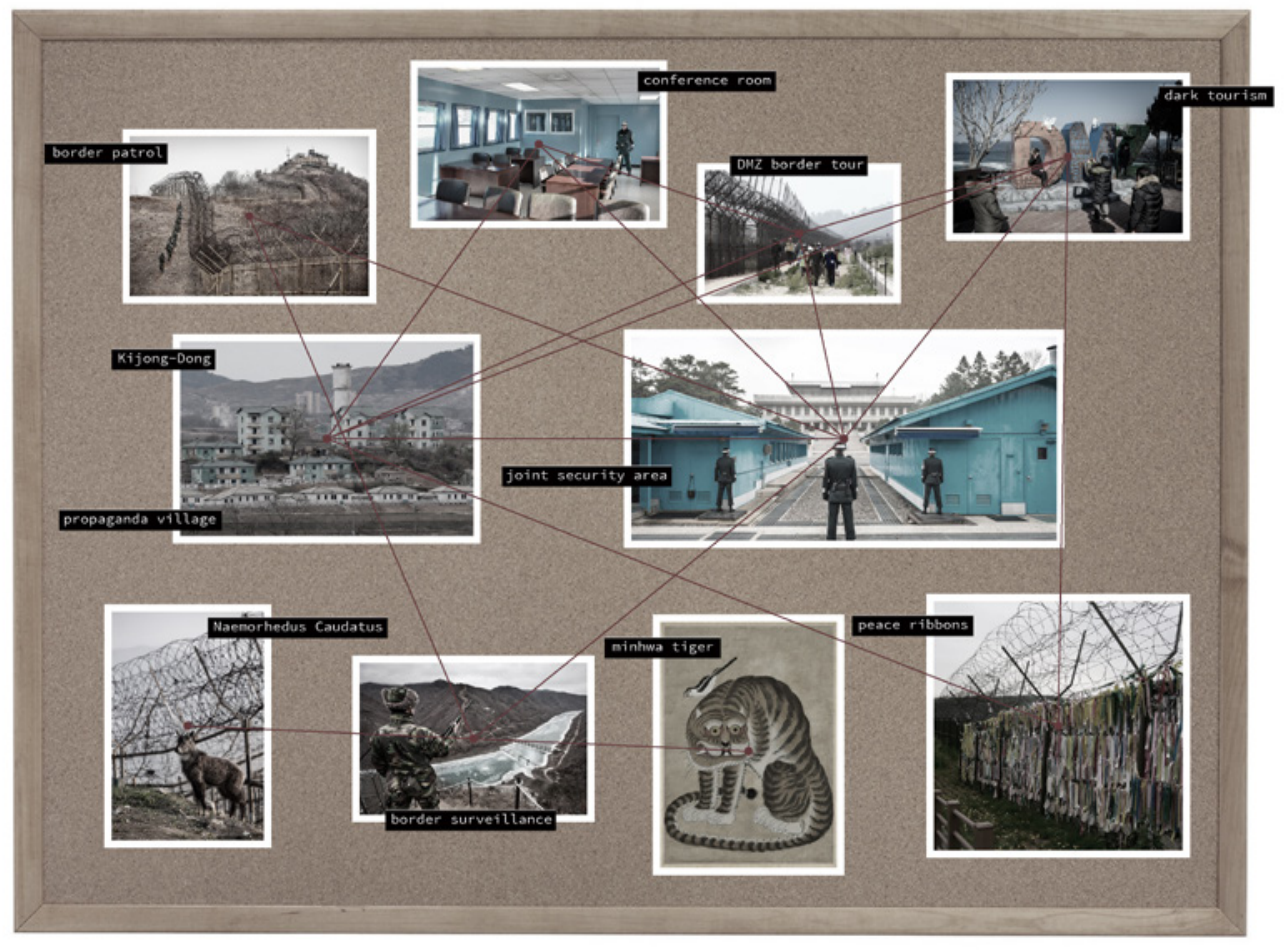

Figure 49| Murderboard: Spaces of the Earth

30 Onishi. 


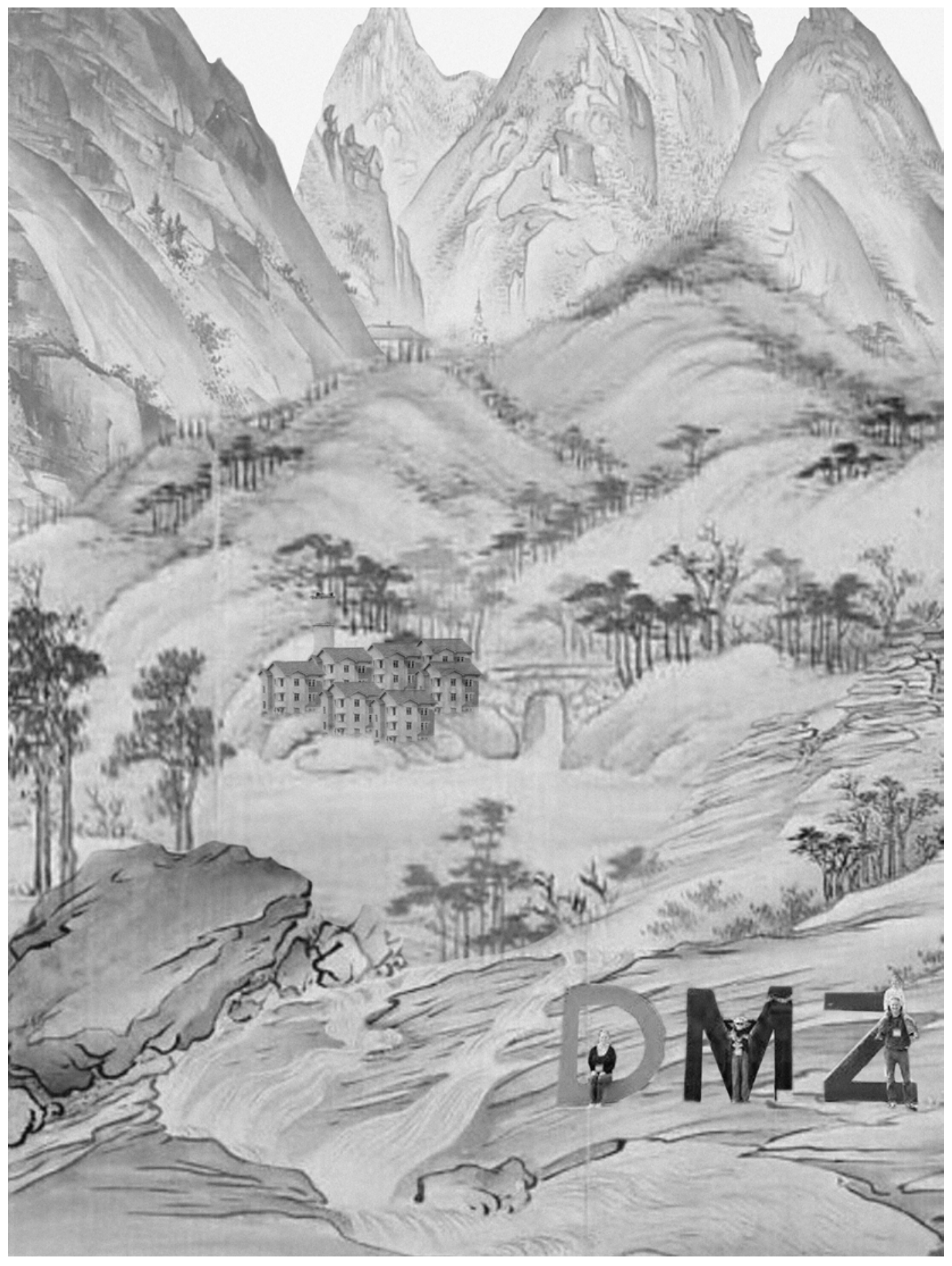

Figure 50 | Spaces of the Earth 


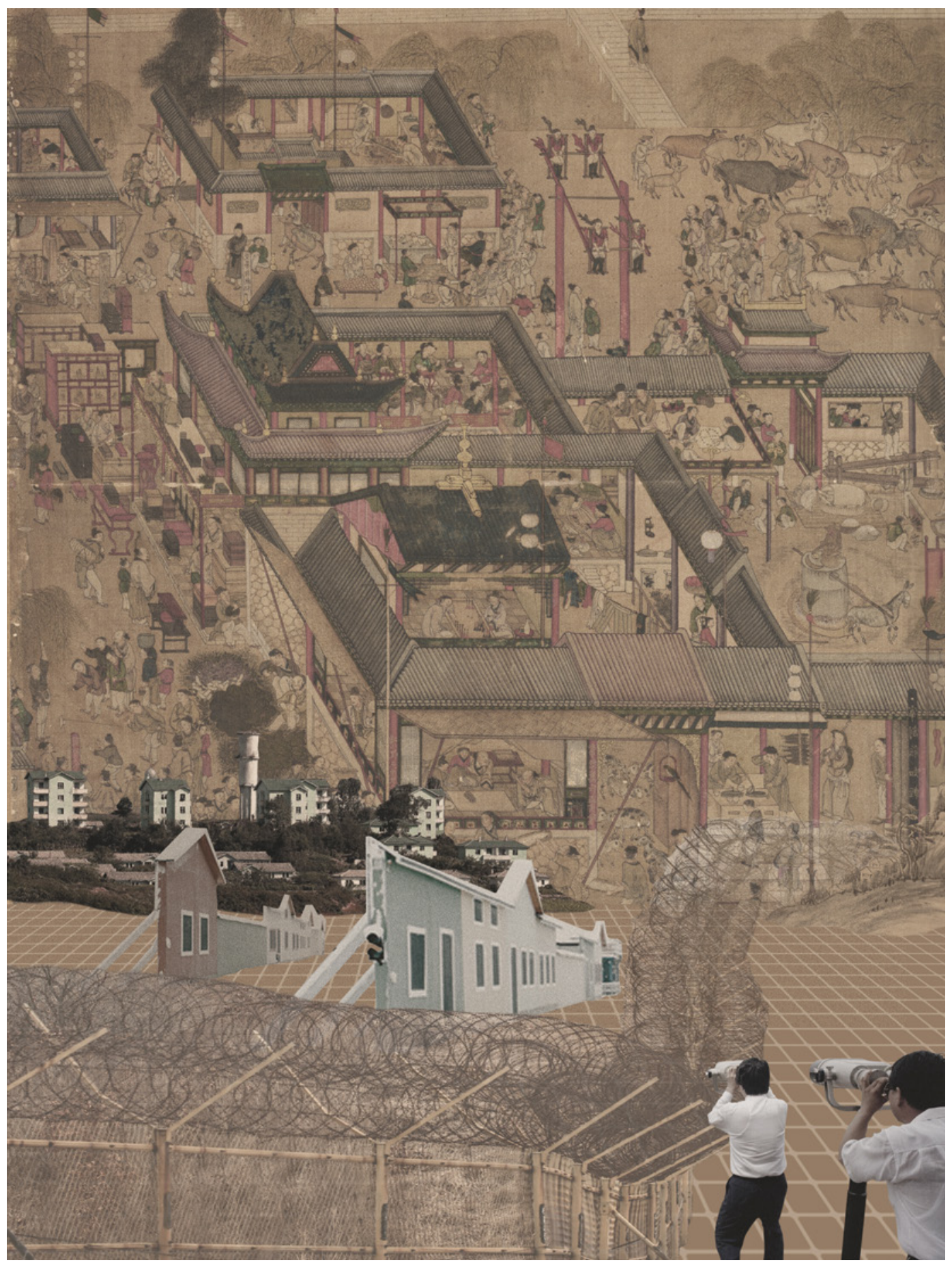

Figure 51। Spaces of the Earth: Potemkin Villages 


\subsection{Spaces of the Water}

In drawing Spaces of Water (figure 55), the absurd appears in Crab Wars, messages in bottles, and DMZ fly-fishing. The Crab Wars, which is also depicted in the form of a collage (figure 56) depicting boat chases, crabbing nets, and the Korean crab-based banchan dish called "gejang", refers to the series

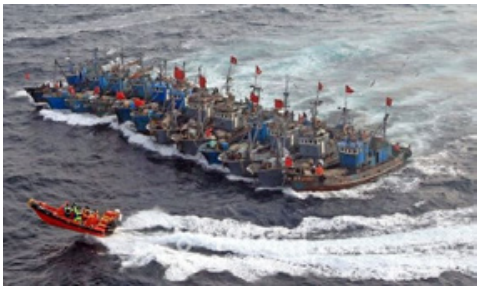

Figure 52 | Crab Wars of skirmishes and aggressions within the waters of the Yellow Sea. A result of the Northern Limit Line drawn by UN command forces, and unrecognized by international law, as well as the DPRK, the Crab Wars centre around the summer crabbing season of the blue crab. ${ }^{31}$ Presenting some of the richest waters for blue crab, South Korean and North Korean sailors are escorted to their crab fields, with the slightest crossing into disputed maritime zones resulting in chase scenes and threats of sinking. The North Korean sale of fishing rights to Chinese fishermen complicates matters further. Yeonpyeong, one of the main islands within these waters, is often a witness, or even a target, of these aggressions. With North Korean territory just 10 kilometres away, Yeonpyeong was the target of 170 North Ko-

31 James Pearson and Ju-min Park, "The War That Never Ends between the Koreas," Reuters, June 2014, https://www.reuters.com/ article/us-northkorea-islands-insight/the-war-that-never-ends-between-the-koreas-idUKKBNOES00720140617. 
rean shells, killing two civilians and two soldiers on the island..$^{32}$ Just a few months before this attack, the South Korean warship “Cheonan” was torpedoed, killing 46 sailors. ${ }^{33}$ These are just some of the aggressions that have occurred in the Yellow Sea, an obvious absurdity resulting from the attempt to control territory and impose border lines within aqueous terrains. Another element of the absurd within Spaces of Water is the evidence of DMZ fly-fishing. Reported in popular fly-fishing blogs, tourists speak of the possibility to access Manchurian trout rich streams within the Civilian Control Zone adjacent to the DMZ. ${ }^{34}$ While the blog warns of potential landmines and questioning by South Korean soldiers, it boasts of untouched streams and undisturbed fishing trips. The last absurdity revealed within Spaces of Water is the deployment of messages in bottles to fight the North Korean regime. Organized by the brother of Park Sang-Hak, who is accredited with the launch of hydrogen propaganda balloons, Park Jong-Oh attempts a similar method in the form of two-litre plastic bottles. ${ }^{35}$ These bottles are filled with propaganda pam-

33 Tim Lister, "Islands, Crabs and Skirmishes: The Koreas' Maritime Mishaps," CNN World, November 2010, https://www.cnn. com/2010/WORLD/asiapcf/11/25/koreas.maritime.explainer/index. html.

34 James Card, "Cold War Trout: Fly Fishing the Korean DMZ Borderlands," Midcurrent, accessed December 12, 2020, https://midcurrent.com/travel/cold-war-trout-fly-fishing-the-korean-dmz-borderlands/.

35 Sang-Hun, "As Floating Propaganda Irks North Korea, the South Isn't Happy Either." 
phlets, dried rice, memory sticks, medicine, and American money, then deployed in the hopes that currents will carry these bottles to North Korean shores. ${ }^{36}$ This voyage of plastic bottles is reconstructed and investigated further through the aid of a tank model (figure 31), where the creation of water currents mimics the path of bottles as they travel to shore. However, locals of the beach used to deploy the two-litre bottles complain of the clogging of fishing nets, and the accumulation of plastic pollution. Yet, organizers claim South Korean guards have witnessed North Korean soldiers and civilians collecting these very bottles on shore, ${ }^{37}$ bringing hope of inciting change within the DPRK.

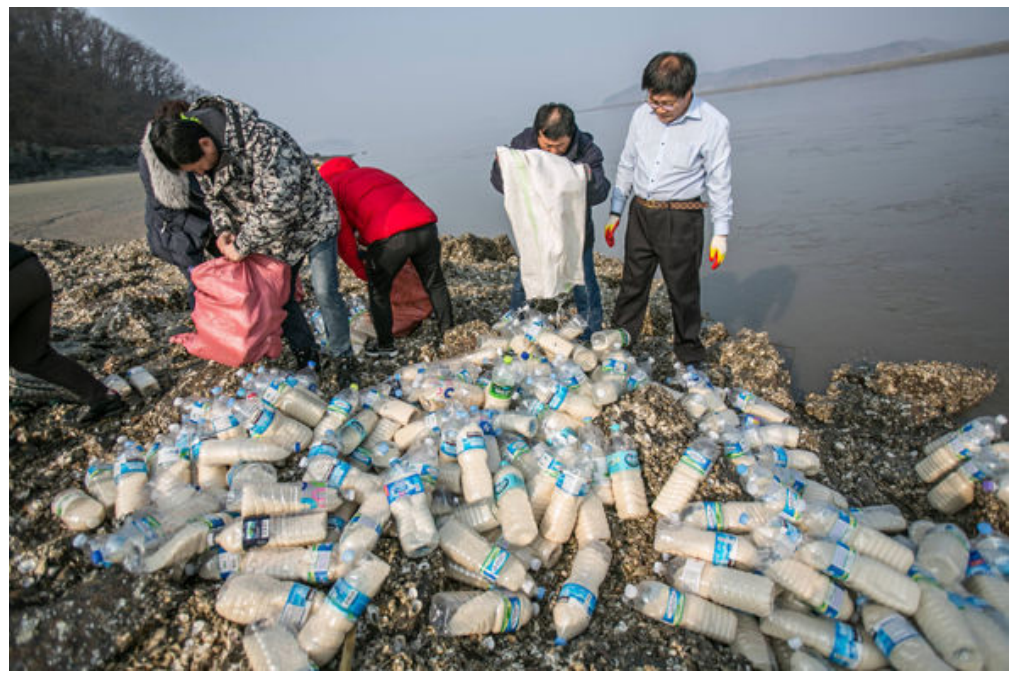

36 Ivan Watson et al., "Messages in Bottles Sent across the Sea to North Korea," CNN World, May 2018, https://www.cnn. com/2018/05/17/asia/north-korea-bottles-dmz-intl.

$37 \quad$ Watson et al. 


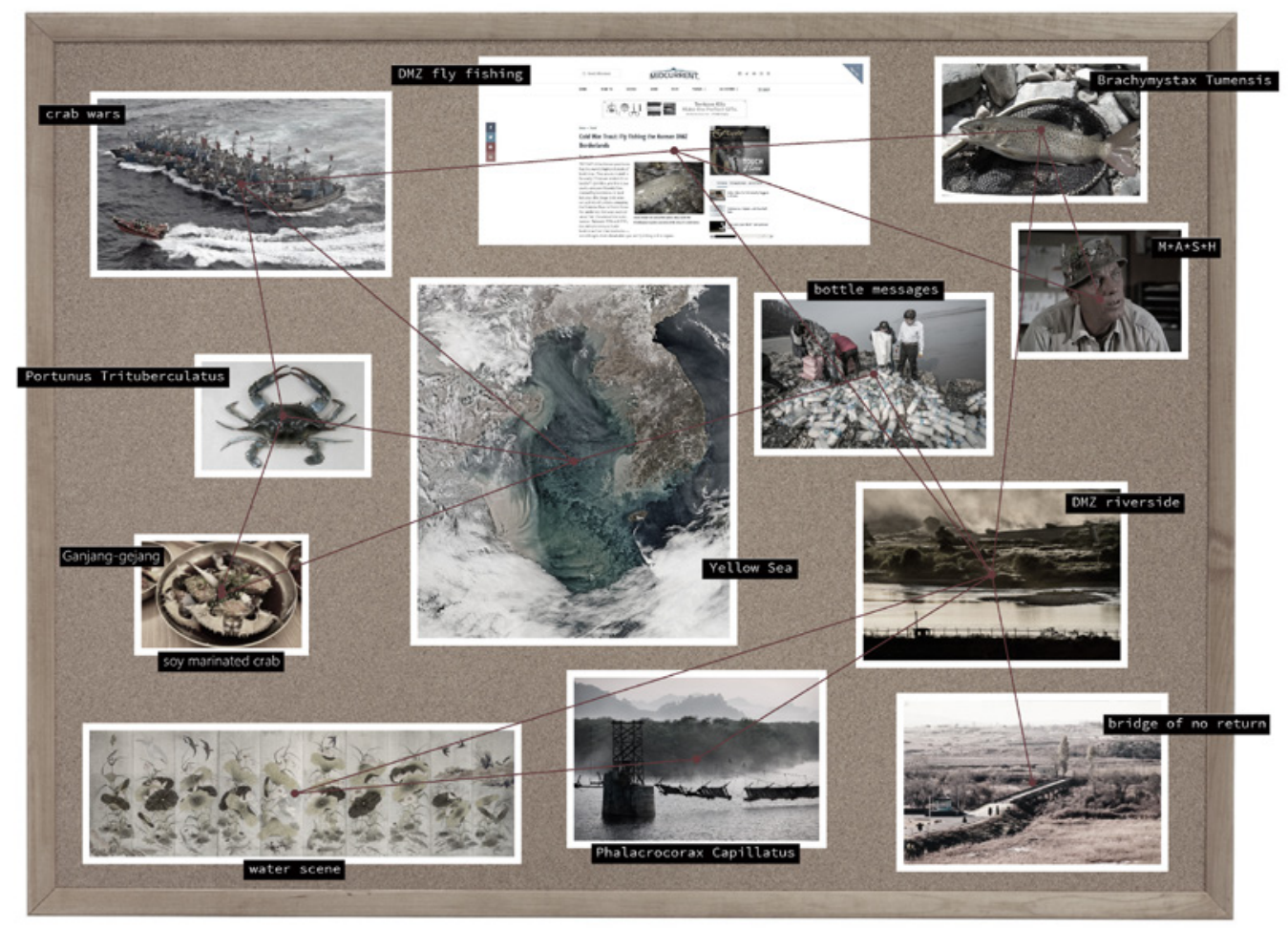

Figure 54 | Murderboard: Spaces of the Water 


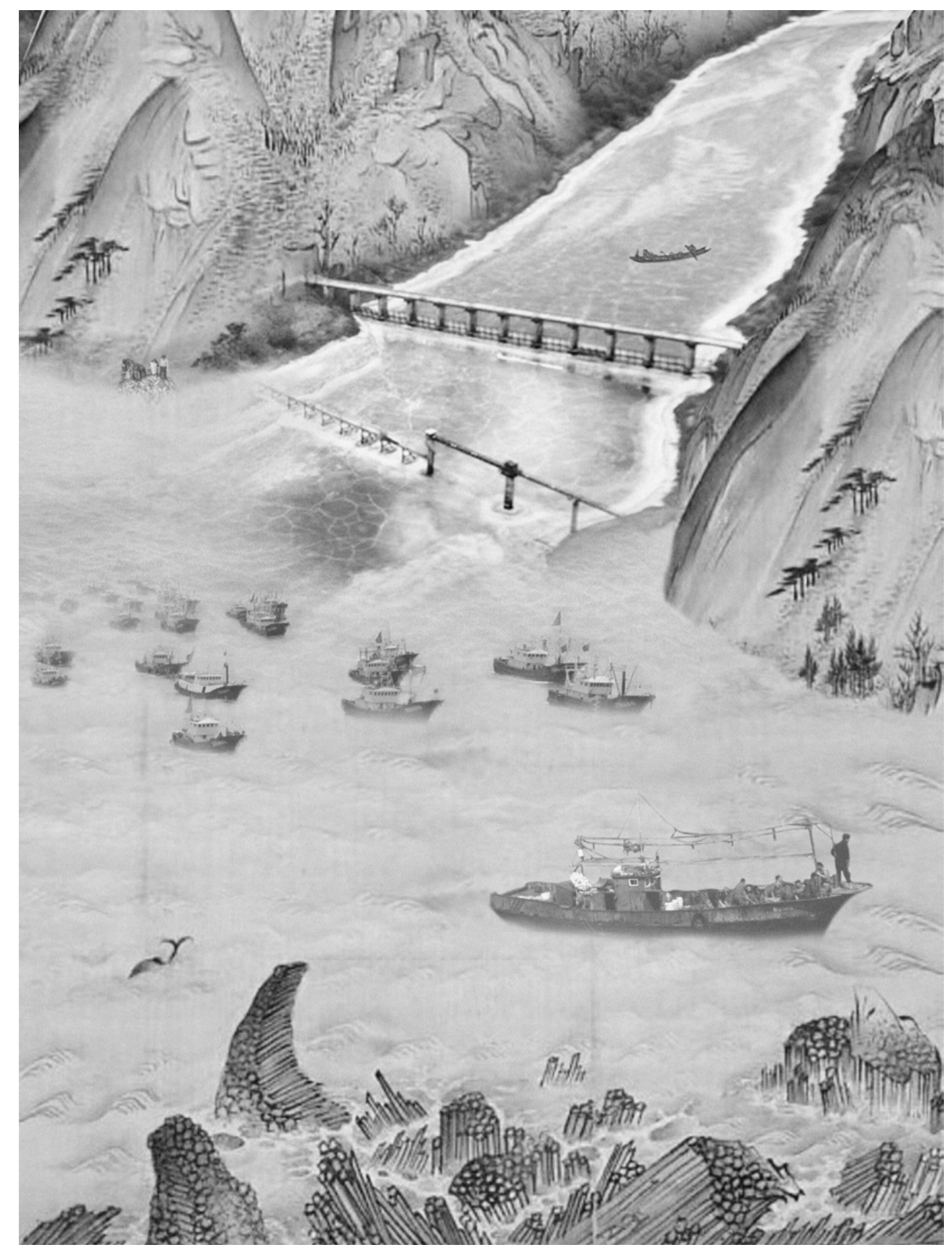

Figure 55 | Spaces of the Water 


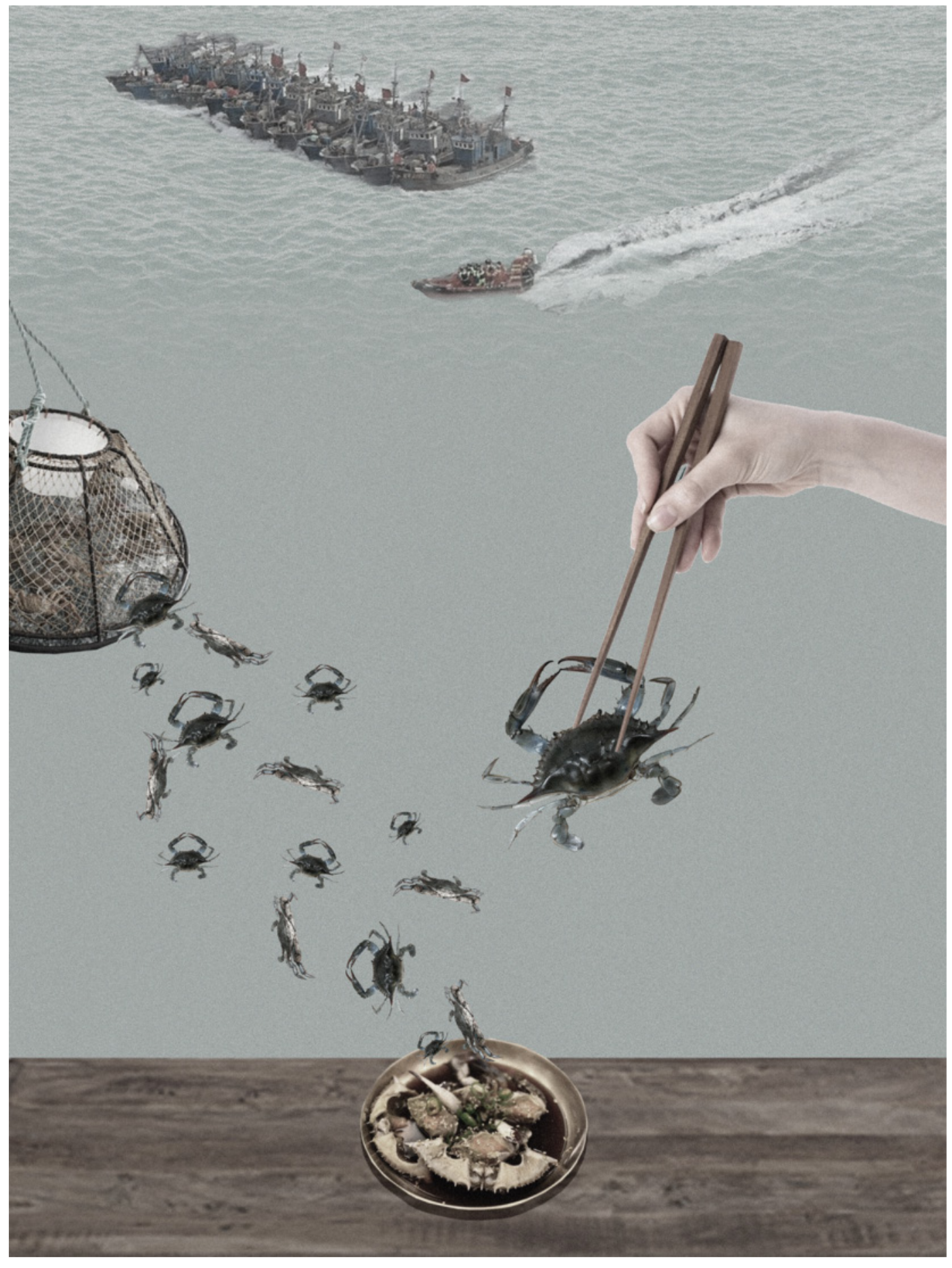

Figure 56 | Spaces of the Water: Crab Wars 


\subsection{Spaces of the Below}

Secret tunnels of infiltration, DMZ agriculture, and landmines comprise the scenes of absurdity within Spaces of the Below (figure 61). Since 1974, a total of four infiltration tunnels have been identified, with the first discovered due to South Korean soldiers noticing steam and suspicious noises. ${ }^{38}$ The following three tunnels were discovered in 1975, 1978, and 1990, with the closest one discovered just thirty-two miles outside of the Re-

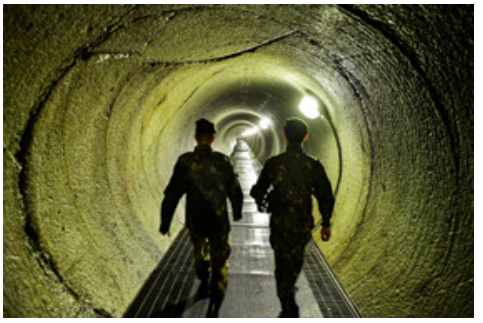

Figure 57| Tunnels of Aggression public of Korea's capital city, Seoul. While no more tunnels have been found, North Korean defectors have suggested that other tunnels do in fact exist, resulting in civilian investigators who, convinced of their existence, spend their free time searching the areas near the Korean Demilitarized Zone for any signs. ${ }^{39}$ These infiltration tunnels, labeled Tunnels of Aggression, are believed to have been built in order to discretely transport North Korean troops into South Korean territory for invasion. Located hundreds of feet below the earth's surface, three of these Tunnels of Aggression are now popular tourist destinations. The absurdity

38 Megan Specia, "Built for Invasion, North Korean Tunnels Now Flow With Tourists," The New York Times, November 2017, https:// www.nytimes.com/2017/11/04/world/asia/north-korea-south-korea-demilitarized-zone-tunnel-tourism.html?

39 Lucy Williamson, "Hunt for North Korea's 'Hidden Tunnels," BBC News (Seoul, August 2012), https://www.bbc.com/news/worldasia-19252862. 
of these tunnels which directly evolves from the conquest for territory is further explored in a collage (figure 62), showing their inner workings, and speculating upon their construction and use. Landmines also present one of the lasting absurdities of the Korean War. An estimated 2.2 million landmines are thought to remain within the Korean Demilitarized Zone, posing a threat

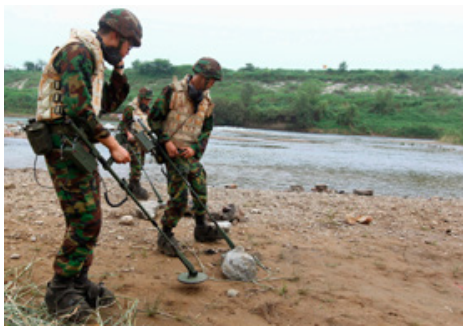

Figure 58 | South Korean Soldiers Search for Land Mines to both soldiers and civilians (whether tourists or inhabitants)..$^{40}$ The investigative tool of the tank model (figure 31), allows the creation of a space to speculate methods of tunnel and landmine detection through the visualization of sound. The detection of landmines play an important role in the task of South Korean soldiers who escort DMZ villagers to their fields and homes. While millions of landmines remain from the era of the Korean War, they still present a tool of aggression for North Korea in their acts of absurdity along the border. In 2015, a group of North Korean soldiers managed to sneak into the southern zone of the DMZ, and successfully planted land mines, maiming two South Korean soldiers. ${ }^{41}$ These absurdities are expressed even further in the day to day lives of the villagers of Taesung, a DMZ village known for the cultivation of rice and ginseng. ${ }^{42}$ These vil-

40 Dongsei Kim, "A White Paper on The Demilitarized Zone: Some Facts and Questions for the Future," in North Korean Atlas, ed. Dongwoo Yim and Rafael Lima (Seoul: Damdi, 2014), 106.

41 Rich, "As North Korea Tensions Rise, Farming in the Demilitarized Zone Goes On."

42 Kim, The Demilitarized Zone (DMZ) of Korea: Protection, Conseration and Restoration of a Unique Ecosystem. 449. 
lagers, who grow and sell rice under the DMZ brand, witness the instruments of absurdity previously mentioned, such as land mines and speaker wars. Taesung, known as the Freedom Village, and built in competition of North Korea's propaganda village of Kijong-Dong, has a population of roughly 197 residents, ${ }^{43}$ and they are believed to be the only civilians living

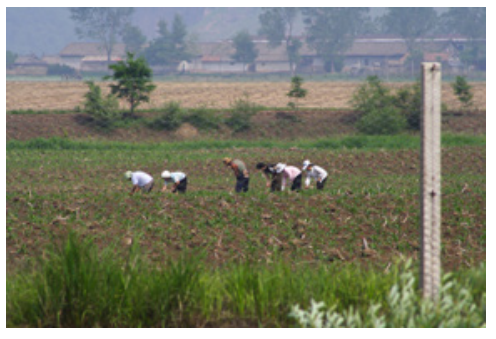

Figure 59 | Farmers of the DMZ within the Korean Demilitarized Zone. While inhabitants do not pay national income taxes, as the $\mathrm{DMZ}$ is administered by the United Nations command, their population has dwindled over the years, as more and more residents abandon the DMZ industry of agriculture to pursue jobs in the city. Additionally, the absurd contradiction of a village under extreme security, where soldiers escort villagers, and visitors must submit applications weeks in advance to pass through Taesung's numerous checkpoints, DPRK is just a field across. Villagers are reminded of the impending threat of attack as North Korean propaganda songs play for 20 hours of the day, a reminder of the absurdities that have arose from the terror of territory. 


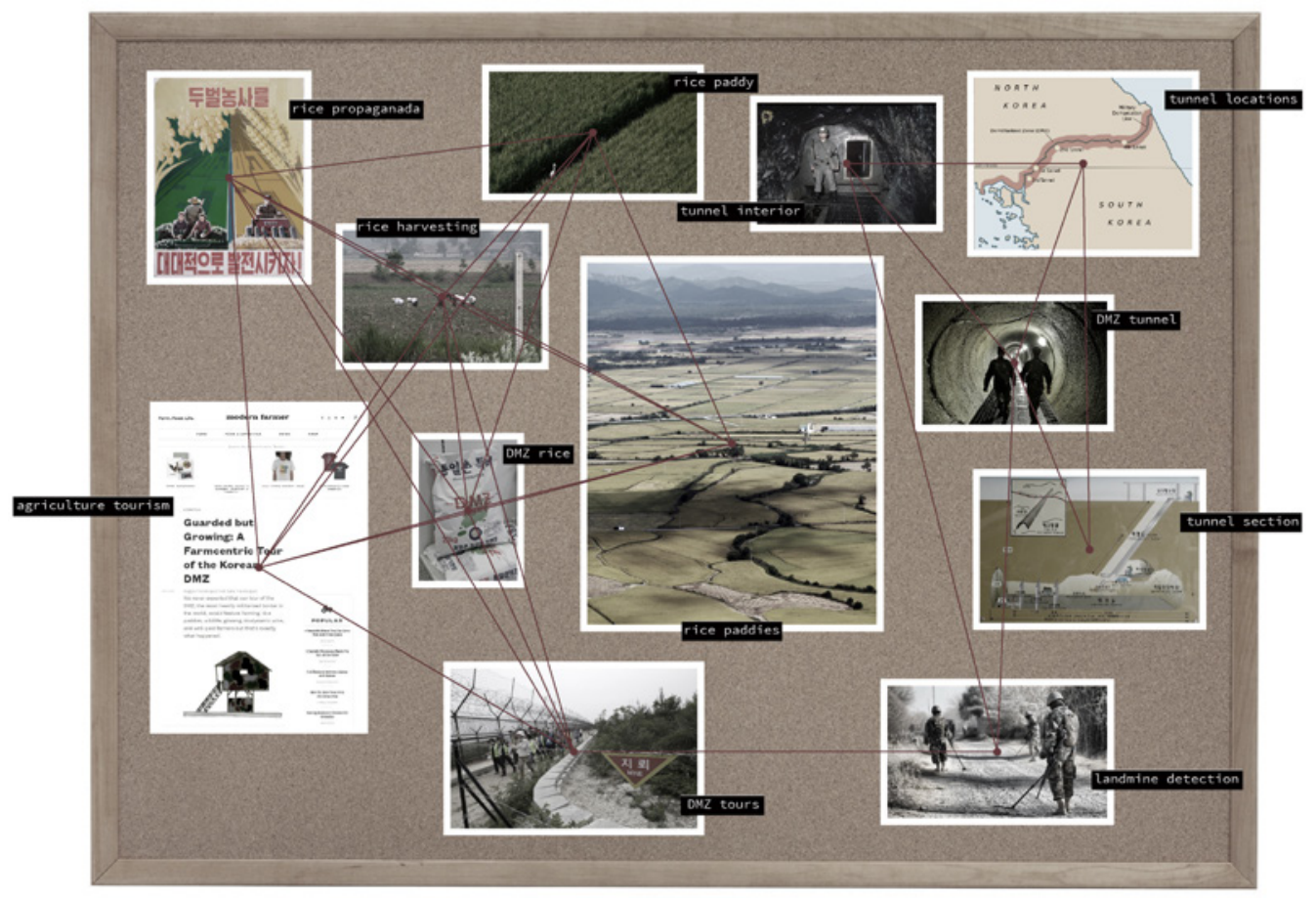

Figure 60 | Murderboard: Spaces of the Below 


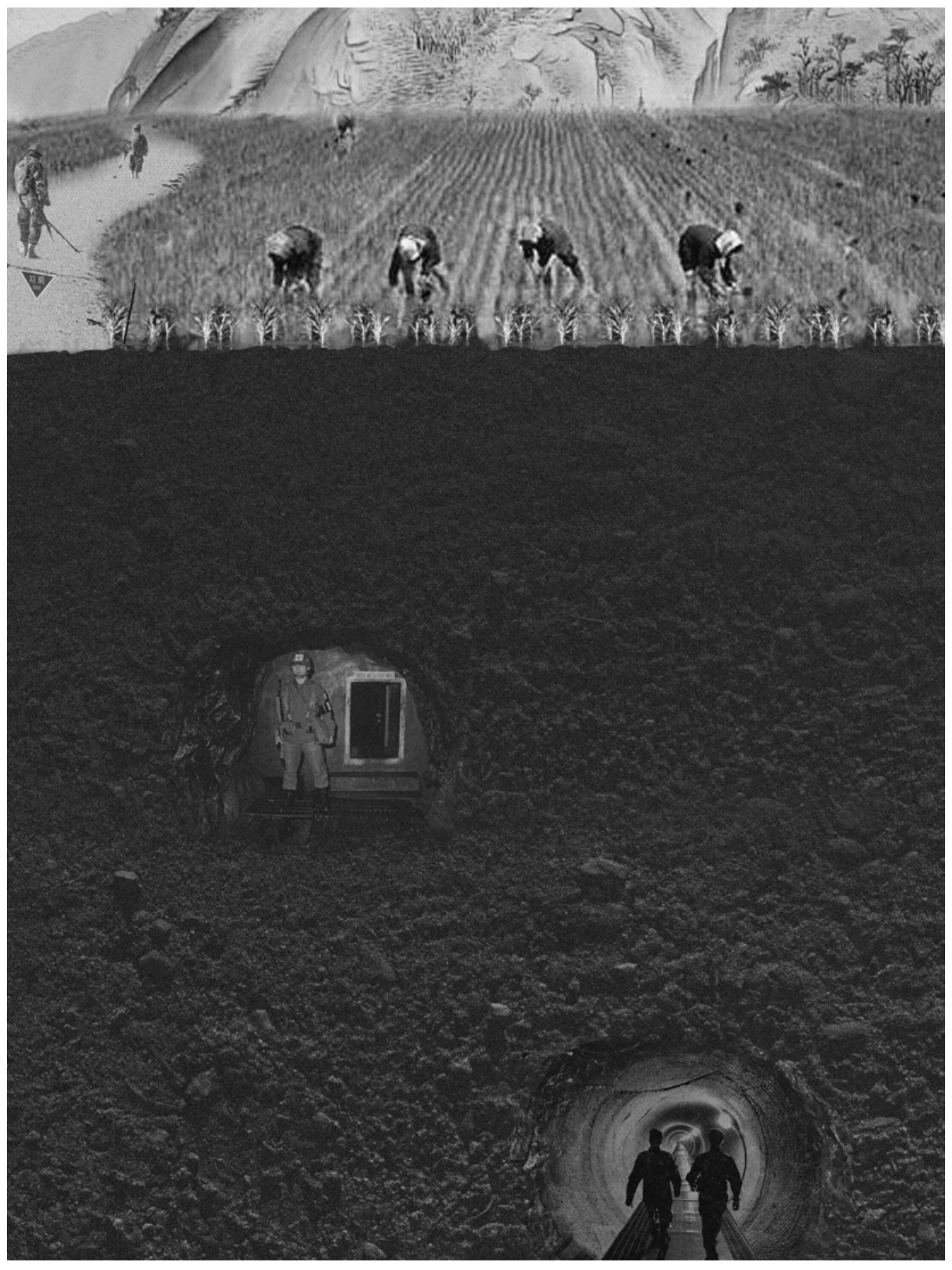

Figure 61| Spaces of the Below 


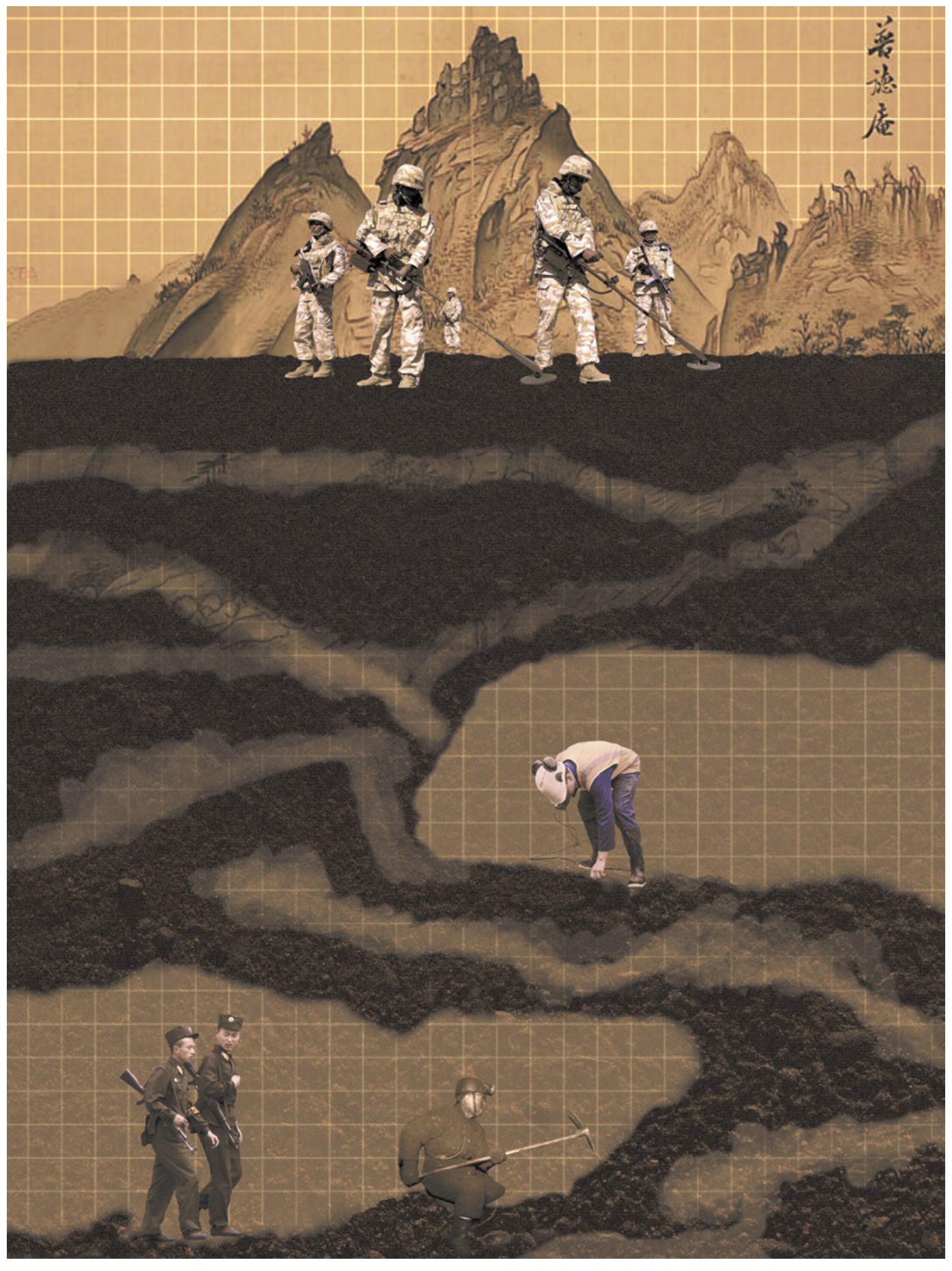

Figure 62 | Spaces of the Below: Tunnels of Aggression 
PART THREE // THE FICTIONAL

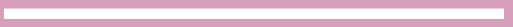

독 안에 든 쥐 


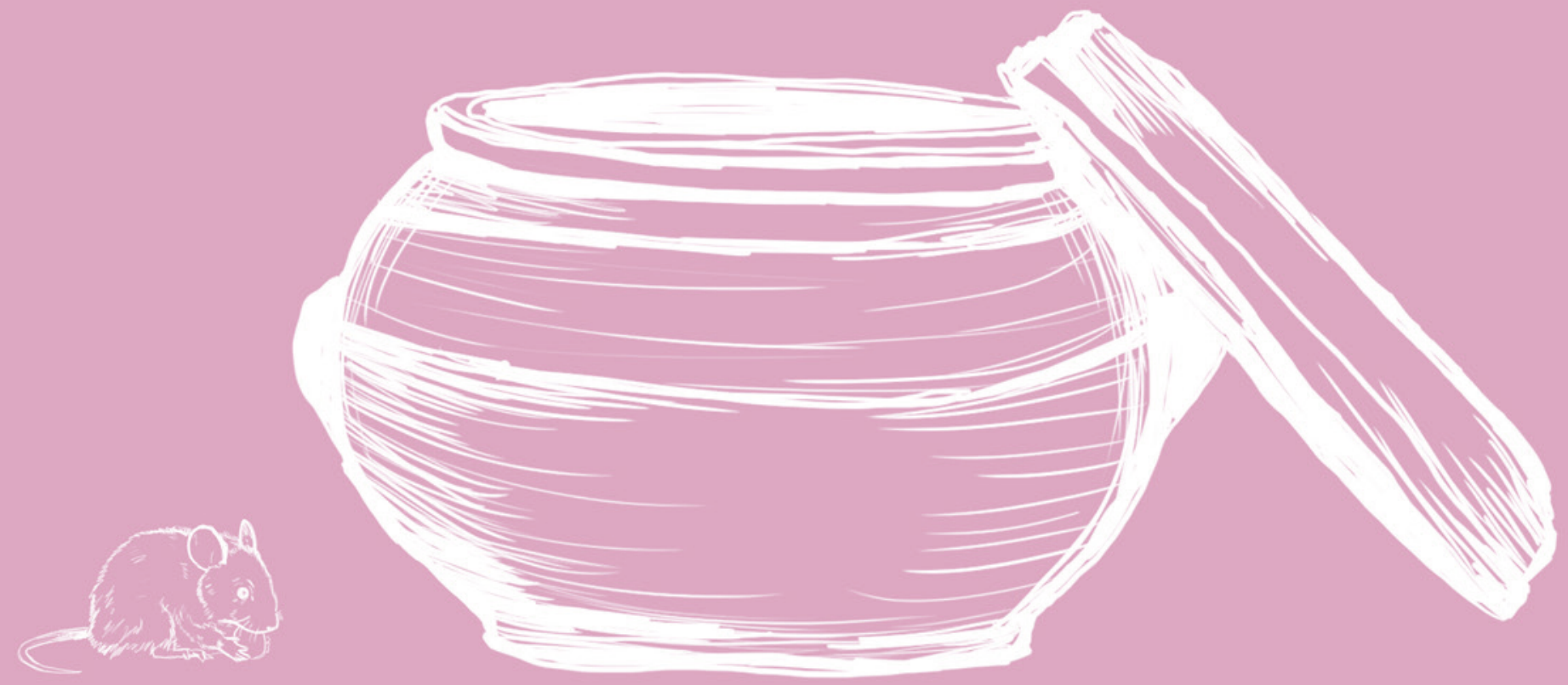




\section{THE FICTIONAL}

\subsection{Preface}

“... what potent role can architecture have in this context? How can architecture contribute to new conceptualizations of alternative peaceful futures for this tense border history? I would suggest that architectural intelligence - rather than architecture as an object - holds significant potency in contributing to this condition."

"In saying so, architectural thinking could specifically facilitate this productive dialogic space to further unfold through envisioning alternative futures that spark debates.”

- Dongsei Kim, Towards a Dialogic Peace in the Demilitarized Zone

Arriving at the creation of the fiction, this thesis recognizes the role of architectural thinking, specifically, its ability to spatialize conflicts and their antagonistic behaviour as a manner to facilitate the conceptualization of future spaces of the Korean Demilitarized Zone. While the following design fiction scenarios do not present perfect images of peace, their dialogical quali- 
ties hope to create a greater understanding of the challenges that present themselves, and how they may need to evolve, acting as a “cautionary anecdote toward blind peace...”. ${ }^{1}$

1 Dongsei Kim, "Towards a Diologic Peace in the Demilitarized Zone," Volume 40, no. 2 (2014): 40-43.43. 


\subsubsection{Instruments of Absurdity}

The theme of the absurd has provided a method to identify key instruments at play in experiencing the numerous spaces of the Korean Demilitarized Zone, its antagonistic spaces of conflict. Building upon the series of absurdities previously investigated, each scenario imagines the evolution of these absurd instruments through the use of design fiction. As identified by Leah Zaidi, in Building Brave New Worlds: Science Fiction and Transition Design, "If we acknowledge that much of what we consider reality is comprised of narratives, and that these narratives can be rewritten, then the process for creating and telling stories may offer insight into how to improve our society." If we imagine narratives as the instruments of absurdity previously seen in the context of this thesis, by rewriting, or speculating upon their possible evolution, we can begin to think about the future of the $\mathrm{DMZ}$ in a critical, dialogic manner.

2 Leah Zaidi, "Building Brave New Worlds: Science Fiction and Transition Design” (OCAD University, 2017). 6. 


\subsubsection{Drawing Absurdity}

Looking back on the prevalence of the scroll or panels in traditional Korean art, paintings such as Seven Jeweled Mountain (figure 60), or the Painting of One Hundred Themes (figure 61), provides a method to represent design fictions as a series of looping and interconnected narratives. Much like the landscape painting Seven Jeweled Mountain, each design fiction scenario is imagined as a single panel of a larger drawing set. Within the upper right corner of each panel, technical drawings of each instrument of absurdity are represented, mimicking the use of text in traditional drawings as supplementary material to understand the narratives at play. Connected by the landscape of the Korean Demilitarized Zone, when panelled together, the drawings create a looping borderline. The borderline is emphasized through a faint site map, situating each micronarrative. Returning to themes found in the absurd, the concept of a looping drawing alludes to Beckettian themes of deadlock and stalemate, while also referring to the political deadlock of the Demilitarized Zone itself. Finally, through the assembly of the drawing, micro narratives can be juxtaposed and re-read within the larger context of three design fiction scenarios. 


\subsection{Spaces of Speculation}

Design fiction serves as the primary tool in creating spaces of speculation for the Korean Demilitarized Zone. Under the three distinct scenarios of the Erased, the Infiltrated, and the Continued, design fiction acts as a means of world making, where distinctive instruments of absurdity are reimagined. Described by Josephy Lindley and Paul Coulton as “... (1) something that creates a story world, (2) has something being prototyped within that story world, (3) does so in order to create a discursive space," ${ }^{3}$ the scenarios of the Erased, the Infiltrated, and the Continued act as these story worlds, and instruments of absurdity act as narratives to be prototyped, resulting in the creation of a dialogic DMZ. The tool of design fiction enables us to better understand the current realm and concerns that surround the $\mathrm{DMZ}$, and aids in creating a productive space that involves the 'other'.

3 Joseph Lindley and Paul Coulton, "Back to the Future: 10 Years of Design Fiction," ACM International Conference Proceeding Series, 2015, 1. https://doi.org/10.1145/2783446.2783592. 


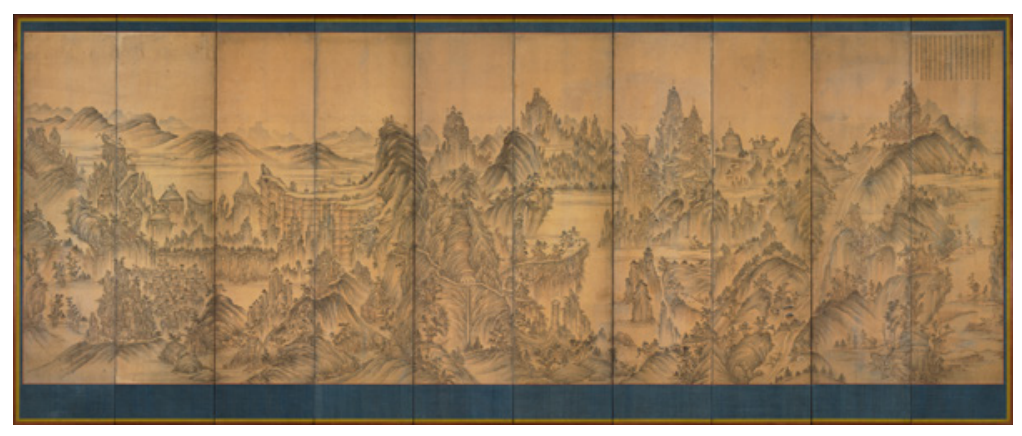

Figure 63 | Seven Jeweled Mountain

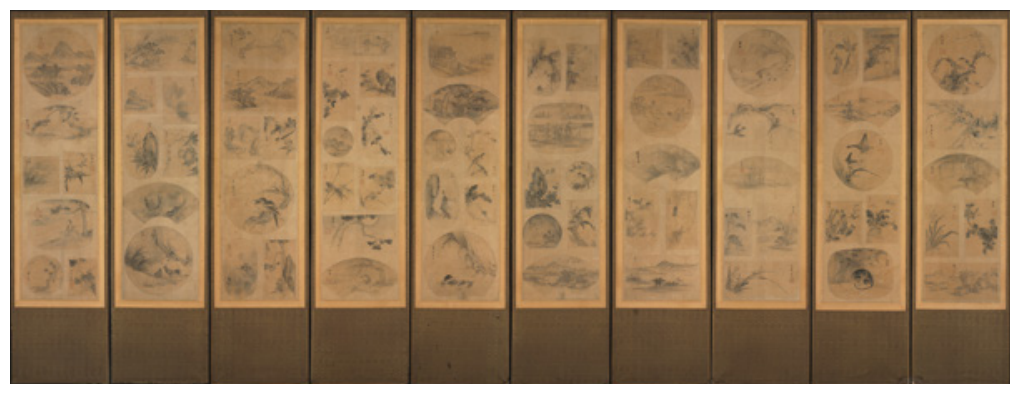

Figure $64 \mid$ Painting of One Hundred Themes 


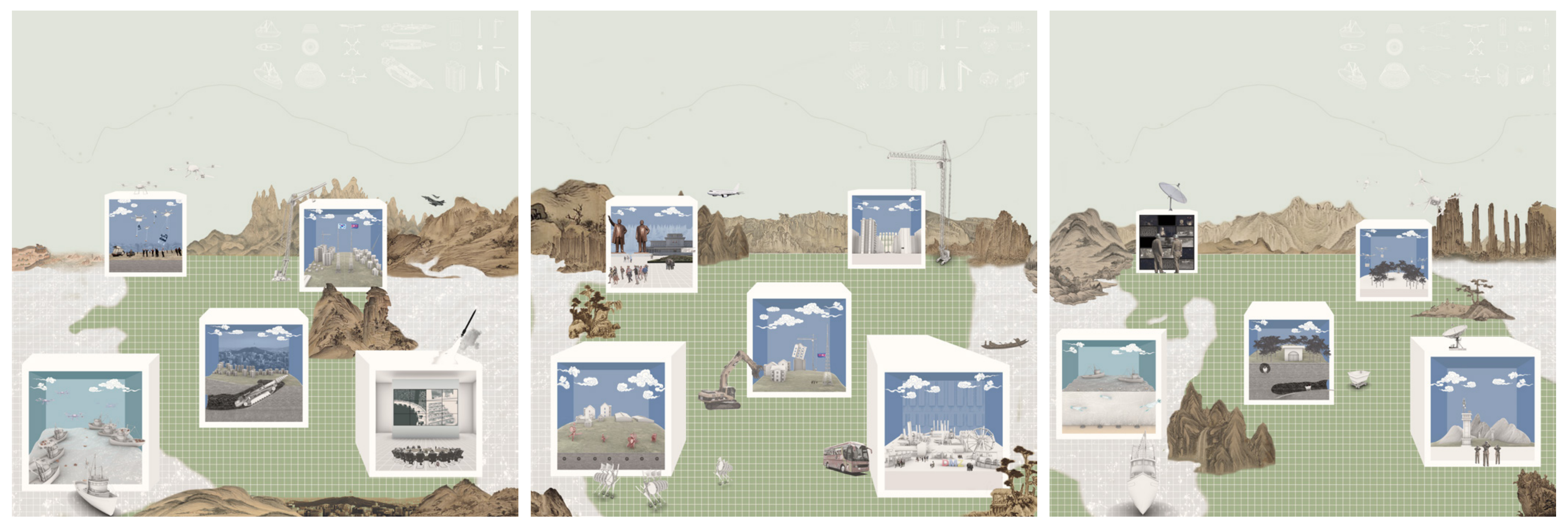




\subsection{Erased}

The fiction of the Erased imagines the reunification of Korea under South Korean hegemony. In this alternate future, the euphoria of reconciliation soon fades away, as former North Koreans are adapting to the reality of life in a society they know little about. As this new population settles the urban centers of the South in search for work, issues of integration and cultural divides arise. While the now useless infrastructure for propaganda is being dismantled, new infrastructure is built to support the rapidly urbanizing population, encroaching on land that had been preserved from development through the century-long political stalemate.

The drawing explores the consequences of reunification on the former landscape of the DMZ, and its impact on the everyday life of former North Korean citizens through a series of micronarratives. The assimilation of North Koreans is paired with scenes of the commodification of Pyongyang as an evolving tourist attraction that represents a relic of the past. In a first scene, zoomorphic land mine cleaning machines are seen sweeping the border. These machines, inspired by the presence of non-human characters within Korean folklore, mimic the 
endangered cranes that once roamed the territory. A following scene shows a frozen Pyongyang that has now become an artifact for tourists to experience. Hordes of tourists now roam once forbidden halls and snap away on their cameras. However, following scenes portray the experience of former North Koreans as they navigate life in a foreign society. A micronarrative fueled by development, depicts a surge in urbanization triggered by the resettlement of populations from the North, and the displacement of animal populations that previously inhabited the pristine land of the Demilitarized Zone. An adjacent scene shows the remnants of infrastructure from the propaganda wars being torn down, as the new nation moves towards reconciliation. Lastly, a boom in dark tourism is seen as tourists can now visit the $\mathrm{DMZ}$ more freely than ever. While enjoying amusement parks and decommissioned tunnels, visitors can also peruse gifts shops fueled by the cheap labour found at the DMZ industrial complex of Kaesong. The scenario of the Erased imagines the frictions that reunification would bring, and the feasibility of merging two largely opposite systems. 

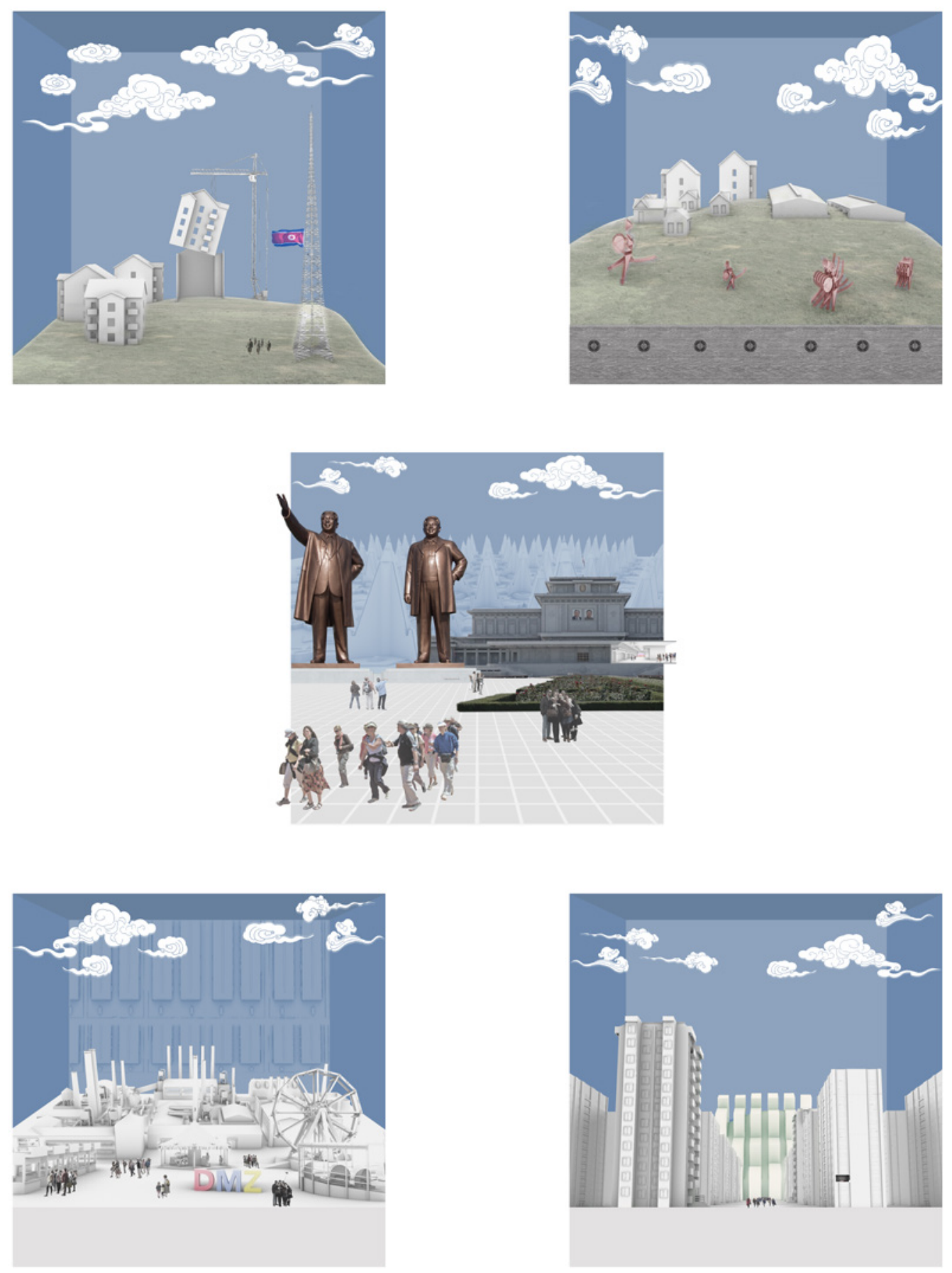

Figure 66 | Erased: Instruments of Absurdity

Left to Right: Propaganda Village, Mine Detection, Frozen Pyongyang, Dark Tourism, Mass Housing 


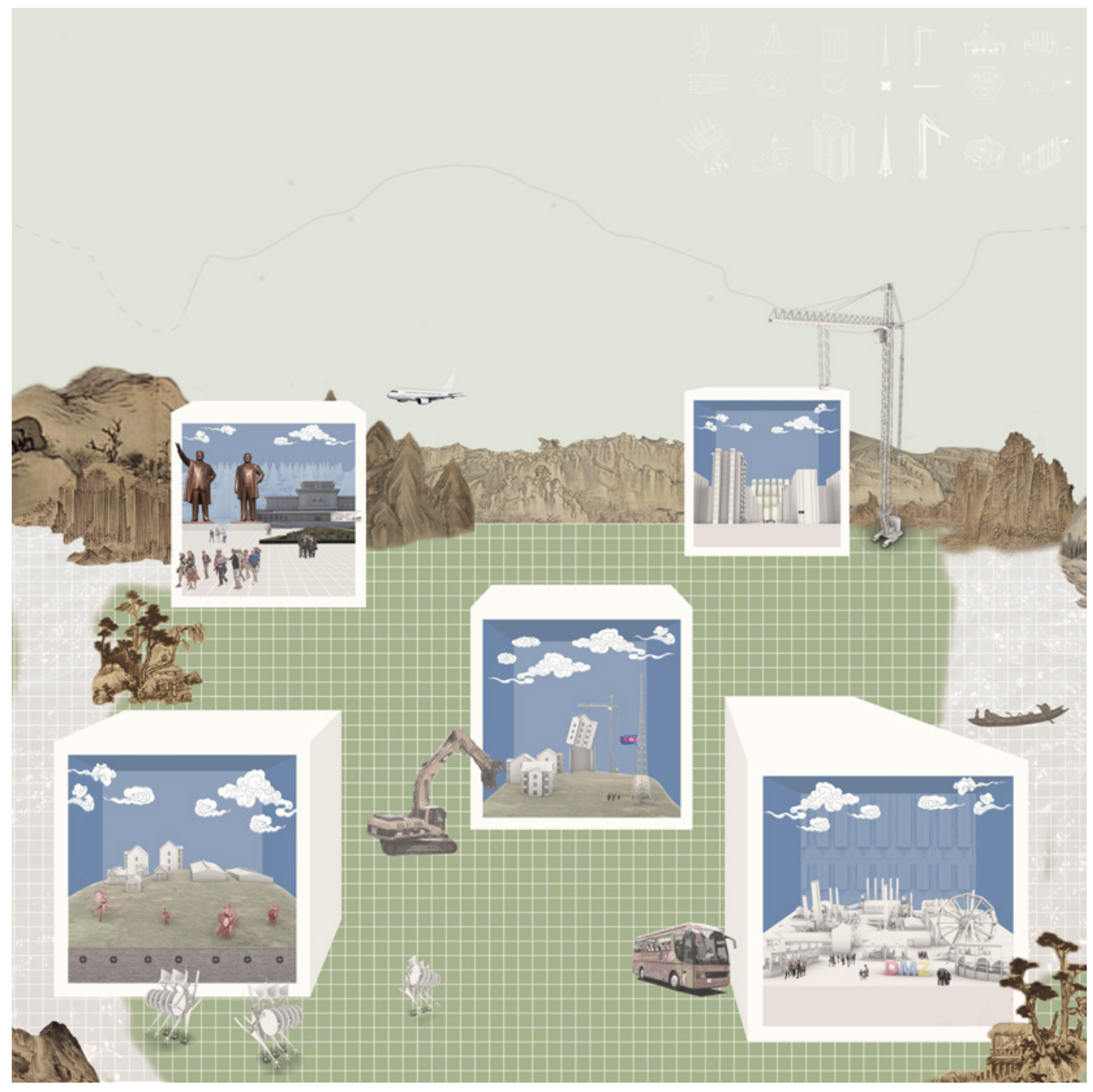

Figure 67| Erased 


\subsection{Infiltrated}

“... Green Korea United, a South Korean nongovernmental organization (NGO) released a report in July 2013, claiming that the agreed 992-km2 footprint of the DMZ in the Armistice Agreement is now close to half. Standing at 570- $\mathrm{km} 2$ this is almost $43 \%$ less than the original footprint, under-mined by the constant military transgressions and territorial contestations nudging into the buffer zone." (A White Paper on The Demilitarized Zone, Dongsei Kim, 106)

This fiction imagines a scenario where environmental activists infiltrate and settle the DMZ in search for traces of the fabled last tigers of Korea. Fearing encroachment from both North and South, this group of activists develops an autonomous society wedged between the warring nations, effectively forming a "Third Korea." As time passes, the new inhabitants of the DMZ adapt their landscape, taking advantage of infrastructure originally designed to keep humans out.

In the drawing, micronarratives track the evolution of this new society, from its inception as an act of environmental conservation to its realization as an autonomous political enti- 
ty. The narratives begin with a scene portraying environmental activists infiltrating the DMZ in search of evidence of the presence of tigers. As their presence grows, a second narrative depicts propaganda loudspeakers from the era of speaker wars, being directed towards the group, blasting calls for activists to vacate the Zone. After this proves unsuccessful, the following scene shows activists taking residence in the empty guard towers found throughout the DMZ. In the next narrative, activists are shown taking advantage of infiltration tunnels to move supplies and information across and out of the DMZ. Finally, the last scene depicts the action of autonomous "anti-crabbing” devices developed by the activists to prevent encroachment from fishermen from the North and South. Overall, this scenario explores the impact of a third actor being introduced between two Koreas and challenges the integrity of the so-called buffer zone. 

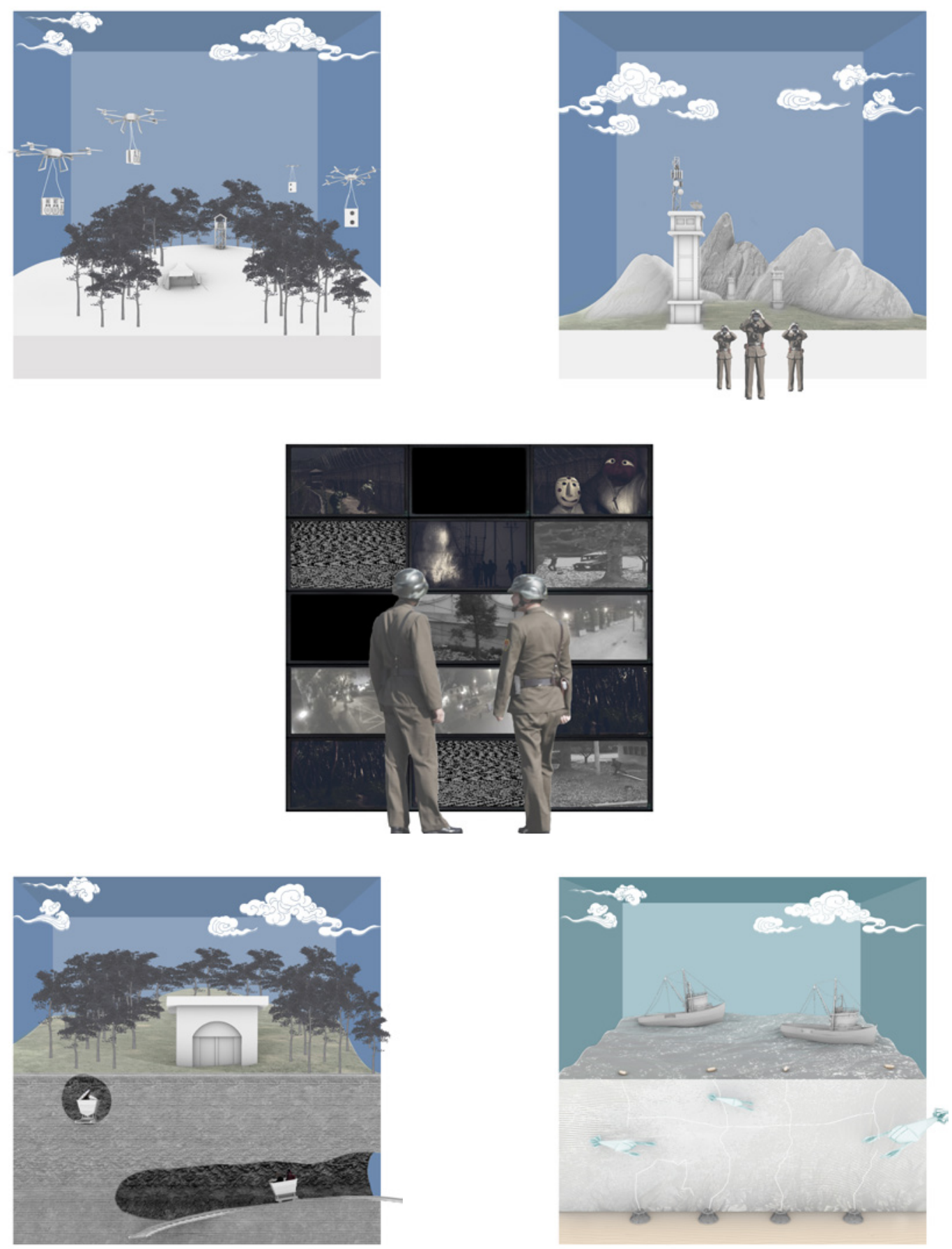

Figure 68| Infiltrated: Instruments of Absurdity

Left to Right: Speaker Wars, Infiltrated Infrastructure, Infiltration, Tunnel Smugging, Crab Wars 


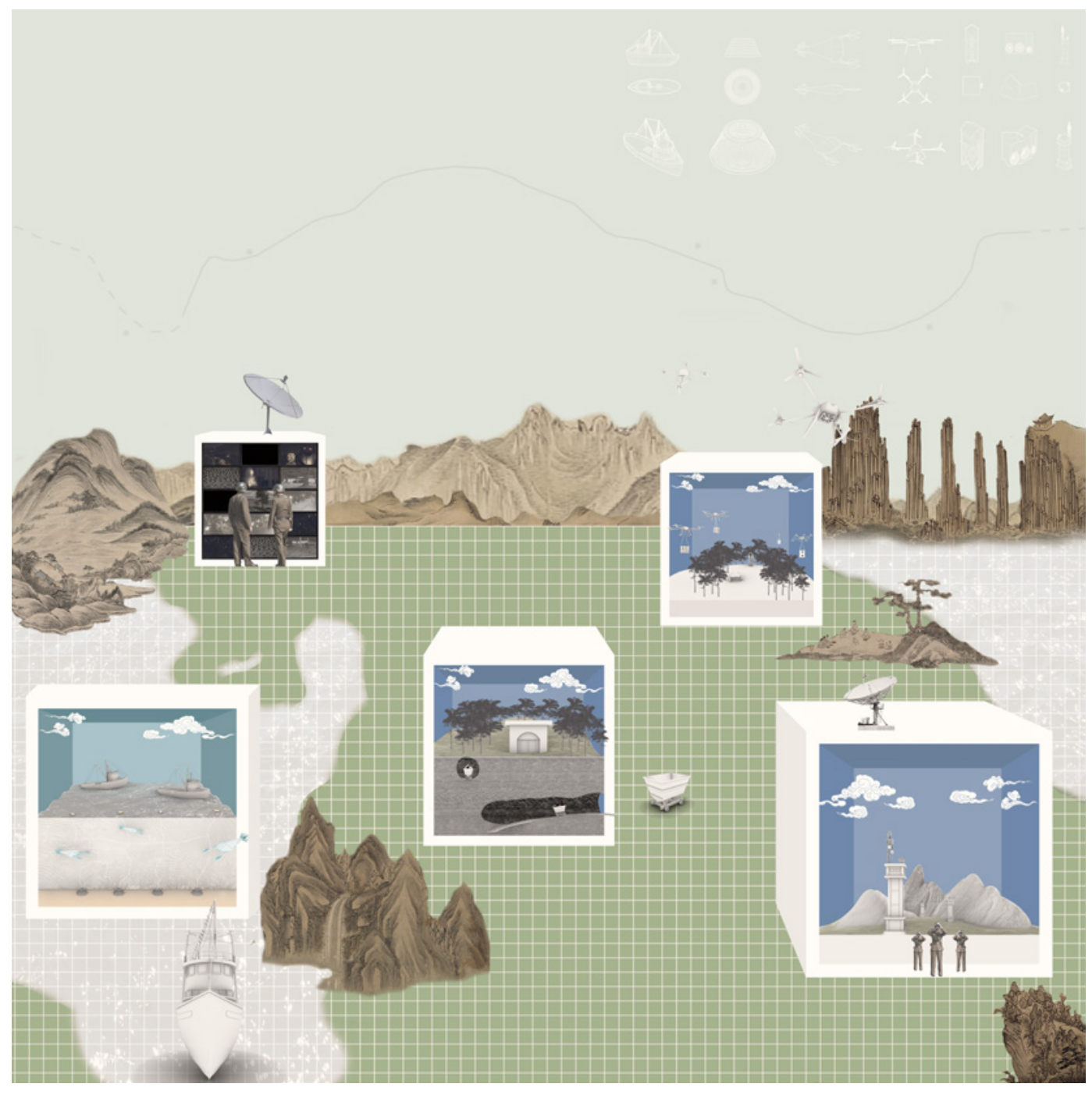

Figure 69| Infiltrated 


\subsection{Continued}

Rather than imagining the transformation of the DMZ, this last fiction speculates on the continuation and evolution of its sites of absurdities guided by an increased use of technological means. In this imagined future, the DMZ persists, but the moments of porosity multiply, as new technologies allow for an exacerbation of cross-border communication.

This drawing depicts an acceleration of these moments of porosity as they become increasingly guided by autonomous technology. The first scene speculates the use of drones to transport propaganda across the border as activists find new ways to get their message across following the ban on hydrogen balloons by the South Korean government. However, this brings further fears of ramifications as the drones prove ever more pervasive as a threat to North Korean ideologies. The use of intensive crabbing instruments is explored in the next narrative, as an escalation in Crab Wars tensions sparks a race towards technical innovation. Drones are again seen as a new tool to monitor Chinese and North Korean operations from afar, while also enabling the interference of fishing lines. As new tools are discovered for de- 
tecting tunnels, so too are new tools to dig them, as explored in the next narrative. A massive new machine silently travels under the DMZ, making way towards Seoul, providing potential new routes for infiltration. As tensions heighten, a show of one-upmanship continues along the border. The scale of the Propaganda Villages increase, as do the height of both North and South Korean flagpoles. Finally, the deployment of massive cyberattack campaigns fuels renewed threats of a nuclear Armageddon on the peninsula. By speculating on a continuation and exacerbation of existing spaces of absurdity, this final scenario magnifies the moments of porosity across the DMZ. 

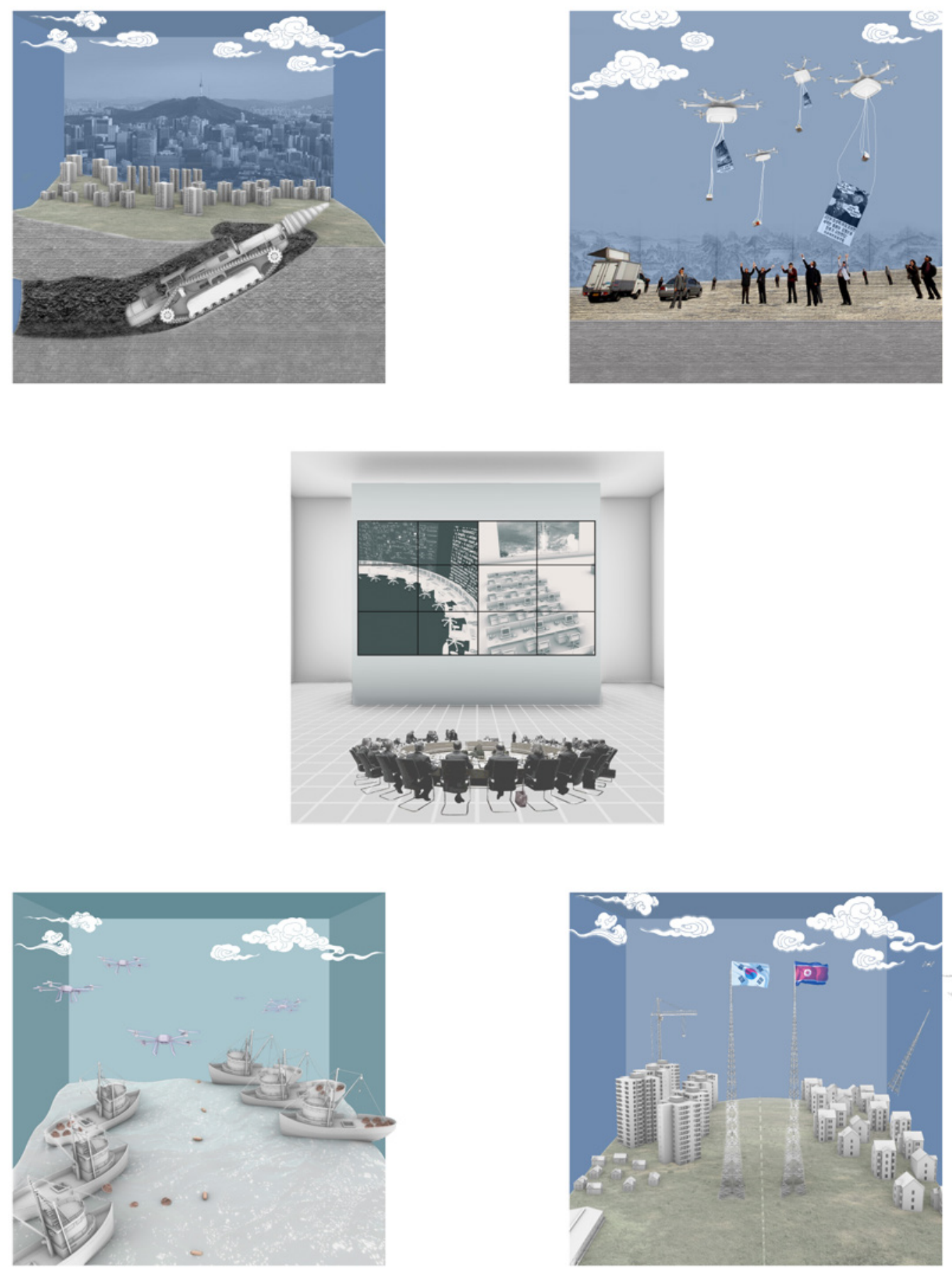

Figure 70 | Continued: Instruments of Absurdity

Left to Right: Tunnel Construction, Propaganda Drones, Surveillance, Crab Wars, Propaganda Village 


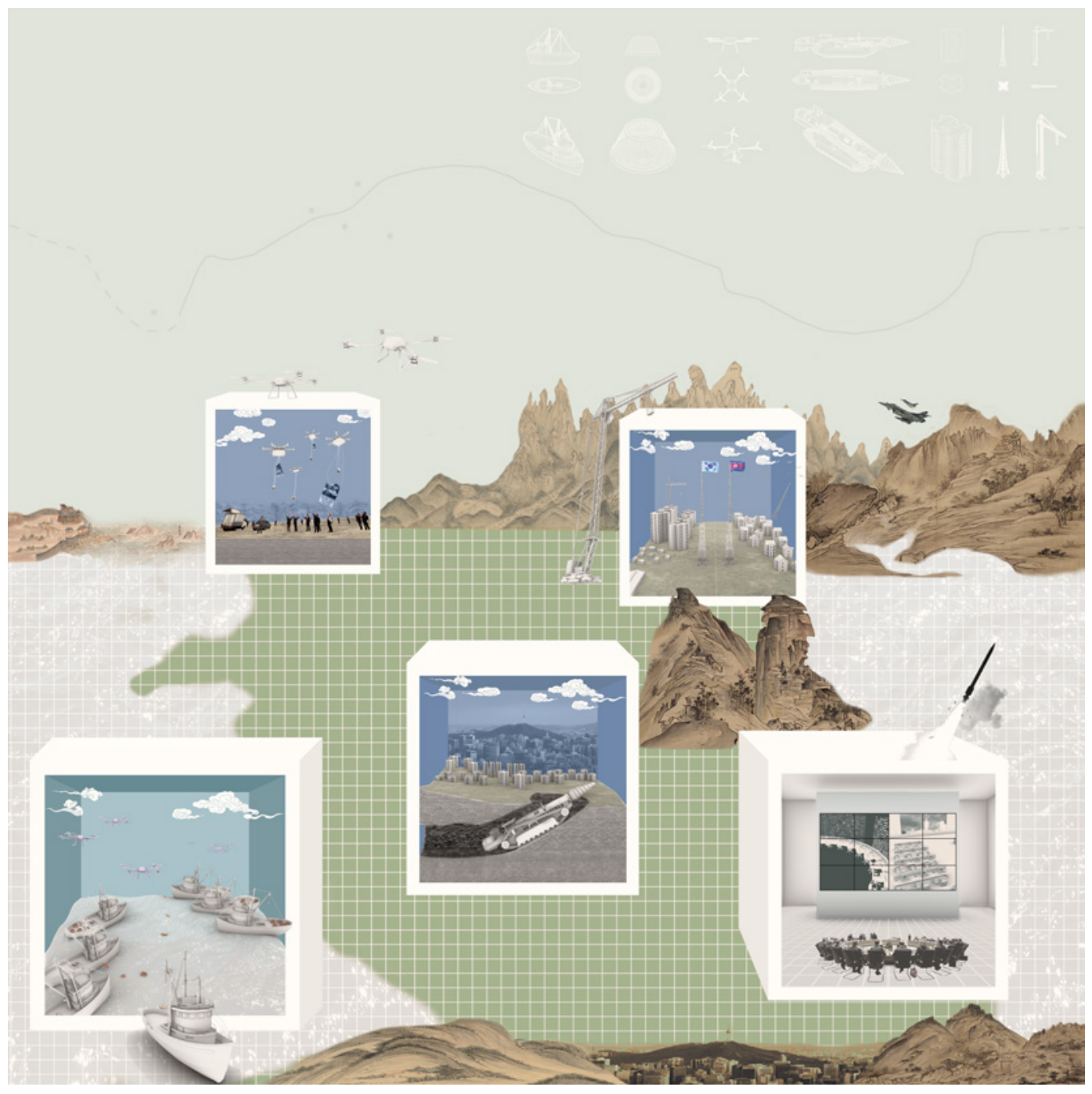

Figure 71 | Continued 


\section{POSTSCRIPT}

While this thesis initially provided my own personal investigation into Korean culture and the memories I had associated, the relevance of memory as a method of understanding site, especially in the perplexing space of Korea's Demilitarized Zone, proves to be fundamental. Han and its various definitions that could be broadly described as Koreans' collective memory, provides a dormant link to a space that few will ever encounter. As time goes on, han is perhaps the driving factor for dialogic peace, as it is the memory of the space, however foggy or distant, that still demands for a unified peninsula. Yet, investigations of the Demilitarized Zone unearth holes in our understanding, revealing the absurdities, however real or imagined. These holes are a direct reflection of both the seen and unseen, providing a space of imagination ranging from secretive tunnels used for smuggling, traces of legendary tigers, or future spaces of tourism. The space for imagination perhaps underlines the potential for han as a key factor in understanding a future Demilitarized Zone, whether it is Erased, Infiltrated, or Continued.

Reflecting upon the speculative fictions produced, it is important to note that these were never an attempt to solve the complexity of the $\mathrm{DMZ}$ or to provide temporary solutions for peaceful interactions, but were simply a method to under- 
stand the site, and provide a dialogic space. In doing so, further questions arise in an attempt to interpret the perplexities of the zone. One can begin to question the thickness of a line, not as a mere tracing on a map, but its physical boundaries that have divided liquid terrains, villages, and people. As the tracing meanders through these boundaries, does it then begin to extend past them? Furthermore, in the imagining of speculative fictions, when can one begin to question the fiction of the space, rather than the fiction of the future? In other words, does speculative fiction question our present more than our future? These questions and the many others that emerge, highlight the potential for the intervention of architecture on contested landscapes as a means of providing dialogic space, where architectural representation provides an equally, if not more powerful response than the design of space itself. 


\section{GLOSSARY}

\section{Han}

Described as «the ineffable sadness of being Korean." It has been called an all-encompassing sense of bitterness by scholars, a mixture of angst, endurance and a yearning for revenge that tests a person's soul, marked by deep sorrow and a sense of incompleteness.

\section{Minbwa}

A traditional form of Korean folk art, which was used to adorn Korean houses according to traditional customs. Minhwa distinguishes itself from previous styles as an "art of the people" not reserved for the elite.

\section{Juche}

Ideology developed by Kim Il Sung as an adaptation of traditional Marxis-Leninism for the Korean context. Juche ideology translates into three essential values, which are political autonomy, economic self-reliance and a strong position of self-defence, and relies on a blind loyalty to a staunchly anti-imperialist state.

\section{Pansori}

A traditional art form of musical storytelling.

\section{Minjung}

A form of political art that emerged in reaction to social unrest in the 1980s.

\section{Sunshine}

Refers to the sunshine policy brought forth under Kim DaeJung's presidency (1998-2003). Under the sunshine policy, families were permitted to cross the border for reunions.

\section{Kremlinology}

Kremlinology refers to the study and analysis of politics and policies of the Kremlin, Russia's government. It is often used to describe the study of secretive states such as North Korea. 


\section{Potemkin village}

A term used to describe a construction whose sole purpose is to provide a façade. The name originates from Grigory Potemkin, a military leader and lover of Catherine the Great, who is said to have commissioned the construction of "fake villages" on a trip to Crimea to impress Catherine.

\section{Banchan}

Refers to side dishes served with cooked rice and a staple of Korean cuisine. 


\section{BIBLIOGRAPHY}

Card, James. "Cold War Trout: Fly Fishing the Korean DMZ Borderlands." Midcurrent. Accessed December 12,2020. https://midcurrent.com/travel/cold-wartrout-fly-fishing-the-korean-dmz-borderlands/.

CIA. “SUNAN-UP AIRFIELD NORTH KOREA,” 1968.

Corner, James. "The Agency of Mapping: Speculation, Critique and Invention.” In Mappings, edited by Denis E. Cosgrove, 213-52. London: Reaktion Books, 1999.

Cunha, Dilip Da. The Invention of Rivers: Alexander's Eye and Ganga's Descent. Philadelphia: University of Pennsylvania Press, 2019.

D’Ignazio, Catherine. "Art and Cartography.” In International Encyclopedia of Human Geography, edited by Rob Kitchin and Nigel Thrift, 1:190-206. Oxford: Elsevier, 2009.

Denyer, Simon. "Where's North Korea's Kim? Let's See What the Satellites Say." The Washington Post, April 2020.

Koryo Tours. "FAQS DPRK (NORTH KOREA) TOURS," n.d. https://koryogroup.com/dprk-north-korea/faqs.

Ghosn, Rania, and El Hadi Jazairy. Geostories: Another Architecture for the Environment. New York, Barcelona: Actar Publishers, 2018.

Im, H., Chan Lee, Woo-ik Yu, Bae-ho Hhahn, and Yong Ick Lew. "South Korea.” In Encyclopedia Britannica, 2021.

Jazairy, El Hadi. “Toward a Plastic Conception of Scale.” New Geographies 4, no. Scales of the Earth (2011). 
Kim, Dongsei. "A White Paper on The Demilitarized Zone: Some Facts and Questions for the Future." In North Korean Atlas, edited by Dongwoo Yim and Rafael Lima, 104-7. Seoul: Damdi, 2014.

"Metamorphosis of a Zone." Topos: The International Review of Landscape Architecture and Urban Design, no. 104 (2018): 74-79.

“The First Iteration.” SITE, no. 35 (2016): 24-33.

"Towards a Dialogic Peace in the Demilitarized Zone." Volume 40, no. 2 (2014): 40-43.

Kim, Kwi-Gon. The Demilitarized Zone (DMZ) of Korea: Protection, Conseration and Restoration of a Unique Ecosystem. The Demilitarized Zone (DMZ) of Korea. Heidelberg: Springer, 2013.

Lindley, Joseph, and Paul Coulton. "Back to the Future: 10 Years of Design Fiction.” ACM International Conference Proceeding Series, 2015, 210-11. https://doi. org/10.1145/2783446.2783592.

Lister, Tim. "Islands, Crabs and Skirmishes: The Koreas' Maritime Mishaps.” CNN World, November 26, 2010.

Mathur, Anuradha, and Dilip Da Cunha. "In Depth: Inscribing the Indian Landscape." Architectural Design 77, no. 6 (2007): 70-77.

Onishi, Norimitsu. "Does a Tiger Lurk in the Middle of a Fearful Symmetry?” The New York Times, 2004.

Paterson, Simeon. "Korean Loudspeakers: What Are the North and South Shouting About?" BBC News, January 12, 2016. 
Pearson, James, and Ju-min Park. "The War That Never Ends between the Koreas." Reuters, June 16, 2014.

Rich, Motoko. "As North Korea Tensions Rise, Farming in the Demilitarized Zone Goes On.” The New York Times, April 20, 2017.

Roberts, Catherine, and Philip R Stone. "Dark Tourism and Dark Heritage: Emergent Themes, Issues and Consequences.” Displaced Heritage: Dealing with Disaster and Suffering, 2014, 1-11.

Sang-Hun, Choe. "As Floating Propaganda Irks North Korea, the South Isn't Happy Either." The New York Times, June 11, 2020.

"South Korea Takes down Propaganda Speakers at Border." BBC News, May 1, 2018.

"South Korean Balloons: Plans to Stop People Sending CrossBorder Messages.” BBC News, June 4, 2020.

Specia, Megan. "Built for Invasion, North Korean Tunnels Now Flow With Tourists." The New York Times, November 4, 2017.

Springer, Kate. "How to Visit the Korean Demilitarized Zone." CNN Travel, February 6, 2019.

Watson, Ivan, Jungeun Kim, Stella Ko, and Jo Shelley. "Messages in Bottles Sent across the Sea to North Korea." CNN World, May 17, 2018.

Wharton, David. “'Peace Village,' a Fake City Just Outside the DMZ, Serves as Metaphor for North Korean Athletes at the Olympics." Los Angeles Times, February 17, 2018. 
Williamson, Lucy. "Hunt for North Korea's 'Hidden

Tunnels.” BBC News. August 23, 2012.

Zaidi, Leah. "Building Brave New Worlds: Science Fiction and Transition Design.” OCAD University, 2017. 


\section{FIGURES}

\section{Figure 1 : Magpies and Tiger Smoking Pipe}

Minbwa Tiger and Magpies, ink painting, The Korean Institute of Minhwa Re search, accessed January 20, 2021. http://www.minhwagallery.com/gal lery/gallery.html?b_num $=166 \&$ category $=3$

Figure 3 : South Korean Soldier at the Southern Limit Overlooking the Han River

Jong-Woo Park, South Korean Soldier at the Southern Limit Line Overlooking the Han River, 2018, Digital Image, Wired Magazine, accessed October 28, 2020. https://www.wired.com/story/inside-the-korean-dmz/

Figure 4: Portrait

Chae-Gwan Yi, Painting, ca. 19th century, ink painting, The British Museum, London, accessed November 15, 2020. https://www.britishmuseum.org/ collection/object/A_1922-0630-0-11

Figure 5 : Portrait of Lady Un

Yong-Sin Chae, Portrait of Lady Un, ca. 19th century, ink painting, National Museum of Korea, Seoul, accessed January 20, 2021. https://www.muse um.go.kr/site/eng/relic/represent/view? relicId=691

\section{Figure 6: The Conquest of Korea}

Yoshitora Utagawa, The Conquest of Korea, 1863, woodblock print, Museum of Fine Arts, Boston, accessed January 25, 2021, https:/collections.mfa.org/ objects/472350/the-conquest-of-korea-sankan-seibatsu-no-zu?ctx $=271 \mathrm{fe} 069$-e154-4c19-95a0-5e632f65d987\&idx=1 


\section{Figure 7: Political Cartoon of China and Japan Trampling Korea as Russia}

Watches

Georges Bigot, Political cartoon of China and Japan trampling Korea as Russia watches, 1904, color lithograph, Museum of Fine Arts, Boston, accessed January 25, 2021 https://collections.mfa.org/

Figure 8 : Seoul Avenue during the Japanese Occupation

Seoul avenue during the Japanese occupation, ca. 1910-1945, digital image, Korea Times accessed January 25, 2021. https://www.koreatimes.co.kr/www/ culture/2020/05/135_160991.html

Figure 9: Korean Liberation Army

Korea Liberation Army, September 17, 1940, digital image, Wikimedia Commons accessed January 26, 2021. https://commons.wikimedia.org/wiki/File:Ko rea_Independence_Army.jpg

Figure 10 : Syngman Rhee

Syngman Rhee, 1939, digital image, Library of Congress, Washington, D.C., accessed March 10, 2021. https://www.britannica.com/biography/Syng man-Rhee

\section{Figure 11 : Kim Il-Sung}

Kim Il-Sung, 1950, digital image, Hulton Archive, Getty Images, Wikimedia Commons accessed March 10, 2021. https://commons.wikimedia.org/ wiki/File:Kim_Il-sung_in_1950.jpg 
Figure 12: Armistice Agreement for the Restoration of the South Korean State

Korean War Armistice Agreement, July 27, 1953, digital image, National Archives, accessed January 25, 2021. https://www.archives.gov/historical-docs/to days-doc/index.html?dod-date $=727$

Figure 13 : Delegates Signing the Korean War Armistice Agreement

Korean War Armistice Agreement, 1953, digital image, Wikimedia Commons ac cessed March 10, 2021. https://commons.wikimedia.org/wiki/File:Kore an_War_armistice_agreement_1953.jpg

Figure 15 : Tiger Family

Tiger Family, ca. late 1800s, ink painting, The Cleveland Museum of Art, accessed January 20, 2021. https://www.clevelandart.org/art/1997.148

Figure 16: Landscape With Streams and Mountains

Landscape with Streams and Mountains, ca. late 1700s or early 1800s, ink and colour on paper, The Cleveland Museum of Art, accessed November 12, 2020. https://www.clevelandart.org/art/1915.216

Figure 17 : "Let Us Achieve The Party's Agriculture Revolution Policy Thoroughly And Brighten The Year With Increased Grain Production”

"Let us achieve the party's agriculture revolution policy thoroughly and brighten the year with increased grain production.", print, University Museum and Art Gallery, The University of Hong Kong, accessed October 15, 2020, https://www.cnn.com/style/article/north-korea-propaganda-posters-de sign/index.html 
Figure 18 : "Rice is Socialism. Let us Concentrate all Efforts on Agriculture!"

"Rice is socialism. Let us concentrate all efforts on agriculture!", print, University Museum and Art Gallery, The University of Hong Kong, accessed Octo ber 15, 2020. https://www.cnn.com/style/article/north-korea-propagan da-posters-design/index.html

Figure 19: Magpies and Tiger Smoking Pipe

Minbwa Tiger and Magpies, ink painting, The Korean Institute of Minhwa Re search, accessed January 20, 2021. http://www.minhwagallery.com/gal lery/gallery.html?b_num=166\&category $=3$

Figure 20 : Jeolla-do Mujanghyeondo

Jeolla-do Mujanghyeondo, Joseon Dynasty, ink painting, National Museum of Korea, Seoul, accessed January 20, 2021. https://www.museum.go.kr/site/ eng/relic/search/view?relicId $=652$

Figure 21 : Detail of Map Royaume de Corée

Jean-Baptiste Bourguignon D'Anville, Detail of Map Royaume de Corée, 1737, Korean History in Maps: From Prehistory to the Twenty-First Century (Cambridge: Cambridge University Press, 2020), 168.

Figure 22: A Squad of South Korean Army Soldiers Near their Guard Post

Jong-Woo Park, A Squard of South Korean Army Soldiers Near their Guard Post, 2018, digital image, Wired Magazine, accessed October 28, 2020. https:// www.wired.com/story/inside-the-korean-dmz/ 


\section{Figure 32 : South Korean Highway Landing Strip}

Department of Defense, A 320th Bombardment Wing B-52 Stratofortress aircraft passes over a group of civilians gathered along a bighway landing strip during the Joint South Korean/United States exercise TEAM SPIRIT'89, March 24, 1989 digital image, National Archives Catalog, accessed Octo ber 10, 2020. https://catalog.archives.gov/id/6459062

\section{Figure 36 -38: Hydrogen Balloon Deployment}

Young-Joon Ahn, Hydrogen Balloon Deployment, 2014, digital image, CNN, accessed October 8, 2020. https://www.cnn.com/2014/08/01/asia/gal lery/north-korea-choco-pie-balloons/index.html

\section{Figure 39: South Korean Speaker Installation}

South Korea's Speakers, 2018, digital image, Getty Images, BBC, accessed October 8, 2020. https://www.bbc.com/news/world-asia-43861161

\section{Figure 40 : South Korean Speaker Installation}

Hong-Ji Kim, South Korean Soldiers Dismantle Loudspeakers, 2018, digital im age, NPR, accessed October 8, 2020. https://www.npr.org/sections/thet wo-way/2018/05/01/607399907/north-and-south-korea-dismantle-loud speakers-blaring-propaganda-on-the-dmz

\section{Figure 41 : Cranes During a Marshland Stopover}

Claire Harbage, White-Naped Cranes in a Rice Paddy in the Civilian Control Zone, 2019, digital imgae, NPR, accessed October 5, 2020 https://www.npr.org/2019/04/20/710054899/in-korean-dmz-wildlifethrives-some-conservationists-worry-peace-could-disrupt-i 


\section{Figure 45 : JSA}

South Korean Guards at Panmunjom, 2017, digital image, Geographical Maga zine, accessed October 8, 2020. https://geographical.co.uk/nature/geo photo/item/2418-dangerous-crossings-photographing-borders

Figure 46: Sites of Dark Tourism

Carl Court, A Tourist Poses by the Goseong Unification Observatory, 2019, digi tal image, Getty Images, CNN Travel, accessed October 8, 2020 https://www.cnn.com/travel/article/visit-korean-dmz/index.html

Figure 47: Amusent Park Ride at the DMZ

Jean Chung, Diverse Attractions, 2019, digital image, Getty Images, CNN Travel, accessed October 8, 2020. https://www.cnn.com/travel/article/visit-kore an-dmz/index.html

\section{Figure 48 : Village of Kijong-Dong}

Alastair Bonnett, North Korea's Creepy Fake Civilian Village, 2014, digital image, BoingBoing, accessed October 12, 2020. https://boingboing. net/2014/07/08/north-koreas-creepy-fake-civ.html

Figure 52: Crab Wars

Chinese Fishing Boats Encounter a South Korean Coast Guard Boat in the Yellow Sea, 2010, digital image, Getty Images, CNN, accessed October 10, 2020 https://www.cnn.com/2012/04/19/world/asia/south-korea-china-fisher man/index.html 
Figure 53 : Preparation for the Release of Bottles

Organisers throw 500 bottles filled with rice, USB sticks and Christian messages, 2018, digital image, Getty Images, Express, accessed October 12, 2020 https://www.express.co.uk/news/world/906024/north-korea-kim-jongun-defectors-south-korea-messages-bottles-starving-citizens

Figure 57 : Tunnels of Aggression

Jong-Woo Park, Two South Korean Soldiers Walk along a Tunnel, 2018, Digital Image, Wired Magazine, accessed October 28, 2020, https://www.wired.com/story/inside-the-korean-dmz/

Figure 58 : South Korean Soldiers Search for Land Mines

Byung-Shick Lim, South Korean Soldiers Search for Land Mines, 2010, digital image, Associated Press, The New York Times, accessed October 7, 2020 https://www.nytimes.com/2018/10/01/world/asia/koreas-land-minesdmz.html

Figure 59: Farmers of the DMZ

North Korean Farmers, 2009, digital image, Wikimedia Commons accessed Octo ber 12, 2020. https://en.wikipedia.org/wiki/File:North_Korean_farm ers_(2009).jpg

Figure 63 : Seven Jeweled Mountain

Seven Jeweled Mountain, ca. late 1800s, ink and colour on silk, The Cleveland Museum of Art, accessed November 12, 2020. https://www.clevelandart. org/art/1989.6 
Figure 64: Painting of One Hundred Themes

Painting of One Hundred Themes, ca. late 1800s, ink and color on silk folding screen, The Cleveland Museum of Art, accessed November 12, 2020

https://www.clevelandart.org/art/1998.286 